Universidade de São Paulo

Instituto de Física

\title{
Identificação de elétrons com um detector de radiação de transição em colisões de íons pesados relativísticos
}

Orientador: Prof. Dr. Olácio Dietzsch.

\author{
Bruno Rodrigues Lenzi
}

Dissertação apresentada ao Instituto de Física da Universidade de São Paulo como parte dos requisitos para obtenção do título de Mestre em Ciências.

\section{Banca Examinadora:}

Prof. Dr. Anderson Campos Fauth (IFGW/UNICAMP)

Profa. Dra. Ivone Freire da Mota e Albuquerque (IF/USP)

Prof. Dr. Olácio Dietzsch (IF/USP) 


\section{FICHA CATALOGRÁFICA}

\section{Preparada pelo Serviço de Biblioteca e Informação}

\section{do Instituto de Física da Universidade de São Paulo}

Lenzi, Bruno Rodrigues

Identificação de elétrons com um detector de radiação de transição em colisões de íons pesados relativísticos -

São Paulo, 2007.

Dissertação (Mestrado) - Universidade de São Paulo. Instituto de Física - Departamento de Física Geral

Orientador: Prof. Dr. Olácio Dietzsch

Área de Concentração: Física

Unitermos: 1. Física de Alta Energia; 2. Física Experimental; 3. Detecção de Partículas 


\section{Resumo}

Este trabalho descreve o desenvolvimento de um simulador para as câmaras de expansão temporal / detectores de radiação de transição (TEC / TRD) do experimento PHENIX, instalado no Colisor de Íons Pesados Relativisticos (RHIC) do Laboratório Nacional de Brookhaven (BNL) nos EUA.

O programa do RHIC prevê a produção e caracterização de um estado da matéria conhecido como plasma de quarks e glúons (QGP), através de colisões entre prótons, dêuterons e íons pesados com energias de centro de massa $\sqrt{s_{N N}}$ entre 20 e $200 \mathrm{GeV}$. O PHENIX, um dos quatro experimentos instalados no acelerador, é especializado na medida de sinais eletrofracos provenientes das colisões e o TEC / TRD é o único subsistema do PHENIX capaz de identificar elétrons de forma eficiente para momentos acima de $5 \mathrm{GeV} / \mathrm{c}$.

Um simulador para reprodução da resposta do detector à passagem de partículas foi desenvolvido e comparado a dados de um detector proporcional monofilar construído no Laboratório de Instrumentação e Partículas da USP, e aos dados do próprio TEC / TRD. Os resultados mostram um acordo razoável entre medidas e simulações. O uso do simulador deverá permitir o estudo de novos métodos e melhoras na capacidade de identificação de elétrons do sistema. 



\section{Abstract}

The present work describes the development of a simulator for the Time Expansion Chambers / Transition Radiation Detectors (TEC / TRD) of the PHENIX experiment, installed at the Relativistic Heavy Ion Collider (RHIC) of Brookhaven National Laboratory (BNL).

The main goal of the RHIC project is the production and study of a state of matter known as Quark Gluon Plasma (QGP), through collisions of protons, deuterons and heavy ions at center of mass energies $\sqrt{s_{N N}}$ ranging between 20 and $200 \mathrm{GeV}$. PHENIX, one of the four experiments of the accelerator, is dedicated to measuring electroweak signals arising from the collisions, and TEC / TRD is the only subsystem capable of identifying efficiently electrons with momenta above $5 \mathrm{GeV} / \mathrm{c}$.

A simulator to reproduce the detector response to the passage of particles was developed and compared to data from a single wire proporcional counter and from TEC / TRD itself. The results show reasonable agreement between measurements and simulations. The use of the simulator allows studies of new methods and possibly improvements in the electron identification capability of the system. 



\section{Sumário}

1 Introdução 1

1.1 O Colisor de Íons Pesados Relativísticos . . . . . . . . . . . . . . 2

1.2 O estudo do QGP e a produção de elétrons . . . . . . . . . . . . . 4

1.3 Descrição e motivação do trabalho . . . . . . . . . . . . . . 5

2 Identificação de elétrons no PHENIX $\quad 7$

2.1 Descrição geral do PHENIX . . . . . . . . . . . . . . . . . . . 8

2.2 Aquisição de dados . . . . . . . . . . . . . . . . . . . . . . . . . 10

2.3 O detector Cherenkov de imagem anular . . . . . . . . . . . . 10

2.4 O calorímetro eletromagnético . . . . . . . . . . . . . . . 12

3 As câmaras de expansão temporal do PHENIX $\quad 17$

3.1 Geometria e design . . . . . . . . . . . . . . . . 20

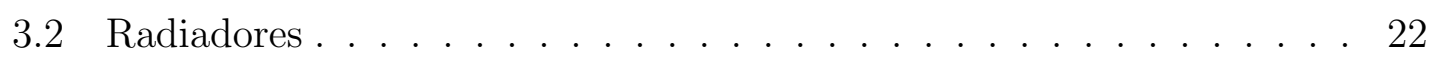

3.3 Gás . . . . . . . . . . . . . . . . . . . . . . . 22

3.4 Eletrônica . . . . . . . . . . . . . . . . . . . . . . . . . 23

3.5 Determinação de trajetórias . . . . . . . . . . . . . . . . 26

3.6 Identificação de partículas . . . . . . . . . . . . . . . 27

3.7 Simulações . . . . . . . . . . . . . . . . . . . . . . 31

4 Processos físicos no TEC / TRD 33 
4.1 Perda de energia de partículas carregadas . . . . . . . . . . . . . 34

4.2 Absorção de fótons . . . . . . . . . . . . . . . . . . . . 37

4.3 Produção de cargas num detector a gás . . . . . . . . . . . . . . 38

4.4 Movimento das cargas . . . . . . . . . . . . . . . . . 41

4.5 Multiplicação e absorção das cargas . . . . . . . . . . . . . . . . . . . 44

4.6 Radiação de Transição . . . . . . . . . . . . . . . . . . . . . . 47

5 Simulação de um detector proporcional 49

5.1 Eletrônica . . . . . . . . . . . . . . . . . 50 50

5.2 Absorção dos fótons no argônio . . . . . . . . . . . . . . . . . 52

5.3 Simulação do processo de avalanche . . . . . . . . . . . . . . . 53

5.4 Curva de multiplicação . . . . . . . . . . . . . . . . 55

5.5 Espectro da energia depositada . . . . . . . . . . . . . 56

5.6 Sinal induzido pela absorção de um fóton . . . . . . . . . . . . . 57

5.7 Conclusões . . . . . . . . . . . . . . . . . . . . . 59

6 Um simulador para o TEC / TRD 61

6.1 Parâmetros do simulador . . . . . . . . . . . . . . . . 61

6.2 Simulação da produção de TR . . . . . . . . . . . . . . . . . . . . 65

6.3 Descrição do simulador . . . . . . . . . . . . . . . . . . 69

6.4 Comparação com os dados do TEC / TRD . . . . . . . . . . . . . . 69

6.5 Conclusões . . . . . . . . . . . . . . . . . . . . . . . . . . . 79

$\begin{array}{llr}7 & \text { Conclusões } & 81\end{array}$

A Gerador de números aleatórios para uma distribuição genérica $\quad 85$

$\begin{array}{ll}\text { B Produção de TR em radiadores } & 87\end{array}$

$\begin{array}{lr}\text { Referências Bibliográficas } & 89\end{array}$ 


\section{Capítulo 1}

\section{Introdução}

A física de altas energias lida com os constituintes básicos da matéria e suas interações. Os métodos experimentais que têm permitido a ampliação do conhecimento nessa área são basicamente colisões de partículas a energias cada vez mais altas em grandes aceleradores.

Um dos grandes avanços das últimas décadas do século 20 foi o reconhecimento da cromodinâmica quântica (QCD) como a teoria que descreve as interações fortes num nível fundamental. A QCD é uma teoria quântica de campos não-abeliana que trata das interações entre os quarks, que em condições normais encontram-se na forma de hádrons, como prótons e nêutrons [1].

A intensidade das interações é descrita por somente uma constante de acoplamento $\alpha_{s}$, que na realidade é uma função do momento $q$ trocado entre as partículas. Alguns aspectos notáveis da QCD são os seguintes: (a) $\alpha_{s}\left(q^{2}\right)$ apresenta uma queda logarítmica a curtas distâncias ou grandes transferências de momento $q$, o que faz com que quarks e glúons se tornem fracamente acoplados. (b) Para grandes distâncias, ao contrário, a constante de acoplamento cresce, o que resulta no confinamento dessas partículas [1].

Este confinamento, no entanto, está fortemente relacionado às condições de temperatura e densidade da matéria nuclear e acredita-se que ele não ocorra em condições extremas $[2,3]$. Com o aumento da temperatura, as interações entre os quarks ocorrem a distâncias cada vez menores, enquanto as interações de longa distância são blindadas [1].

A temperaturas próximas de $170 \mathrm{MeV}$, cálculos de QCD na rede (lattice QCD) prevêem que a matéria nuclear sofre uma transição de fase para o chamado plasma de quarks e glúons (QGP), conforme mostrado no diagrama de fase da fig. 1.1. Nesse estado, a estrutura complicada da matéria nuclear, que a baixas temperaturas é composta por uma miríade de bárions e mésons, dá lugar a uma descrição relativa- 
mente simples de um plasma composto por quarks e glúons fracamente interagentes $[4]$.

Apesar de possuir uma estrutura relativamente simples, o tratamento teórico deste fenômeno é extremamente complexo, pois envolve cálculos da QCD num regime não perturbativo. Por outro lado, este é um campo de grande interesse pois está relacionado ao estudo da matéria em condições extremas, que acredita-se que tenha existido nos primeiros instantes do universo [1].

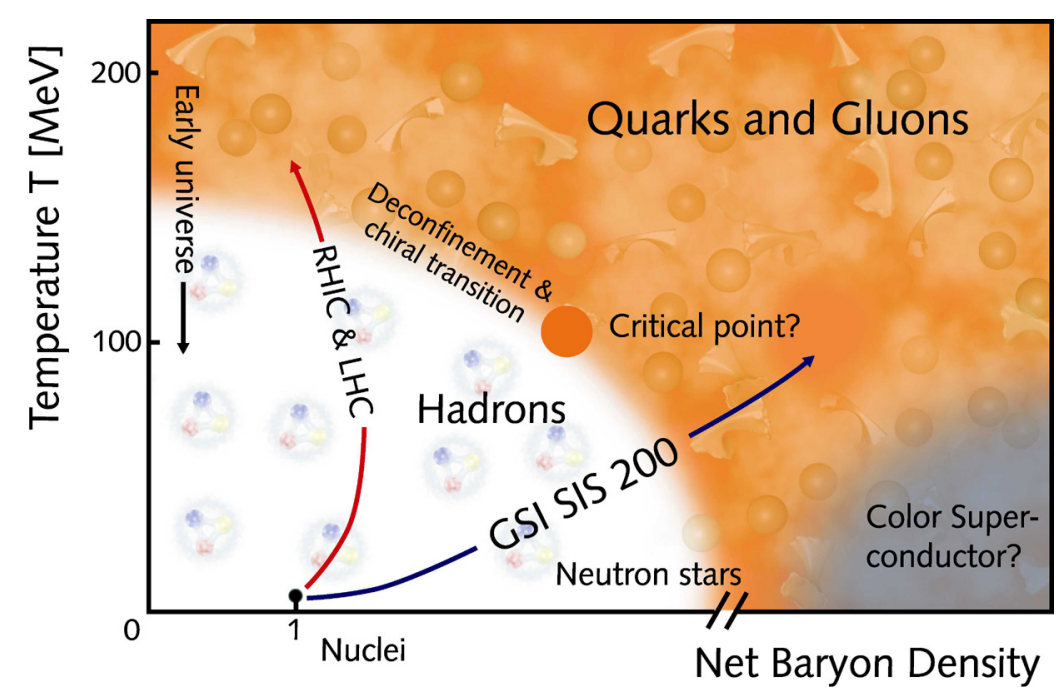

Figura 1.1: Diagrama de fase da QCD [5].

\subsection{O Colisor de Íons Pesados Relativísticos}

O grande interesse no estudo da matéria hadrônica em condições extremas está ligado também à possibilidade de produção de tais regimes experimentalmente, através de colisões entre íons pesados a energias relativísticas. Em 1986, o Alternating Gradient Synchroton (AGS) do Laboratório Nacional de Brookhaven (BNL) e o Super Proton Synchroton (SPS) do Centro Europeu de Física de Partículas (CERN) iniciaram suas operações com essa finalidade [1].

Desde o ano 2000 está em operação o Colisor de Íons Pesados Relativísticos (Relativistic Heavy Ion Collider - RHIC) do Laboratório Nacional de Brookhaven. O programa de física do RHIC inclui a produção e caracterização do plasma de quarks e glúons e o estudo do spin do próton, através de colisões a energias de 19.6 a $200 \mathrm{GeV} /$ nucleon entre feixes de prótons, dêuterons e íons pesados [6]. 
O acelerador, mostrado na fig. 1.2, conta com dois anéis instalados num túnel de cerca de $3.8 \mathrm{~km}$ de comprimento, nos quais circulam feixes em sentidos opostos, compostos por 60 segmentos (bunches) de cerca de $30 \mathrm{~cm}$ cada, que se cruzam a cada $106 \mathrm{~ns}(9.4 \mathrm{MHz})$.

As colisões ocorrem a taxas que variam de alguns $\mathrm{kHz}$ para colisões $\mathrm{Au}+\mathrm{Au}$, o que implica uma luminosidade ${ }^{1}$ de $2 \times 10^{26} \mathrm{~cm}^{-2} \mathrm{~s}^{-1}$, a cerca de $500 \mathrm{kHz}$ para colisões $\mathrm{p}+\mathrm{p}$, com luminosidades de $10^{31} \mathrm{~cm}^{-2} \mathrm{~s}^{-1}$.

Os cruzamentos entre os feixes ocorrem em seis pontos de interação. Em quatro destes pontos foram instalados os experimentos BRAHMS, PHENIX, PHOBOS e STAR para investigação das propriedades da matéria formada nas colisões [7]. Em 2005, os quatro experimentos do RHIC divulgaram evidências sobre a criação de um novo estado da matéria com características consideravelmente diferentes das previsões teóricas [8]. O estudo do QGP deve receber grandes contribuições nos próximos anos, com novos dados do RHIC e com o início das operações do Large Hadron Collider (LHC) no CERN, em fase de construção.

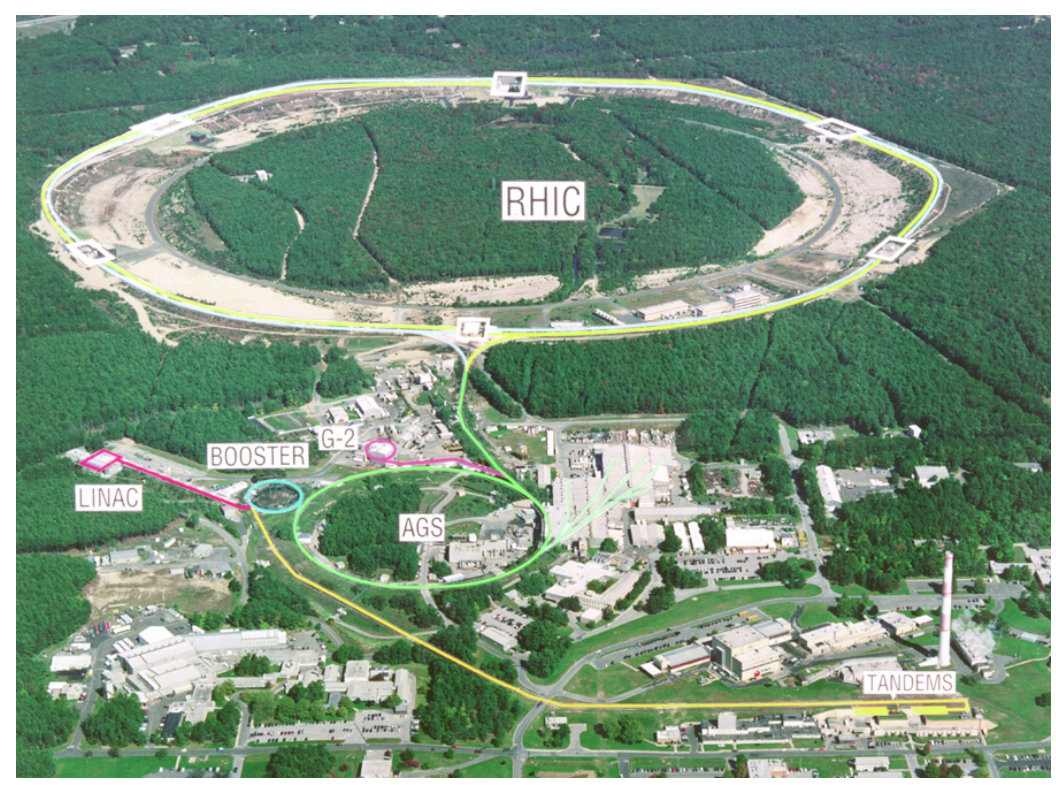

Figura 1.2: O Colisor de Íons Pesados Relativísticos (RHIC) [9].

\footnotetext{
${ }^{1}$ A luminosidade corresponde ao número de interações por unidade de tempo por unidade de seção de choque.
} 


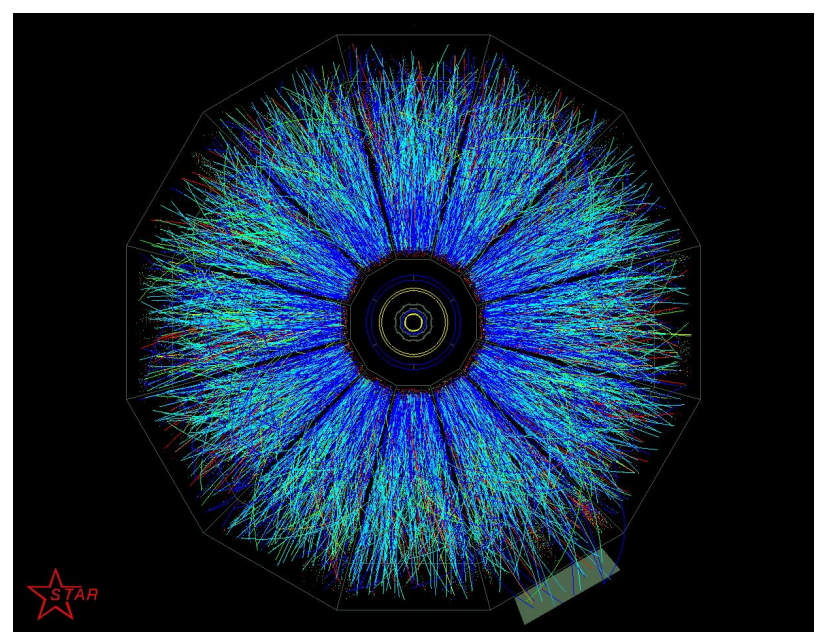

(a)

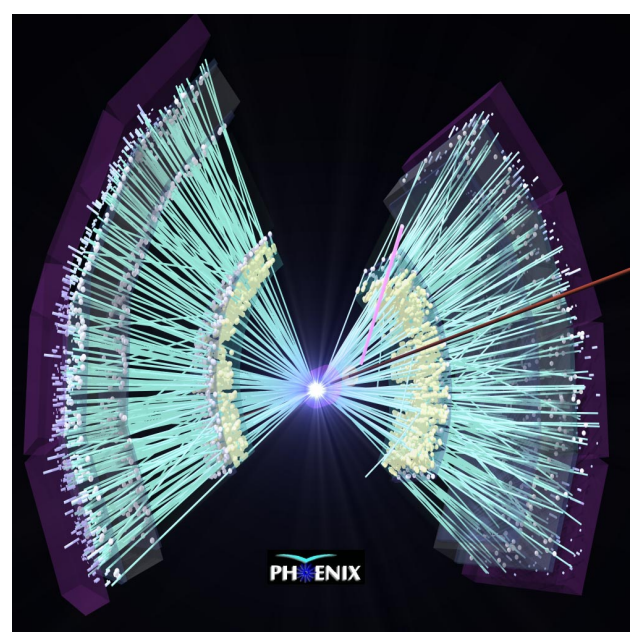

(b)

Figura 1.3: Colisão central Au+Au no RHIC vista pelos detectores (a) STAR [10] e (b) PHENIX [11].

\subsection{O estudo do QGP e a produção de elétrons}

O estudo da matéria formada nas colisões do RHIC é uma tarefa experimental bastante complexa que requer a observação dos sinais do QGP num ambiente dominado pelos sinais da fase de hadronização, na qual a maioria das partículas são produzidas [7].

Os dois maiores experimentos do RHIC - PHENIX e STAR - apresentam características bastante diferentes. Enquanto o STAR é especializado na medida e identificação de hádrons num TPC (Time Projection Chamber) com grande cobertura angular, o PHENIX, por sua vez, foi projetado para a medida de léptons e fótons, além de hádrons, porém com cobertura angular mais limitada. As figuras 1.3(a) e 1.3(b) mostram a medida de uma colisão central $\mathrm{Au}+\mathrm{Au}$ pelos detectores, na qual tipicamente 700 partículas por intervalo de pseudo-rapidez ${ }^{2}$ são produzidas [12].

Os sinais eletrofracos - fótons e léptons - carregam informações sobre os estágios iniciais da colisão por não serem afetados pelas interações do estado final. A abundância destas partículas corresponde a apenas $0.01 \%$ do total [7] e a medida de sinais diretos é dificultada por um fundo proveniente de decaimentos eletromagnéticos dos hádrons formados nas fases posteriores.

Medidas dos espectros de léptons e di-léptons são duas ferramentas experimentais de grande importância, já que além de sinais diretos do QGP - como fótons

\footnotetext{
${ }^{2}$ Pseudo-rapidez é definida como $\eta=-\ln [\operatorname{tg}(\theta / 2)]$ onde $\theta$ é o ângulo entre a trajetória (momento) da partícula e a direção do feixe. [2]
} 
térmicos e fótons virtuais - trazem informações sobre a produção de quarks pesados e mésons vetoriais. A supressão do estado fundamental do charmônio - J/ $/$ - devido à blindagem das forças de cor no QGP a temperaturas pouco acima da temperatura crítica, é uma das grandes evidências para a formação do plasma. Nesse cenário, pares de quarks charm (c-i) tendem a ligar-se a quarks leves formando mésons de charme aberto $[2,4]$.

O espectro de di-elétrons é constituído basicamente por fontes fotônicas, decaimentos de Dalitz de mésons neutros e decaimentos leptônicos de mésons vetoriais como o $\mathrm{J} / \psi$, enquanto o espectro de elétrons recebe ainda contribuição de decaimentos semi-leptônicos. Uma outra grandeza relacionada à supressão do $\mathrm{J} / \psi$ é a medida da contribuição do decaimento semi-leptônico destes mésons ao espectro de elétrons. Estes dados trazem informações sobre a perda de energia de quarks pesados num meio quente e denso. Outros exemplos relacionados à produção de elétrons e pares de elétrons são apresentados em [1].

\subsection{Descrição e motivação do trabalho}

O Laboratório de Instrumentação e Partículas (LIP) da USP participa da colaboração PHENIX desde o seu início. O LIP está particularmente envolvido com a medida de quarks pesados através de decaimentos nos canais de elétrons e com a instalação e manutenção das câmaras de expansão temporal. A identificação de elétrons, discutida no cap. 2, é um dos grandes focos de atenção do experimento, que conta com diversos sistemas especializados nestas medidas cobrindo uma grande região de momentos.

As câmaras de expansão temporal, descritas no cap. 3, são o único subsistema capaz de selecionar elétrons de forma eficiente para momentos acima de $5 \mathrm{GeV} / \mathrm{c}$. A separação entre elétrons e hádrons requer o uso de diversos métodos de análise, frequentemente baseados em simulações. Este trabalho teve como objetivo o estudo dos processos físicos que permitem a detecção das partículas com este subsistema, descritos no cap. 4, e o desenvolvimento de um simulador para reproduzir esses processos, descrito nos caps. 5 e 6 . 



\section{Capítulo 2}

\section{Identificação de elétrons no PHENIX}

O PHENIX (Pioneering High Energy Nuclear Interaction eXperiment) é um dos quatro experimentos instalados no RHIC, e é formado por uma colaboração de cerca de 500 cientistas de 13 países. Um dos principais objetivos da colaboração é a medida de sinais eletrofracos provenientes das colisões [3, 7, 13], cuja importância para a caracterização da matéria produzida no RHIC foi discutida no capítulo anterior.

A análise dos dados em experimentos de física de altas energias requer o conhecimento do quadri-momento das partículas produzidas nas colisões. Enquanto o momento das partículas carregadas geralmente é determinado através da deflexão da trajetória num campo magnético, a quarta componente pode ser determinada através da medida da energia, da massa ou da velocidade. Como essa medida determina completamente a espécie da partícula, esse processo é denominado identificação de partículas [14].

A energias da ordem de $\mathrm{MeV}$ a identificação de partículas é feita tradicionalmente por técnicas de tempo de vôo, calorimetria ou perda de energia $(d E / d x)$. A energias mais altas - da ordem de alguns GeV - essas técnicas apresentam sérias limitações práticas para detectores com tamanhos usuais (entre alguns cm e $1 \mathrm{~m}$ ) [14].

Nesse contexto, outros efeitos físicos podem ser utilizados para diferenciação entre as espécies, como a alta relativística na perda de energia, a radiação de transição e a radiação Cherenkov. Todas as técnicas mencionadas são utilizadas no experimento PHENIX para a separação entre elétrons, píons, káons e prótons.

Este capítulo descreve as características gerais do detector, com especial atenção para os sistemas que participam na identificação de elétrons. As câmaras de expansão temporal (TECs), tema de estudo deste trabalho, são descritas em maior detalhe no capítulo 3 . 


\subsection{Descrição geral do PHENIX}

O PHENIX é composto por quatro braços ou espectrômetros e dois detectores globais para caracterização dos eventos ${ }^{1}$. A fig. 2.1 traz uma foto do detector e a fig. 2.2 mostra um esquema com os subsistemas que compõe o PHENIX.

A caracterização dos eventos é feita através da medida do instante, da posição e da centralidade da colisão. O vértice e o momento da colisão são determinados por um par de detectores instalados ao redor do cano do feixe, os Beam-Beam Counters. Os BBCs são compostos por radiadores de quartzo para produção de radiação Cherenkov ligados a fotomultiplicadoras. A centralidade é determinada de acordo com a carga depositada nos BBCs e a medida dos fragmentos neutros por calorímetros hadrônicos denominados Zero-Degree Calorimeters. Os ZDCs são detectores comuns a todos os experimentos do RHIC, e estão instalados a cerca de $15 \mathrm{~m}$ do ponto de interação $[15,16]$.

O sistema coordenadas que localiza os detectores e as trajetórias das partículas é um sistema cartesiano centrado no ponto de interação, no qual o eixo z é paralelo ao feixe e aponta para o Norte, o eixo $x$ aponta para o Oeste, e o eixo $y$ é paralelo à direção vertical.

Os braços de múons (braços Norte e Sul) são responsáveis pela medida de partículas carregadas e pela identificação de múons para valores altos de rapidez ${ }^{2}$ $(-2.25 \leq \xi \leq-1.15$ e $1.15 \leq \xi \leq 2.44)$. Dois ímãs permitem a determinação do momento das partículas carregadas pela deflexão das trajetórias.

Os braços centrais (braços Leste e Oeste) cobrem a região de pseudo-rapidez entre $-0.35<\eta<0.35$, e têm cobertura azimutal de $90^{\circ}$ cada. São compostos por subsistemas para reconhecimento de trajetórias (tracking) e identificação de partículas, além de dois calorímetros eletromagnéticos [13].

O sistema de tracking dos braços centrais determina as trajetórias das partículas carregadas, mede seus momentos através da deflexão no campo gerado pelo íma central, reconstrói a massa invariante de pares de káons e elétrons, e contribui na identificação de partículas [17]. O sistema é composto pelas Drift Chambers - DC, Pad Chambers - PC e pelo TEC. O campo magnético é desprezível na região externa às Drift Chambers.

A identificação de partículas é feita pelo Detector Cherenkov de Imagem Anular (Ring Imaging Cherenkov Detector - RICH), por um sistema de tempo de vôo (TOF), pelo calorímetro eletromagnético (EmCal) e pelo TEC.

\footnotetext{
${ }^{1} \mathrm{Um}$ evento corresponde a um cruzamento dos feixes.

${ }^{2}$ Rapidez é definida como $\xi=\frac{1}{2} \ln \left(\frac{E+p_{z}}{E-p_{z}}\right)$, onde $E$ é a energia da partícula e $p_{z}$ a componente do momento na direção do feixe [2].
} 


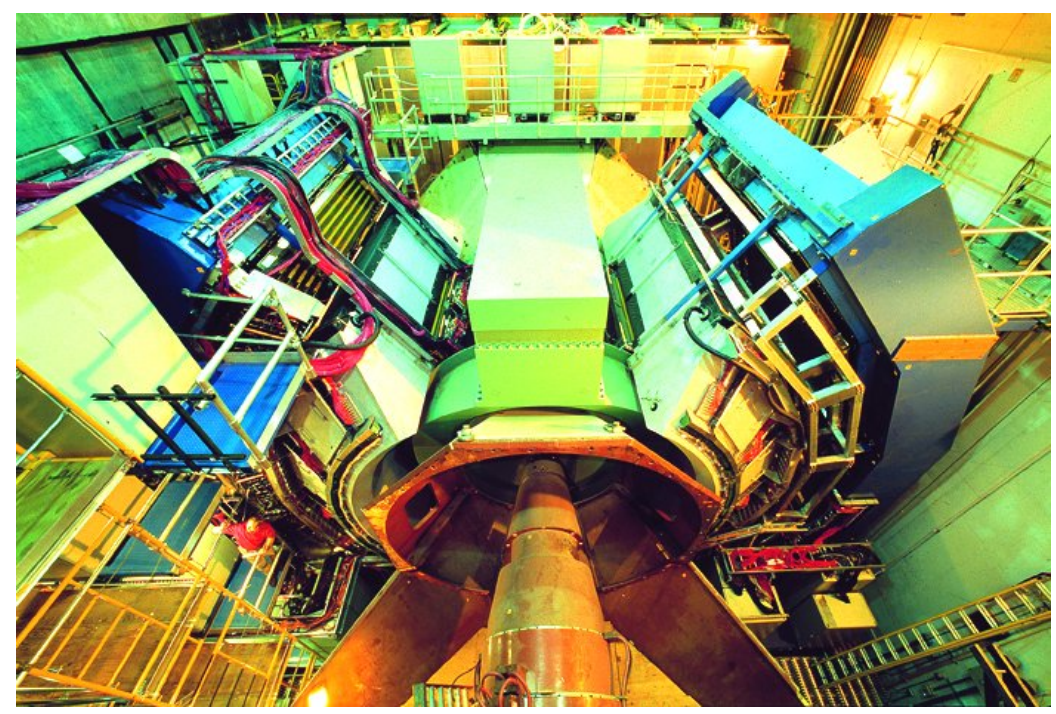

Figura 2.1: Foto do PHENIX [13].

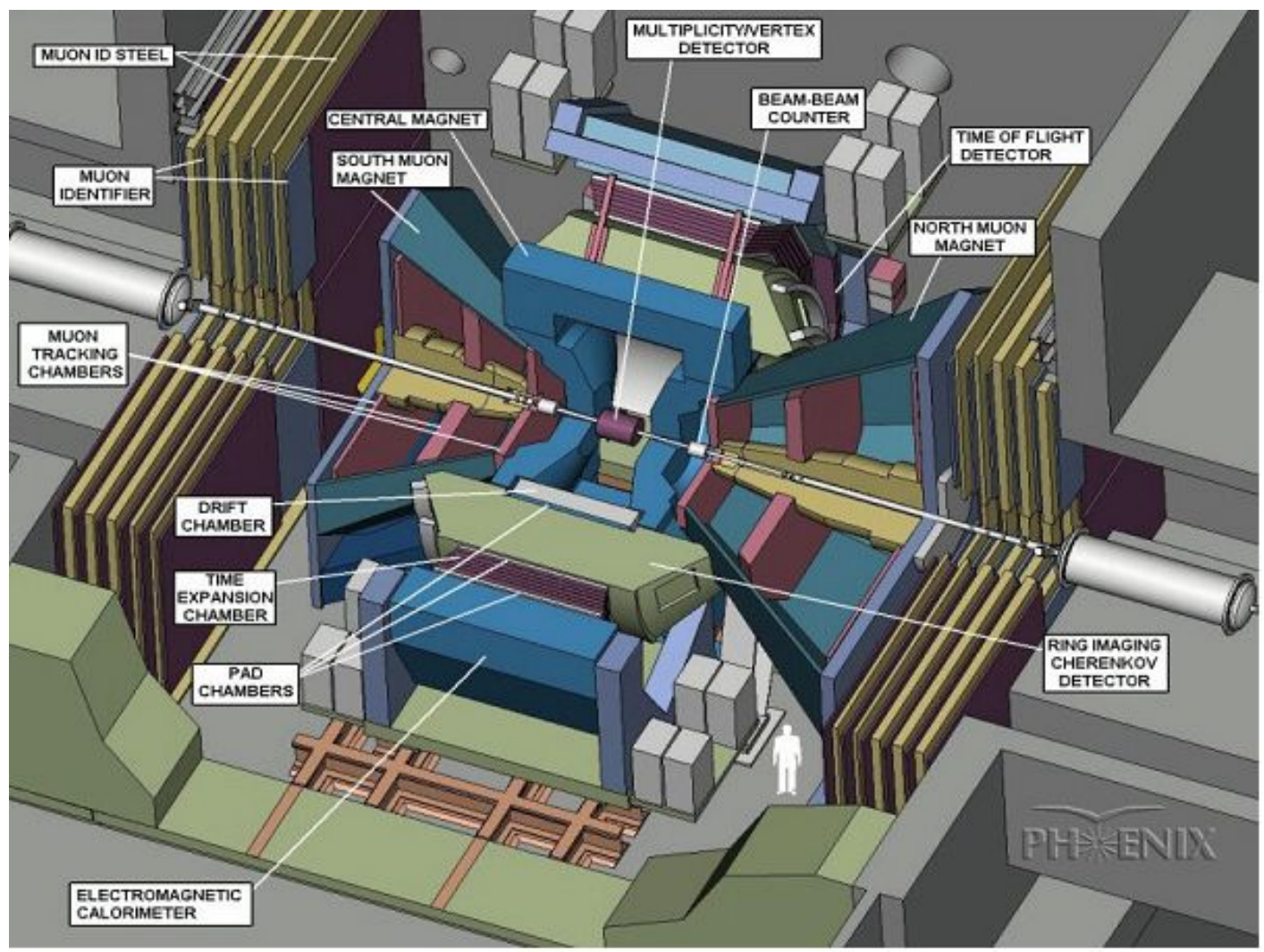

Figura 2.2: Esquema dos subsistemas que compõe o PHENIX [13]. 


\subsection{Aquisição de dados}

A alta luminosidade do RHIC e a grande quantidade de informações geradas pelos subsistemas do PHENIX representam um grande desafio para o sistema de aquisição de dados (DAQ). O cruzamento entre os feixes no RHIC ocorre a uma frequência de $9.4 \mathrm{MHz}$, e a taxa de colisões p+p chega a $500 \mathrm{kHz}$, enquanto o DAQ opera numa taxa máxima de $25 \mathrm{kHz}$.

Um sistema flexível de trigger (Level One Trigger) foi desenvolvido para a seleção e armazenamento somente dos eventos de interesse físico. O sistema permite que se combine independentemente informações de quaisquer subsistemas em 32 modos diferentes e conta ainda com um mecanismo de scale down, que prioriza eventos raros reduzindo a taxa de armazenamento de outros eventos [18].

No caso das colisões entre íons pesados o trigger é baseado tipicamente nas características globais do evento como centralidade e posição do vértice, medidas pelos BBCs e ZDCs. A seleção de eventos raros é particularmente importante para estudos do spin do próton e da produção de quarks pesados, medidos através de decaimentos leptônicos e semi-leptônicos.

O Level One Trigger conta com modos dedicados às medidas de múons nos braços Norte e Sul, e de elétrons nos braços centrais. Os dois subsistemas utilizados nesta configuração são o RICH e o EmCal, descritos neste capítulo.

\subsection{O detector Cherenkov de imagem anular}

O RICH é o principal subsistema para identificação de elétrons no intervalo de momento de 0.2 a $5 \mathrm{GeV} /$ c. O subsistema consiste num meio radiador para estimular a emissão de radiação Cherenkov e uma matriz de tubos fotomultiplicadores (PMTs) para detecção dos fótons [19].

Cada um dos braços centrais do PHENIX contém um módulo do RICH com uma região radiadora de $40 \mathrm{~m}^{3}$ preenchida por $\mathrm{CO}_{2}, 48$ espelhos esféricos formando duas superfícies esféricas refletoras de $20 \mathrm{~m}^{2}$ e duas matrizes com 1280 fotomultiplicadoras de $29 \mathrm{~mm}$ de diâmetro.

A passagem de uma partícula carregada com velocidade superior à velocidade da luz no gás que preenche o RICH, o que corresponde a um fator de Lorentz $\gamma>35$, provoca a emissão de fótons de radiação Cherenkov formando um cone em torno da direção de incidência da partícula. Os fótons são refletidos pelos espelhos esféricos, formando um anel centrado na projeção da trajetória da partícula sobre os tubos fotomultiplicadores. A figura 2.3 ilustra o processo de detecção de elétrons no RICH. 
A identificação de elétrons consiste em procurar PMTs sensibilizados em torno das projeções das trajetórias. A passagem de elétrons, que atravessam entre 87 e $150 \mathrm{~cm}$ da região radiadora, produz em média 11 fótons, de acordo com a distribuição da fig. 2.4. O uso de métodos simples de análise como a contagem do número de fótons ou de PMTs sensibilizados permite a seleção de amostras de elétrons com contaminação desprezível até momentos da ordem de $5 \mathrm{GeV} / \mathrm{c}$.

O RICH possui uma resolução temporal de 200 ps e uma ocupância extremamente baixa (da ordem de $3.4 \%$ para eventos centrais $\mathrm{Au}+\mathrm{Au}$ ), o que o torna adequado para o trigger de elétrons. A principal limitação do sistema para eventos com alta multiplicidade é a resolução espacial, dada pelo diâmetro das fotomultiplicadoras. No caso de duas trajetórias muito próximas, eventualmente ocorre a associação incorreta de anéis Cherenkov com trajetórias de hádrons. Além disso, a partir de $5 \mathrm{GeV} / \mathrm{c}$ os píons emitem radiação Cherenkov, mas a seleção de amostras com contaminação menor que $40 \%$ é possível com critérios mais rígidos até cerca de $9 \mathrm{GeV} / \mathrm{c}[20,21]$.

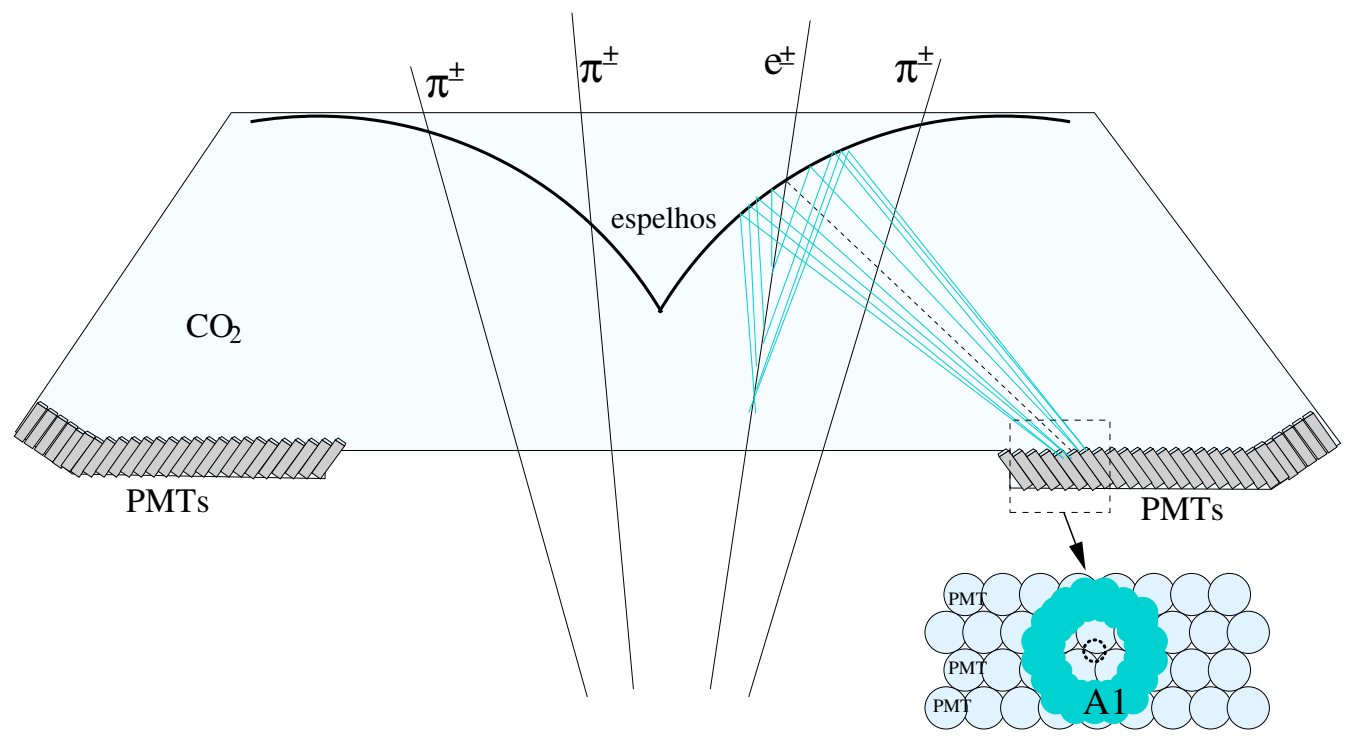

Figura 2.3: Esquema da produção e detecção de fótons de radiação Cherenkov no RICH. 


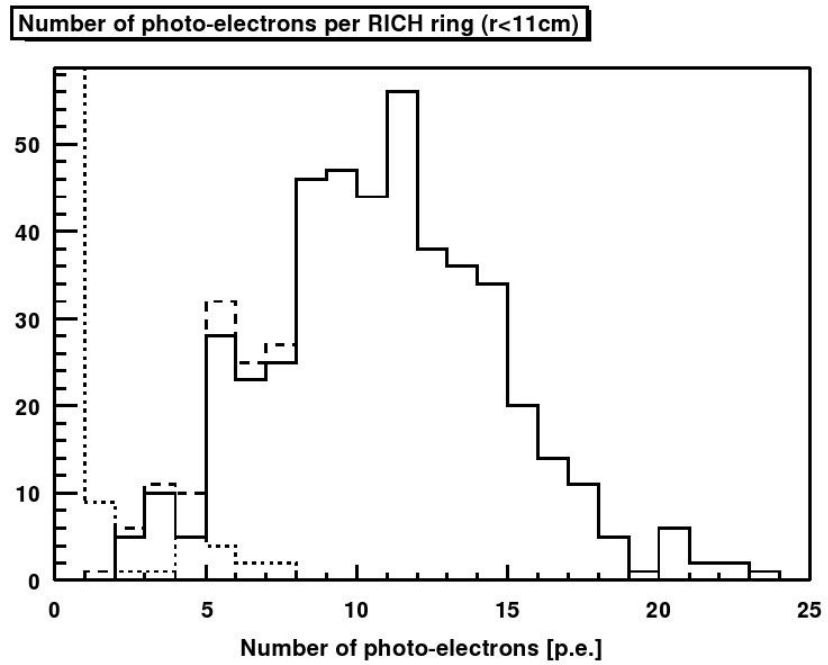

Figura 2.4: Distribuição do número de fotoelétrons em um anel gerados pela passagem de um elétron no RICH [19].

\subsection{O calorímetro eletromagnético}

O calorímetro eletromagnético do PHENIX mede a posição e a energia das partículas produzidas nas colisões, contribuindo com os sistemas de determinação de trajetórias e identificação de partículas.

Elétrons e fótons interagem eletromagneticamente com o meio através da produção de pares elétron-pósitron e de fótons de bremsstralung, que por sua vez produzem mais partículas pelos mesmos processos, gerando um chuveiro [22]. O processo é interrompido quando o limiar de produção de pares é alcançado, de modo que toda a energia da partícula incidente é depositada no meio. Os hádrons, ao contrário, produzem chuveiros basicamente através de processos hadrônicos, e depositam somente parte da energia no calorímetro [23].

A identificação de elétrons baseia-se exatamente nesse fato, considerando-se a razão entre a energia total depositada pela partícula e seu momento. No caso dos elétrons essa razão vale 1, enquanto para os hádrons, que depositam apenas uma fração da energia, esta razão é tipicamente menor que 1, como mostrado na fig. 2.7.

O EmCal é composto por dois sistemas bastante diferentes. Um calorímetro de amostragem com placas de chumbo e cintilador (Lead Scintillator - PbSc) ocupa seis setores (fig. 2.5) e possui resoluções em tempo e energia de 200 ps e $8 \% / \sqrt{E}(\mathrm{GeV})$, respectivamente. O PbSc é formado por cerca de 15 mil torres de $5.5 \mathrm{~cm} \times 5.5 \mathrm{~cm}$ $\times 33 \mathrm{~cm}$, compostas por 66 camadas de $1.5 \mathrm{~mm}$ de chumbo onde ocorre a produção de partículas (meio absorvedor) e $4 \mathrm{~mm}$ de um cintilador plástico onde as partículas são detectadas (meio ativo). A luz produzida nos cintiladores é transportada a uma 
fotomultiplicadora, instalada na parte traseira da torre, por uma fibra ótica que converte o comprimento de onda da luz gerada.

Os outros dois setores são ocupados por um calorímetro Cherenkov homogêneo ${ }^{3}$ que possui melhor resolução em energia - $6 \% / \sqrt{E}(\mathrm{GeV})$ - e resolução temporal de 300 ps. O sistema é composto por um vidro contendo chumbo (Lead Glass - PbGl) que estimula a produção de um chuveiro de partículas, que por sua vez produzem radiação Cherenkov. A radiação é mantida no interior das torres por uma camada de mylar ${ }^{4}$ aluminizado que as envolve, e detectada por fotomultiplicadoras instaladas na parte traseira.

Uma outra técnica para identificação de elétrons consiste em parametrizar o perfil do chuveiro detectado de acordo com um chuveiro eletromagnético, através de uma variável $\chi^{2}$ [23]. Essa variável é basicamente independente da energia ou do ângulo de entrada da partícula incidente e segue aproximadamente uma distribuição de $\chi^{2}$ com $N$ graus de liberdade, onde $N$ é o número de torres do calorímetro utilizadas no cálculo. A distribuição desta variável para elétrons e píons de $2 \mathrm{GeV}$ está mostrada na fig. 2.8.

O EmCal é um dos principais subsistemas utilizados no trigger do PHENIX devido à alta resolução temporal. Chuveiros eletromagnéticos com alta deposição de energia são indicadores da produção de eventos raros, contendo fótons de alta energia e elétrons provenientes de mésons de quarks pesados. O trigger é feito de acordo com a soma da energia depositada em grupos de torres adjacentes, e combinado ao trigger fornecido pelo RICH identifica a presença de elétrons num evento [23].

\footnotetext{
${ }^{3} \mathrm{Em}$ um calorímetro homogêneo, não há distinção entre o meio ativo e o meio absorvedor.

${ }^{4}$ Filme de poliéster, marca registrada da DuPont.
} 


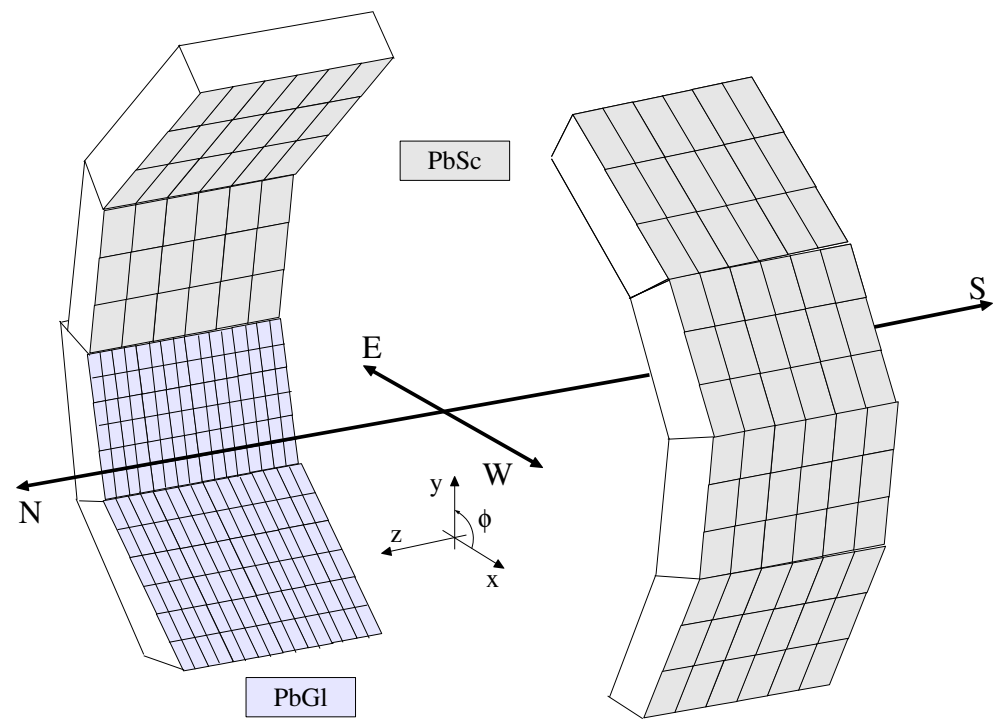

Figura 2.5: Esquema dos setores do calorímetro eletromagnético do PHENIX.

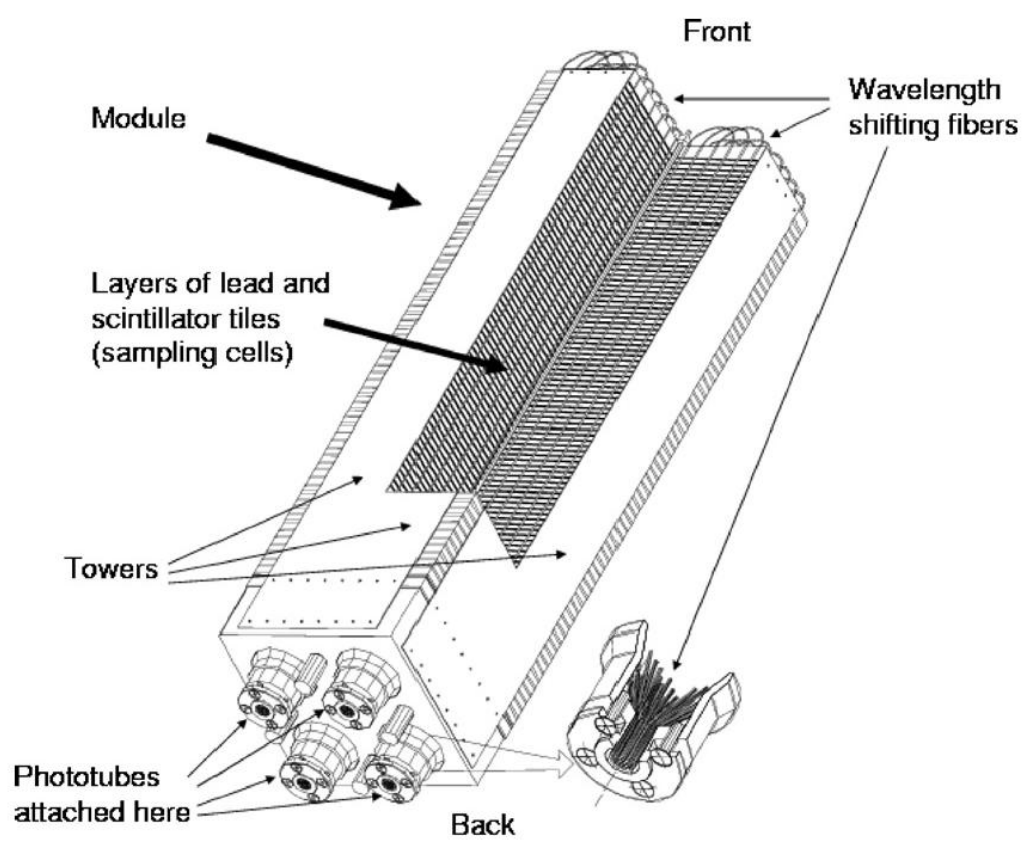

Figura 2.6: Esquema de um módulo (conjunto de 4 torres) do calorímetro PbSc [23]. 

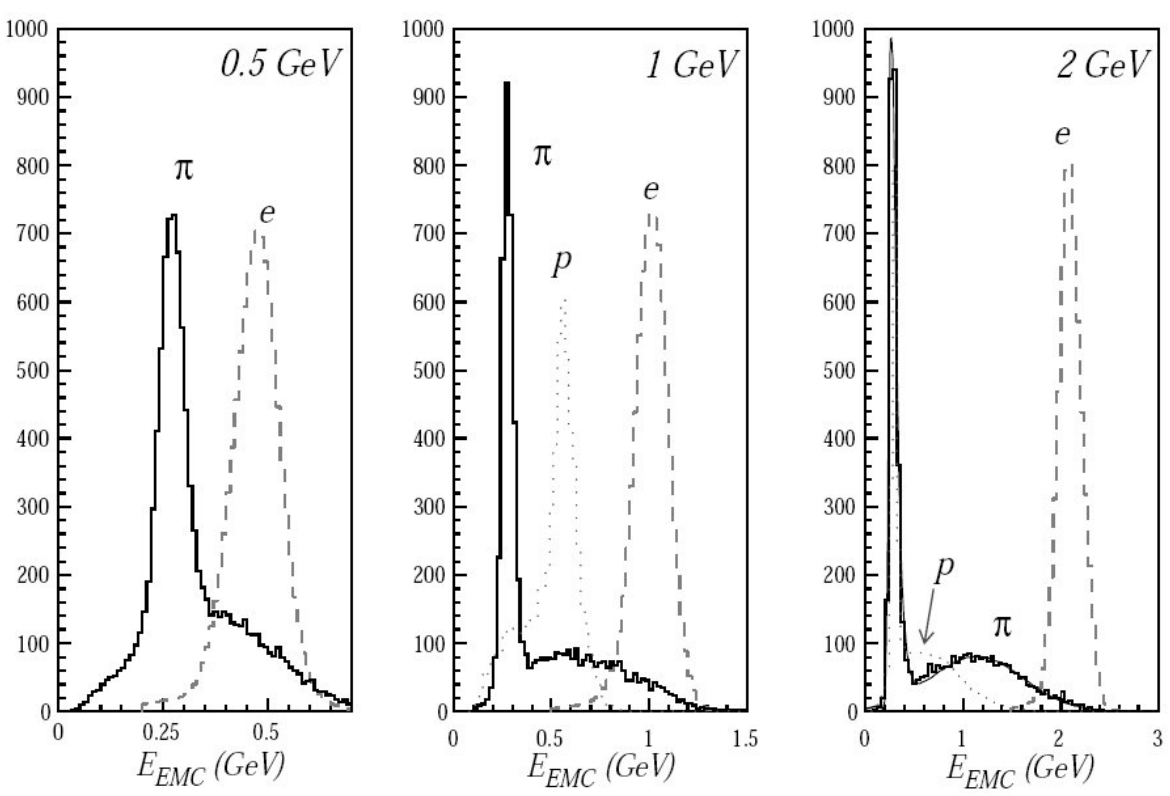

Figura 2.7: Espectros de energia medidos no calorímetro para píons, prótons e elétrons de $0.5,1$ e $2 \mathrm{GeV} / \mathrm{c}[23]$.

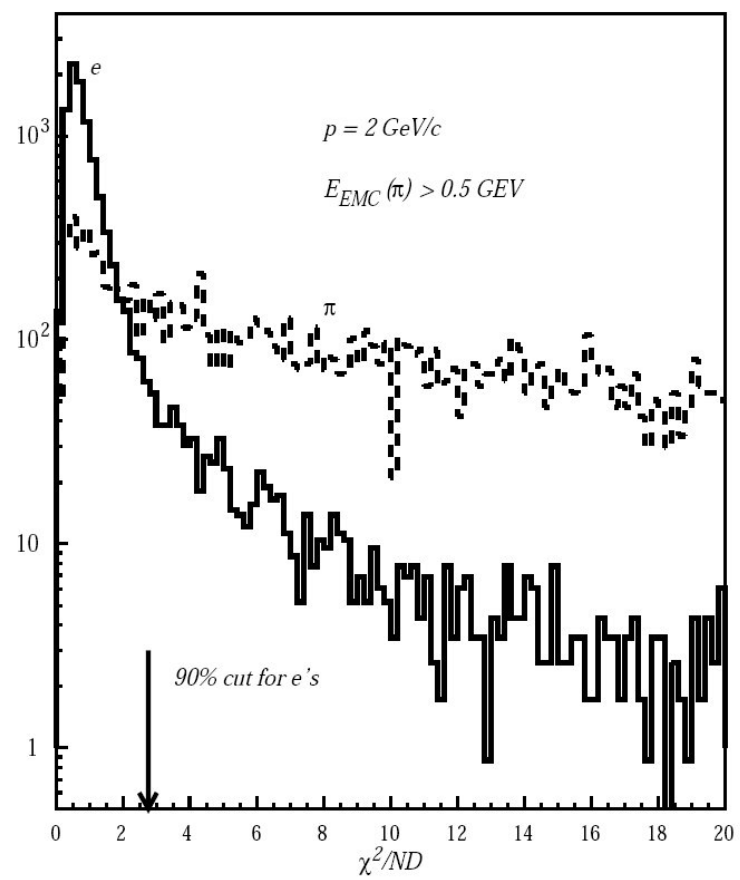

Figura 2.8: Distribuição da variável $\chi^{2}$ para chuveiros induzidos por elétrons e píons de $2 \mathrm{GeV}$ no calorímetro PbSc [23]. 



\section{Capítulo 3}

\section{As câmaras de expansão temporal do PHENIX}

Uma câmara de arrasto (drift chamber) é um detector utilizado na medida das coordenadas da trajetória de uma partícula carregada. Isso é possível através da detecção das cargas produzidas por ionização no gás que preenche a câmara, e da determinação da posição e do tempo de chegada destas cargas nos eletrodos do detector [24].

Usualmente os campos elétricos na câmara são escolhidos para que ocorra a multiplicação das cargas próximo aos elétrodos, de modo que os sinais induzidos possuam amplitudes suficientemente altas para detecção. A velocidade dos elétrons também é definida por esse campo elétrico, e para velocidades típicas (da ordem de dezenas ou centenas de $\mu \mathrm{m} / \mathrm{ns}$ ) a separação temporal entre grupos de cargas (clusters) produzidos em posições próximas é inferior à resolução temporal do sistema como um todo [25].

A câmara de expansão temporal é uma variante das câmaras de arrasto com alta resolução espacial, inventada por Walenta et al [25]. Trata-se de uma câmara proporcional multifilar composta por duas regiões distintas. A região de arrasto, onde tipicamente ocorrem as ionizações, possui um campo elétrico relativamente baixo e baixa velocidade de arrasto $^{1}$, de modo a maximizar a separação temporal entre os clusters. Nessa região, a velocidade dos elétrons é da ordem de alguns $\mu \mathrm{m} / \mathrm{ns}$.

A multiplicação das cargas ocorre na região próxima aos fios, conhecida como região de multiplicação, onde o campo elétrico é intenso e a velocidade dos elétrons é alta. Essa configuração dos campos elétricos é obtida através do uso de uma grade

\footnotetext{
${ }^{1}$ Velocidade de arrasto é a velocidade com que os elétrons se movimentam na direção dos eletrodos na presença de um campo elétrico.
} 
ou um plano de fios, que definem o limite entre as duas regiões.

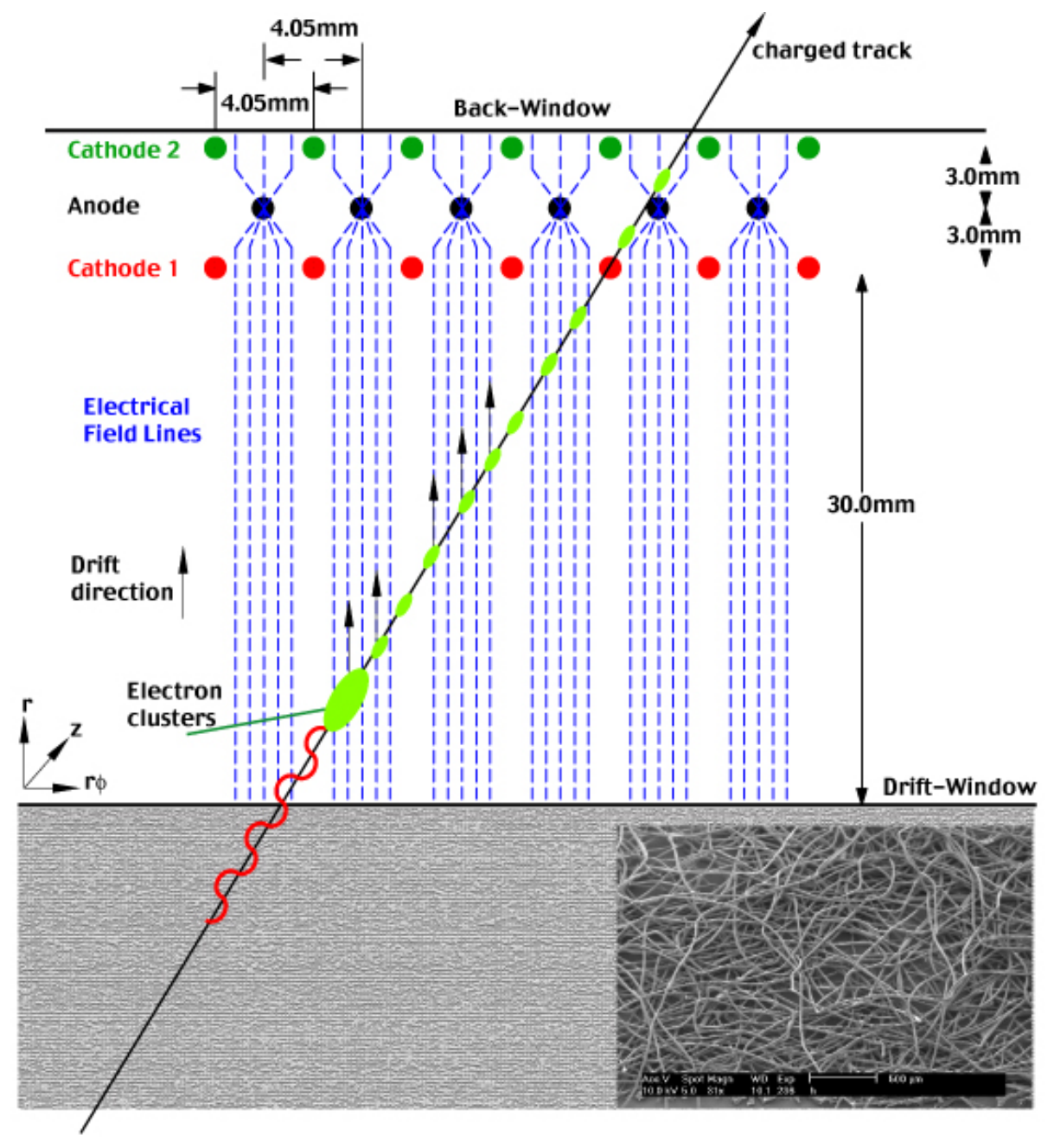

Figura 3.1: Esquema das câmaras de expansão temporal do PHENIX [11]. A passagem de partículas carregadas e a absorção de fótons de radiação de transição (em vermelho) produzidos nos radiadores, descritos na seção 3.2 (região em cinza, com o detalhe das fibras de polipropileno), geram clusters de elétrons que são atraídos para os eletrodos. O tempo de chegada dos elétrons é proporcional à posição de produção do cluster. 
As câmaras de expansão temporal do PHENIX são um conjunto de 48 câmaras adaptadas para a detecção de radiação de transição ${ }^{2}$, utilizadas na determinação de trajetórias e na identificação de partículas $[26,27]$. Os objetivos do subsistema são os seguintes:

- Determinação das trajetórias de todas as partículas carregadas entre o RICH e o EmCal.

- Identificação de elétrons usando medidas de perda de energia $(d E / d x)$ e radiação de transição (TR).

- Aumento da resolução em momento medida pela Drift Chamber para partículas com alto momento transversal $\left(p_{T}>5 \mathrm{GeV} / \mathrm{c}\right)$.

A passagem de partículas carregadas e a absorção de fótons de radiação de transição, que possuem energias na região dos raios-X, geram ionizações no gás, e os elétrons são atraídos para os fios de anodo. A posição da ionização pode ser determinada de acordo com o fio sensibilizado e o tempo de arrasto, e estas informações são utilizadas na determinação bi-dimensional das trajetórias. A fig. 3.1 ilustra o princípio de funcionamento do subsistema, indicado pela sigla TEC / TRD (Time Expansion Chambers / Transition Radiation Detectors).

Este capítulo descreve as características gerais do TEC / TRD. Uma descrição dos processos físicos envolvidos na detecção das partículas, cujo estudo foi necessário para o desenvolvimento do simulador, é apresentada no cap. 4.

\footnotetext{
${ }^{2}$ Uma descrição da radiação de transição é apresentada na seção 4.6.
} 


\subsection{Geometria e design}

O TEC está instalado no braço leste do PHENIX, representado na fig. 3.2, entre 423 e $488 \mathrm{~cm}$ em relação ao ponto de colisão, e apresenta uma cobertura azimutal de $\pi / 2$ em $\phi$ e $|\eta|<0.35$.

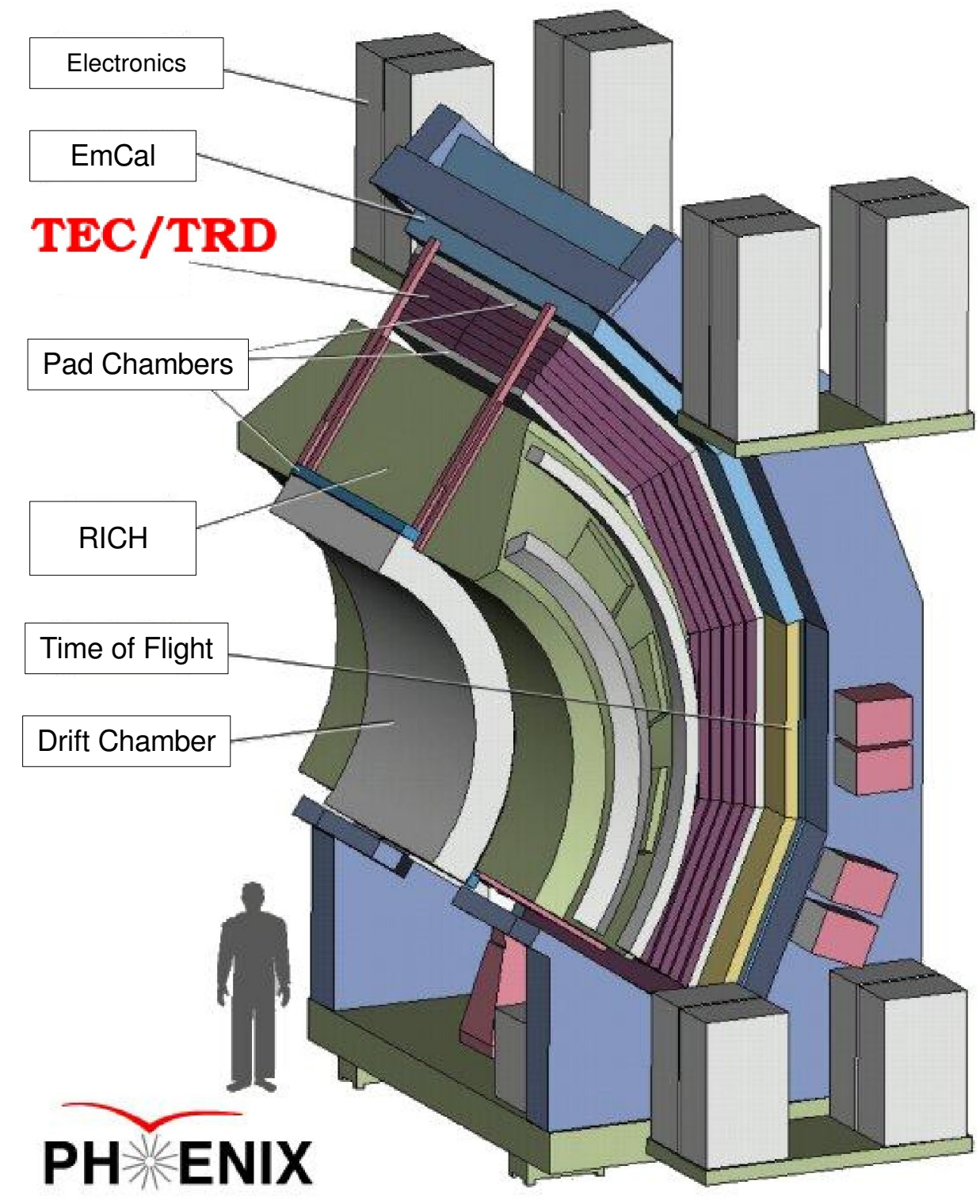

Figura 3.2: Esquema do braço leste do PHENIX [11]. 
O detector conta com 4 setores planos em $\phi$ com geometria projetiva, cobrindo $22.5^{\circ}$ cada. Cada setor é formado por uma pilha de 6 câmaras dispostas em formato de cunha, conforme o esquema da fig. 3.3. Os setores são divididos em 2 lados (Norte e Sul) em $\eta=0$ de modo a reduzir a ocupância de cada câmara. A câmara interna de cada setor tem dimensão de $3.1 \mathrm{~m} \times 1.7 \mathrm{~m}$ e a câmara externa tem dimensão de $3.5 \mathrm{~m} \times 1.9 \mathrm{~m}$.

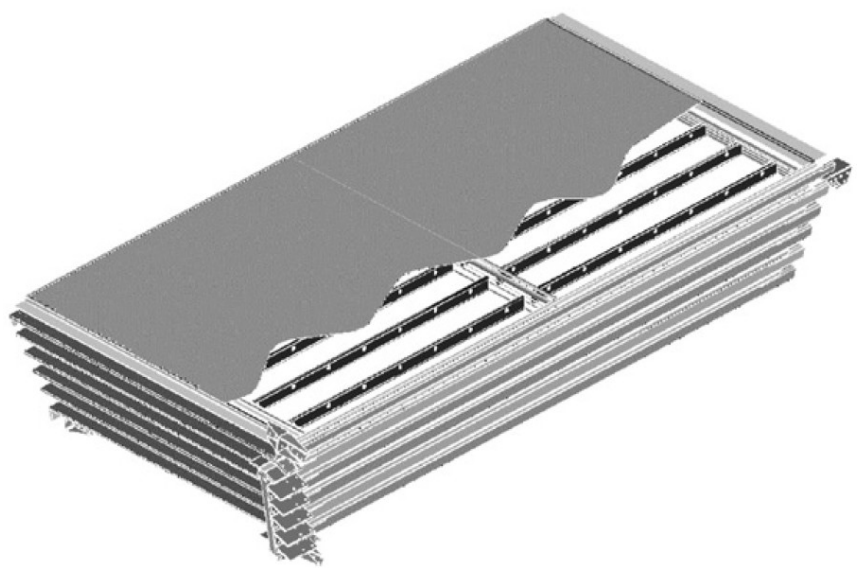

Figura 3.3: Esquema de um setor do TEC [17].

Cada câmara é composta por uma janela de cobre e mylar de $25 \mu \mathrm{m}$, seguida por uma região de arrasto de $3 \mathrm{~cm}$, três planos de fios (catodo, anodo, catodo) separados de $3 \mathrm{~mm}$, e uma janela traseira idêntica à dianteira. O espaçamento entre os fios é de 4.05 ou $4.15 \mathrm{~mm}$ dependendo da câmara, e o número de fios de anodo por câmara varia entre 415 e 468.

A alta tensão pode ser alterada em cada câmara individualmente, e tipicamente é mantida a $-3000 \mathrm{~V}$ na janela dianteira, $1600 \mathrm{~V}$ nos fios de anodo e $0 \mathrm{~V}$ nos fios de catodo e na janela traseira. A tensão utilizada nos fios de anodo é próxima ao valor máximo que permite a operação do detector no regime proporcional [24, 28]. Essa configuração permite que se tenha campos elétricos da ordem de $1 \mathrm{kV} / \mathrm{cm}$ na região de arrasto, e campos de até $200 \mathrm{kV} / \mathrm{cm}$ próximo aos fios, na região de multiplicação. 


\subsection{Radiadores}

À frente de cada uma das câmaras está instalado um radiador de fibras de polipropileno para produção de radiação de transição, onde circula gás carbônico à pressão atmosférica. As fibras, mostradas no detalhe da fig. 3.1, possuem $17 \mu \mathrm{m}$ de diâmetro e estão orientadas aleatoriamente no plano perpendicular à direção de incidência das partículas.

O radiador consiste em sanduíches compostos por 11 camadas de fibras e 1 camada de $0.6 \mathrm{~cm}$ de uma espuma rígida de baixa densidade (polimetacrilimida Rohacell IG51 (R), dispostos conforme o esquema da fig. 3.4. Os sanduíches são envoltos por uma camada de $25 \mu \mathrm{m}$ de mylar e instalados em molduras à frente da janela de entrada de cada câmara.

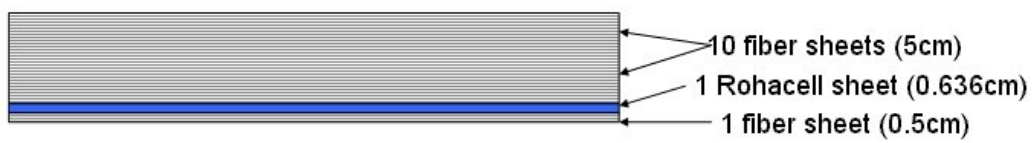

Figura 3.4: Esquema dos sanduíches do radiador do TEC / TRD.

\subsection{Gás}

O gás é o meio ativo do detector, onde ocorre a produção e a multiplicação das cargas ${ }^{3}$. De maneira geral, o uso de misturas que apresentam vida útil longa e que são pouco eletronegativas e pouco reativas é bastante desejável, de modo a garantir a durabilidade e a eficiência do detector. Essas características restringem as possibilidades dos gases que podem ser utilizados, e sugerem o uso de gases nobres ou compostos orgânicos.

No caso de um detector de radiação de transição, é recomendável o uso de elementos com número atômico elevado como o xenônio ou o argônio, de modo a maximizar a absorção dos fótons. Misturas contendo estes elementos são tipicamente empregadas juntamente com um composto orgânico. Isso permite a operação com ganhos da ordem de $10^{3}-10^{4}[22,24,28]$.

Devido ao alto custo do xenônio e ao grande volume total das câmaras do TEC - cerca de 12 mil litros - o uso de uma mistura com alta concentração deste gás é economicamente inviável. Durante os períodos de tomada de dados, uma mistura

\footnotetext{
${ }^{3}$ Estes fenômenos serão discutidos em detalhe no cap. 4.
} 
com $45 \%$ de xenônio, $45 \%$ de hélio $(\mathrm{He})$ e 10\% de metano à pressão atmosférica é utilizada.

Para verificação das condições do detector nos períodos em que não há tomadas de dados é utilizado o P10 - 90\% de argônio (Ar) e 10\% de metano $\left(\mathrm{CH}_{4}\right)$ - à pressão atmosférica, que é amplamente empregado em drift chambers [24]. Para ambas as misturas, a temperatura do sistema é mantida próxima de $22^{\circ} \mathrm{C}$.

\subsection{Eletrônica}

A eletrônica associada ao detector deve ser capaz de registrar a amplitude e a posição das ionizações, através do tempo de chegada das cargas nos fios de anodo. Cada fio está associado a um canal de eletrônica independente, esquematizado na fig. 3.5. Os fatores determinantes para a escolha do sistema de aquisição são o grande número de canais e as grandes variações na amplitude dos sinais, de acordo com os processos de produção de cargas $(d E / d x \text { e TR })^{4}$.

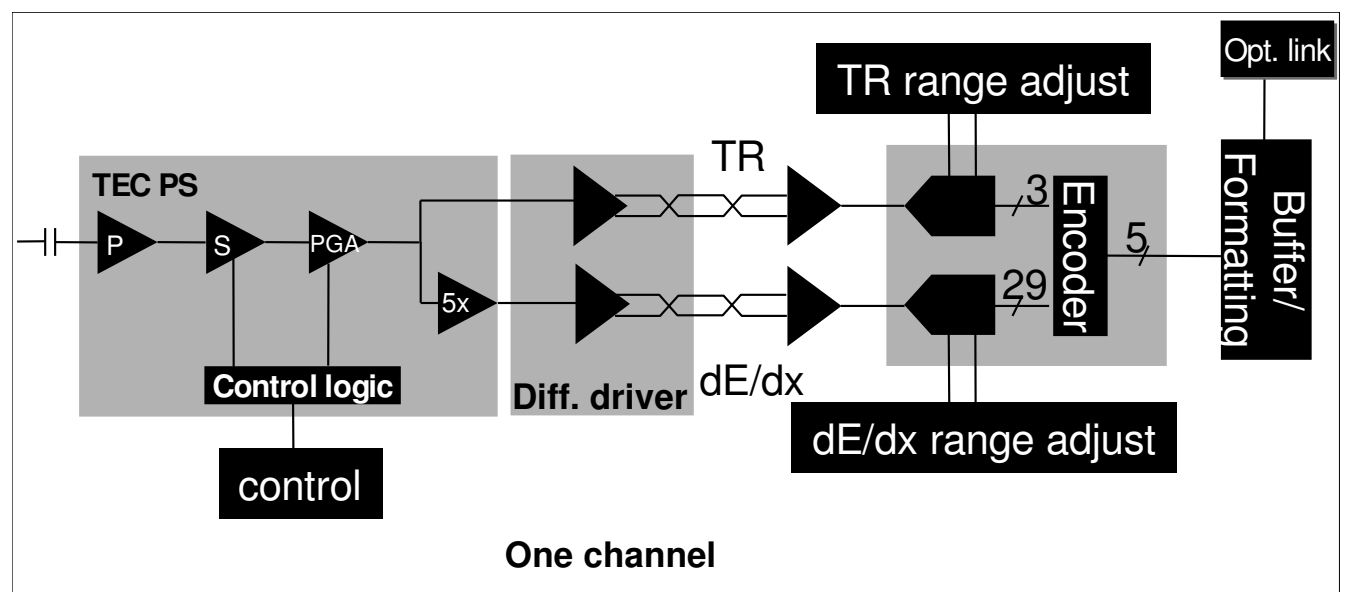

Figura 3.5: Esquema de um canal da eletrônica do TEC.

O TEC conta com cerca de 20 mil canais de eletrônica, divididos entre aproximadamente 600 placas de circuito impresso responsáveis pela formatação analógica de 32 canais cada, e cerca de 300 placas onde ocorre a digitalização dos sinais de 64 canais. Os pré-amplificadores estão ligados a placas responsáveis pelo desacoplamento da alta tensão, na região próxima aos fios de anodo para evitar perdas nos sinais.

\footnotetext{
${ }^{4}$ Os clusters associados a $d E / d x$ possuem energias da ordem de $0.5 \mathrm{keV}$ contra $1-20 \mathrm{keV}$ dos fótons de TR.[27]
} 
O tratamento analógico das correntes induzidas é feito por pré-amplificadores de carga e formatadores programáveis. É possível desabilitar ou ajustar o ganho e o tempo de formatação dos sinais de cada canal individualmente, e injetar cargas com valores conhecidos para calibração e verificação de canais defeituosos. O tempo de formatação é escolhido de modo a maximizar a relação sinal / ruído e minimizar a probabilidade de empilhamento dos sinais. O valor padrão é definido em $75 \mathrm{~ns}$ e pode variar entre 60 e 120 ns.

A solução adotada para cobrir a grande faixa de amplitudes dos sinais foi o uso de duas linhas de amplificação para cada canal, com ganhos relativos de cerca 5 vezes. Sinais de baixa amplitude, correspondentes a medidas de $d E / d x$ possuem ganhos típicos de $21 \mathrm{mV} / \mathrm{fC}$, enquanto os sinais de TR com alta amplitude têm ganho típico de $4.3 \mathrm{mV} / \mathrm{fC}$.

Os sinais formatados e amplificados são transmitidos diferencialmente por cabos de até $8 \mathrm{~m}$ para os Front-End Modules (FEMs), onde a digitalização é feita por flashADCs a uma taxa de cerca de $37.6 \mathrm{MHz}$. Essa frequência corresponde ao quádruplo da frequência de colisões entre os feixes, e foi definida de acordo com o volume de dados suportado pelo sistema de aquisição e a resolução espacial necessária para determinação do ponto de produção das cargas.

São utilizados um ADC bilinear com 29 valores para $d E / d x$ e um ADC de 3 valores para $\mathrm{TR}$, ambos com limites superior e inferior das faixas de conversão ajustáveis individualmente. As faixas de conversão padrão dos ADCs estão mostradas nas figs. 3.6(a) e 3.6(b). O uso de ganhos diferentes e de três faixas de conversão permite a cobertura de um range dinâmico ${ }^{5}$ de 9 bits, codificado numa saída de 5 bits. Os dados digitalizados e formatados são armazenados num buffer nas FEMs, e transferidos por fibra ótica ao sistema de aquisição do PHENIX.

\footnotetext{
${ }^{5} \mathrm{O}$ range dinâmico corresponde à razão entre o valor da carga que satura o sistema (400 fC) e a precisão na menor escala de conversão (1 fC).
} 


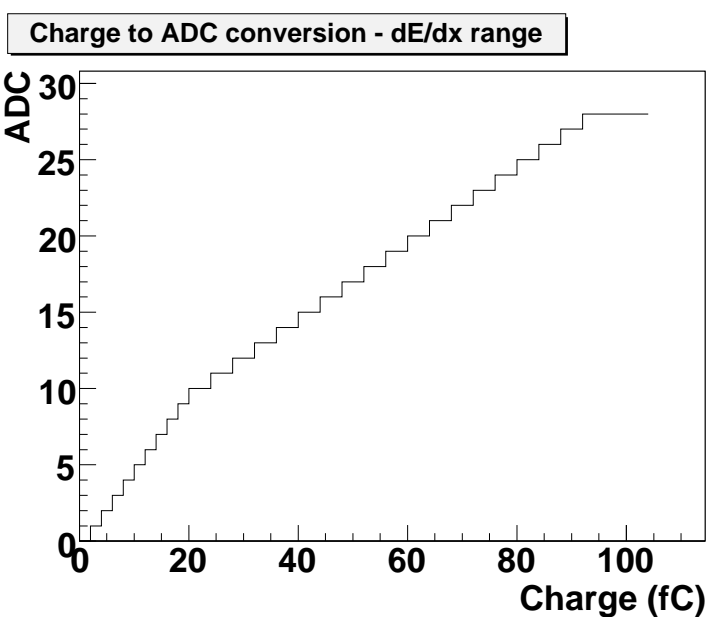

(a)

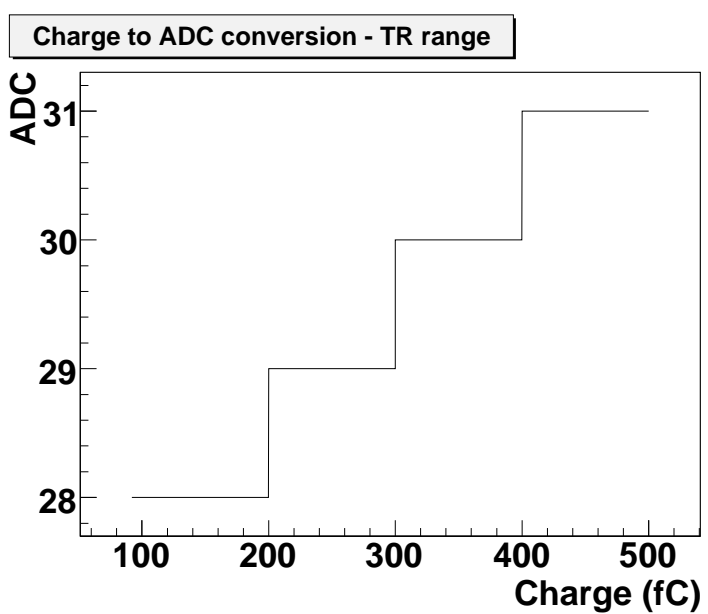

(b)

Figura 3.6: Conversão entre carga e valor de ADC para (a) $d E / d x$ e (b) TR.

A digitalização converte as informações de tempo e amplitude dos sinais em valores de $\mathrm{ADC}$ e amostras temporais (timebins). A fig. 3.7 mostra um esquema do tratamento das correntes, a partir da simulação da corrente induzida por uma ionização localizada, considerando a formatação e a digitalização.

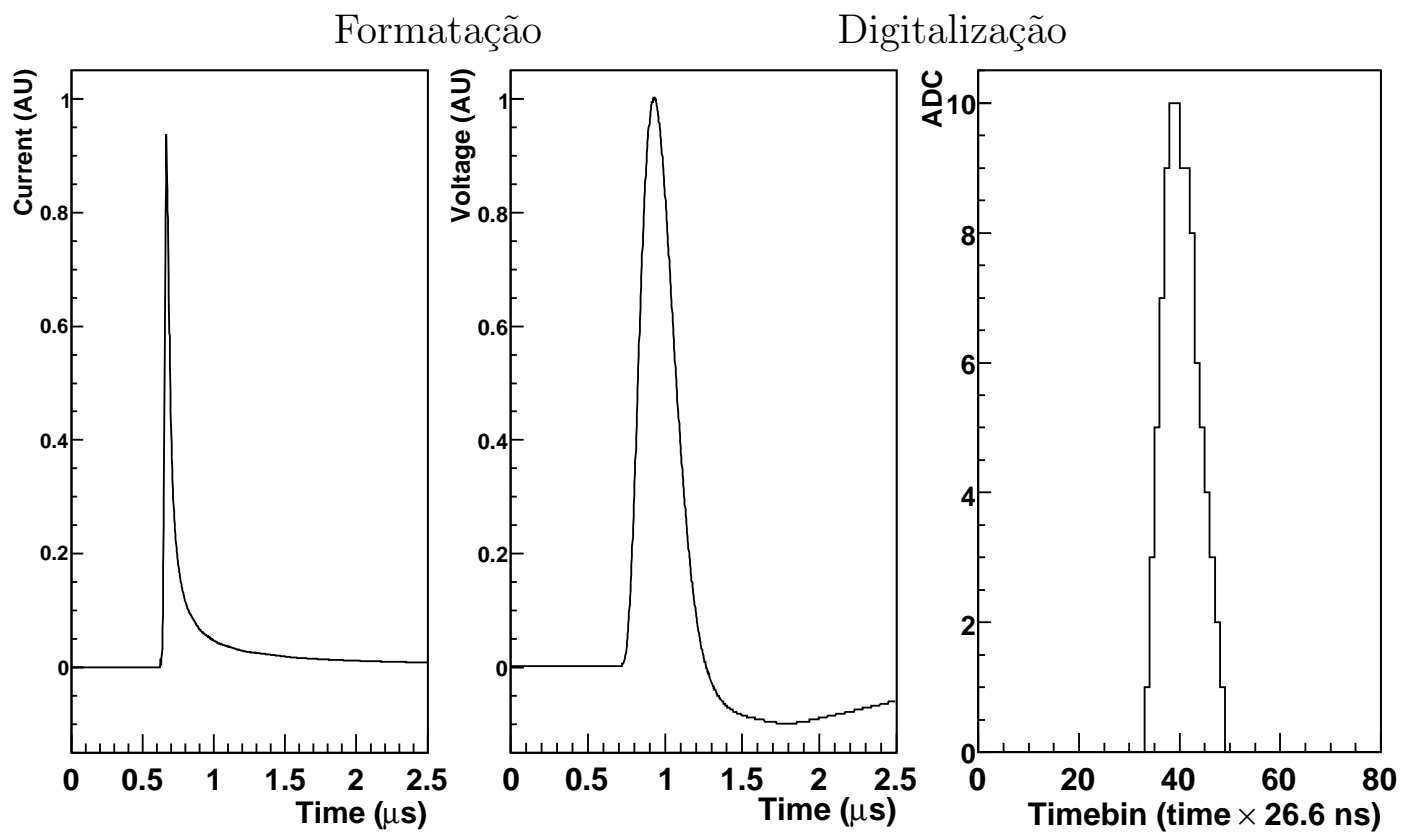

Figura 3.7: Esquema da formatação e digitalização dos sinais no TEC / TRD a partir da simulação da corrente induzida por uma ionização localizada. 


\subsection{Determinação de trajetórias}

A posição bi-dimensional das ionizações produzidas na passagem de partículas pode ser determinada de acordo com o fio sensibilizado e o tempo de arrasto, dividido em 80 amostras de aproximadamente 26.6 ns.

A determinação das trajetórias (tracking) utiliza a transformada de Hough [29], um método empregado normalmente no processamento digital de imagens para identificação de formas simples. A identificação de uma linha, por exemplo, é feita notando que cada par de pontos pode ser associado a um par de coeficientes angular e linear de uma reta. O mapeamento de vários pares de pontos pertencentes à mesma trajetória num espaço definido por estes coeficientes gera uma região com alta concentração de pontos, em torno dos valores verdadeiros destes coeficientes.

No caso do TEC, cada par de itts $^{6}$ determina um ponto no espaço $\phi \times \alpha$, onde $\phi$ é o ângulo polar em relação a um raio de referência, e $\alpha$ é a inclinação da trajetória em relação a $\phi$ neste ponto (fig. 3.8(a)), que é inversamente proporcional ao momento da partícula. As trajetórias reais são identificadas por picos num histograma $\phi \times \alpha$, e os hits que não estão associados às trajetórias são desprezados. A fig. 3.8(b) mostra algumas trajetórias medidas pelo TEC em colisões $\mathrm{Au}+\mathrm{Au}$.

Esses coeficientes são os mesmos utilizados pelo tracking da Drift Chamber, e isso permite uma fácil associação entre as trajetórias medidas pelos dois subsistemas. Devido à maior distância do TEC em relação ao ponto de colisão, a combinação das informações dos dois subsistemas resulta numa melhora na resolução em momento para $p_{T}>4 \mathrm{GeV}[17]$.

\footnotetext{
${ }^{6}$ Um hit corresponde a uma amostra temporal de um fio do TEC.
} 


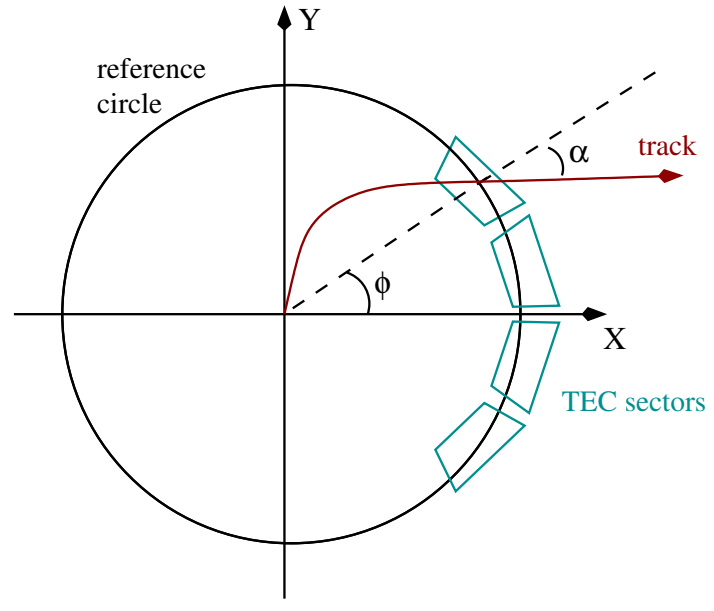

(a)

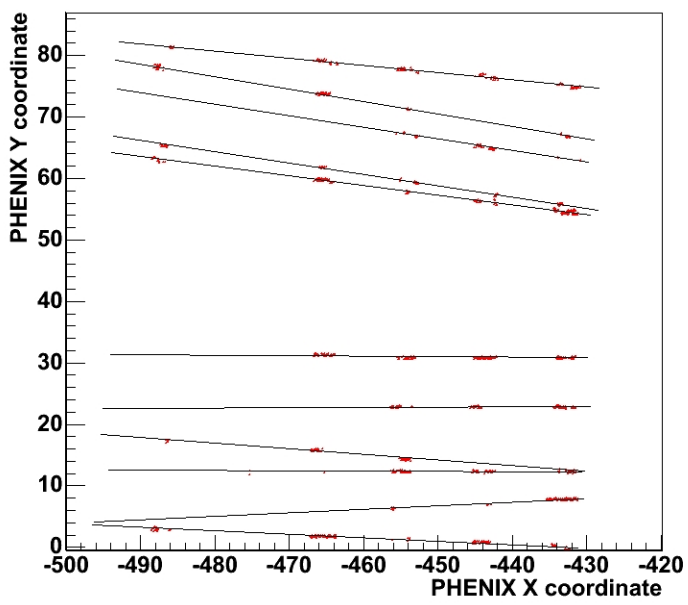

(b)

Figura 3.8: (a) Esquema das variáveis usadas no tracking do TEC / TRD. A curvatura da trajetória é causada pelo campo magnético produzido pelo ímã central. (b) Trajetórias medidas por 5 câmaras de um setor do TEC / TRD em colisões $\mathrm{Au}+\mathrm{Au}$. Os pontos escuros representam os hits associados às trajetórias.

\subsection{Identificação de partículas}

A separação entre elétrons e hádrons - na maioria píons - no TEC / TRD baseia-se em dois fenômenos, descritos no cap. 4:

- Para momentos de cerca de $1 \mathrm{GeV} / \mathrm{c}$, a perda de energia dos elétrons é superior à dos píons, que são partículas mínimo-ionizantes, enquanto os elétrons estão na região da alta relativística da equação de Bethe-Bloch (eq. 4.1).

- Os elétrons produzem fótons de TR nos radiadores do TEC / TRD a partir de $0.5 \mathrm{GeV} /$ c. Para os píons esse limiar é de $140 \mathrm{GeV} / \mathrm{c}$.

A probabildade de absorção dos fótons de radiação de transição é maior na região próxima aos radiadores, que corresponde a valores altos de tempo de arrasto. O seu sinal é sobreposto ao sinal de ionização, o que gera um aumento na carga coletada, conforme se observa na fig. 3.9.

As grandes flutuações na perda de energia, representadas pelas distribuições na fig. 3.10, fazem com que o uso de técnicas simples de análise não permitam a seleção de amostras com baixa contaminação, como é feito no caso de detectores de radiação Cherenkov. Diversos métodos utilizados para identificação de partículas podem ser encontrados na literatura [30-32], e alguns são exemplificados aqui com dados de colisões $\mathrm{p}+\mathrm{p}$ do run-5 do RHIC (2005). Os elétrons foram selecionados de acordo com os critérios do RICH e EmCal, descritos no cap. 2. 


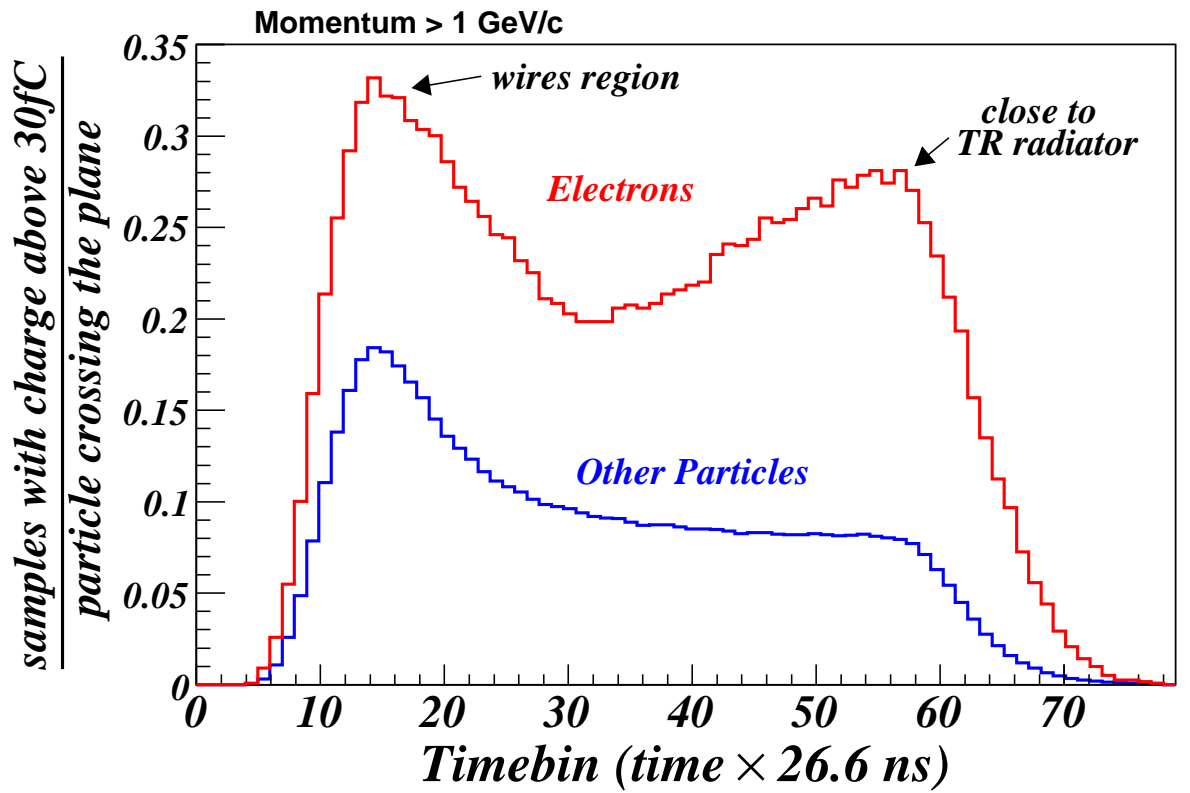

Figura 3.9: Número médio de amostras com deposição de carga acima de 30 fC por partícula em função do tempo (timebin) em uma das 48 câmaras do TEC / TRD.

\section{dE/dx distributions on TEC / TRD}

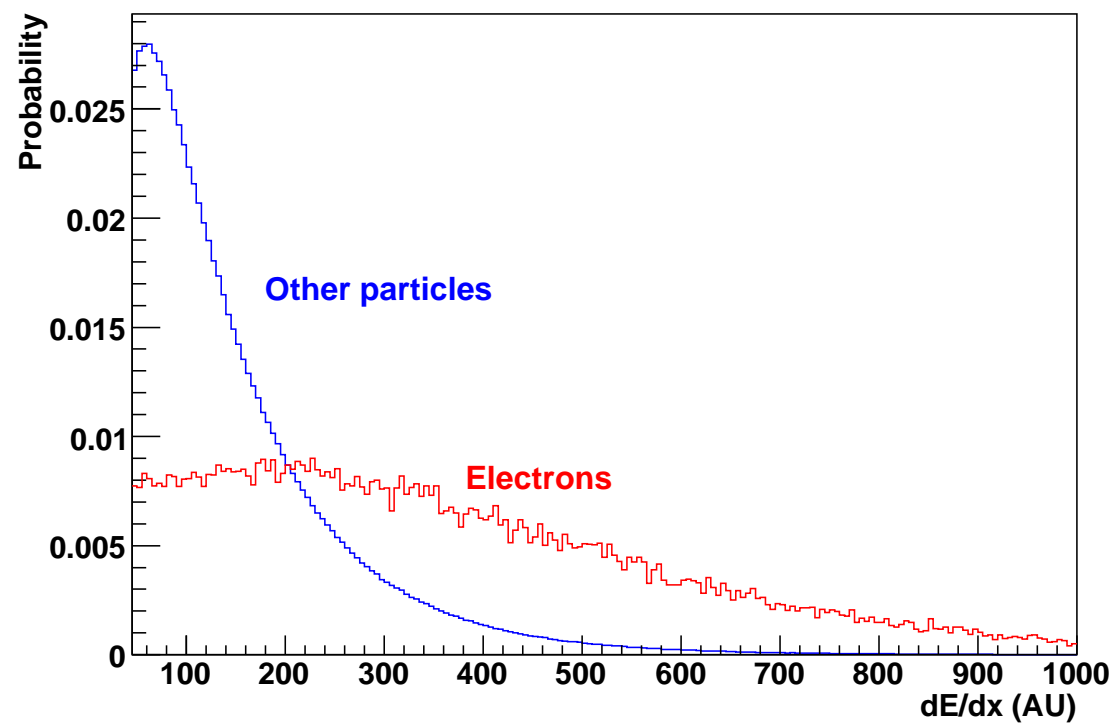

Figura 3.10: Distribuição da perda de energia nas câmaras do TEC / TRD para elétrons e outras partículas. 


\section{Média truncada}

O método da média truncada consiste em desprezar uma certa porcentagem das amostras com maior deposição de carga para cada partícula. Isso reduz as flutuações na perda de energia, eliminando parte da cauda da distribuição. Por outro lado, no caso de um detector de radiação de transição esse método elimina as amostras provenientes da absorção de fótons. O truncamento em geral é definido por meio de simulações, de modo a maximizar a eficiência de separação entre as partículas. A fig. 3.11 mostra a distribuição da perda de energia truncada em $60 \%$.

\section{$\mathrm{dE} / \mathrm{d} \times 60 \%$ truncated distributions on TEC / TRD}

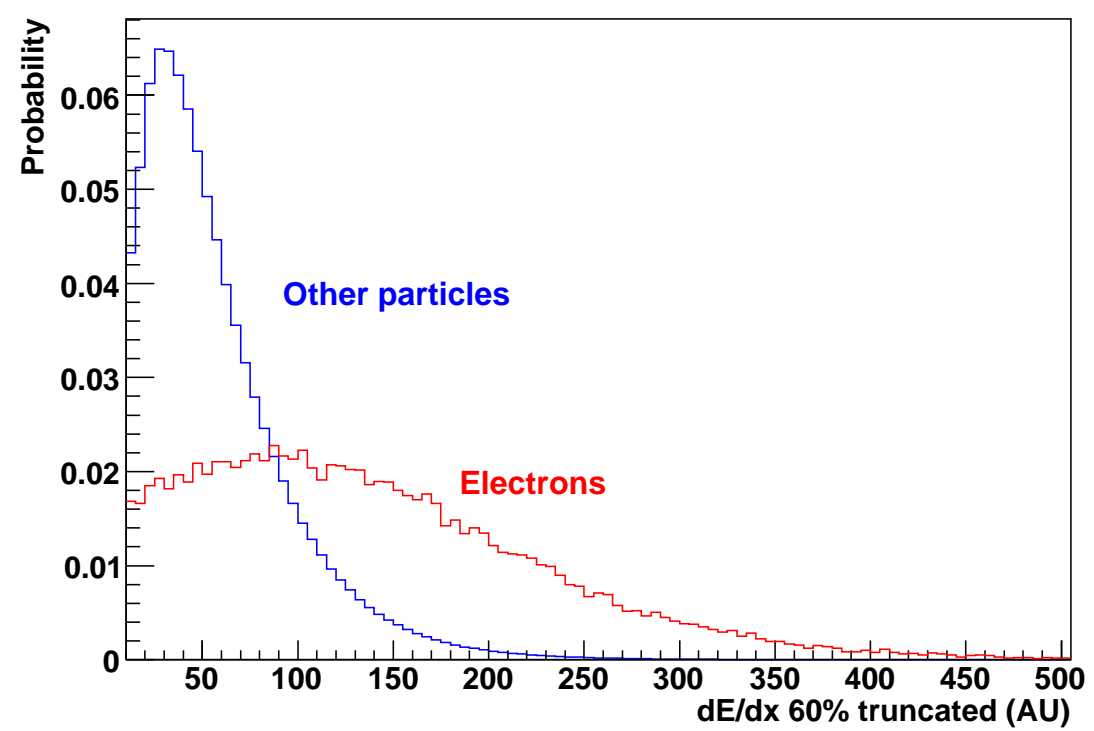

Figura 3.11: Distribuição da perda de energia nas câmaras do TEC / TRD truncada em $60 \%$ para elétrons e outras partículas.

\section{Contagem de clusters}

Outro método bastante empregado é a contagem do número de hits acima de um certo valor de carga, preferencialmente para valores altos de tempo de arrasto. Dependendo do corte no valor de carga, este número corresponde ao número de ionizações ou ao número de fótons de radiação de transição absorvidos. Na fig. 3.12 observa-se um aumento acima do limiar de produção de TR para os elétrons, e fundo é dado basicamente pelas grandes deposições de carga. 


\section{Cluster counting method - TEC / TRD}

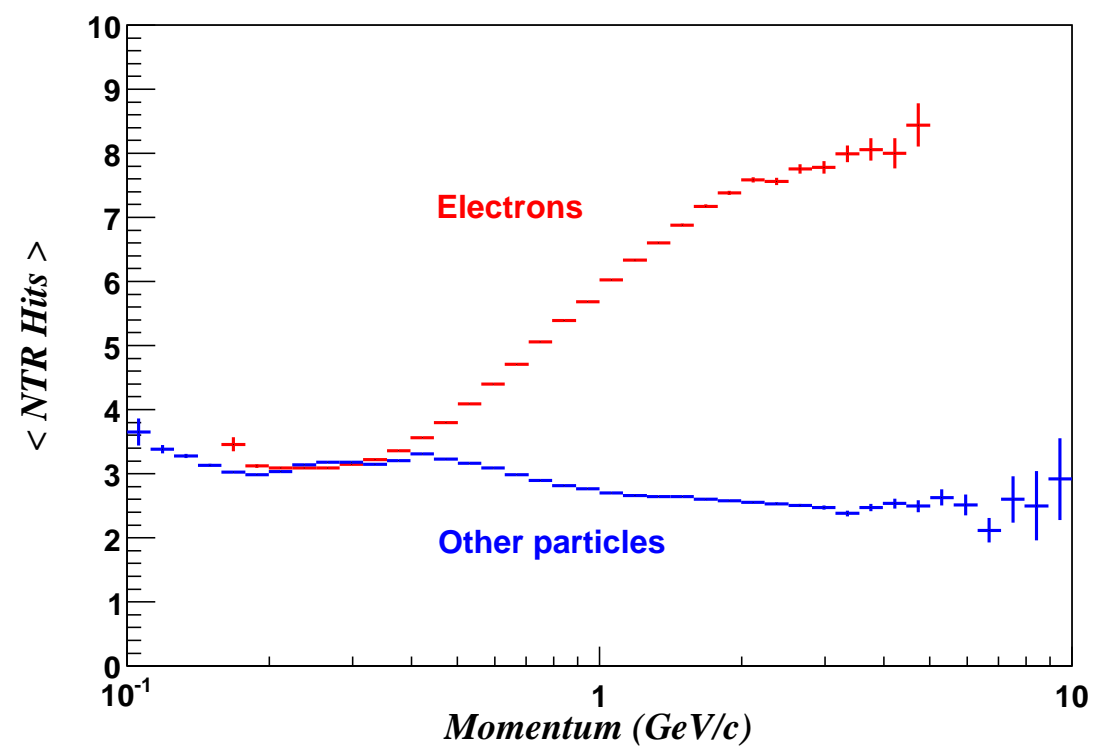

Figura 3.12: Número médio de hits de TR (amostras acima de um certo valor de ADC) medidos no TEC / TRD em função do momento para elétrons e outras partículas.

\section{Máxima verossimilhança}

O método da máxima verossimilhança consiste genericamente em assumir que uma medida está associada ao evento com maior probabilidade de ocorrência nas condições dadas. No caso da identificação de partículas, isso se traduz por exemplo na seguinte relação: é $p$ vezes mais provável que a partícula responsável pela deposição da energia medida $E_{i}$ seja um elétron, onde $p$ é dado pela razão ente os valores das funções de probabilidade de deposição de energia para um elétron ou um píon no ponto $E_{i}$ :

$$
p=\frac{P\left(E_{i} \mid e\right)}{P\left(E_{i} \mid \pi\right)} .
$$

A partir de um conjunto de medidas em $n$ câmaras, é construído um estimador de verossimilhança, dado por:

$$
\mathscr{L}=\sum_{i=1}^{n} \log \frac{P\left(E_{i} \mid e\right)}{P\left(E_{i} \mid \pi\right)},
$$

e um valor mínimo de $\mathscr{L}$ é definido para que se aceite a partícula como um elétron. Na fig. 3.13 são mostradas as funções de verossimilhança construídas a partir das distribuições do número de hits para elétrons e outras partículas. 
Likelihood distribution for the number of hits on TEC / TRD

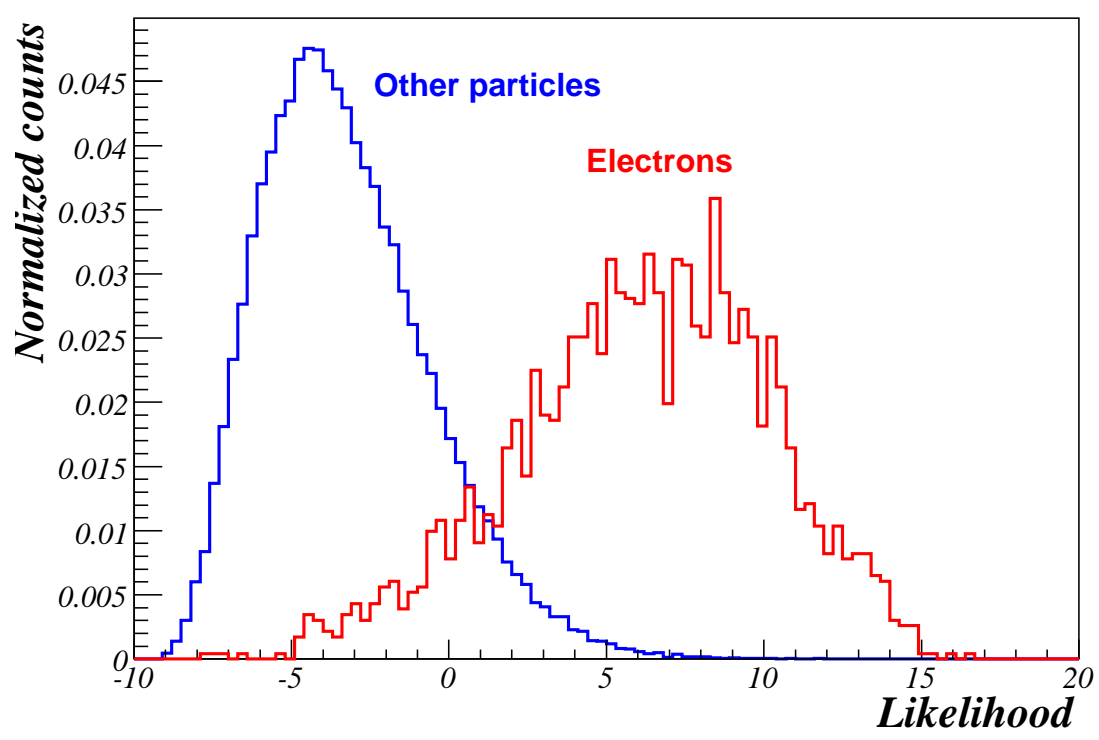

Figura 3.13: Funções de verossimilhança (Likelihood) do número de hits para elétrons e outras partículas no TEC / TRD.

\subsection{Simulações}

Os métodos para identificação de partículas descritos acima, frequentemente baseiam-se no uso de simuladores para obtenção das distribuições de probabilidade associadas. No caso do TEC isso geralmente é feito a partir de dados reais de amostras de elétrons selecionados pelos outros subsistemas - RICH e EmCal.

Estas amostras possuem baixa estatística e estão limitadas à região de momentos até $5 \mathrm{GeV} / \mathrm{c}$, a partir da qual o RICH não é eficiente na identificação das partículas. Um simulador capaz de reproduzir essas distribuições num intervalo de momentos extenso contribuiria na aplicação destes métodos.

Os métodos tradicionais tratam as amostras temporais separadamente, e portanto ignoram a forma dos sinais. Alguns autores já mencionaram que estes métodos não exploram toda a informação contida na forma de onda induzida [33], e o uso dessa informação eventualmente permitiria um aumento na separação $\mathrm{e}^{-} / \pi$.

Com o intuito de reproduzir a resposta das câmaras do TEC à passagem das partículas, incluindo todos os processos físicos até a geração dos sinais, um simulador baseado no programa Garfield [34] foi desenvolvido. 



\section{Capítulo 4}

\section{Processos físicos no TEC / TRD}

O desenvolvimento das drift chambers está fortemente relacionado ao conhecimento dos processos físicos envolvidos na detecção das partículas. Na época em que a primeira câmara multifilar foi construída por Charpak et al em 1968, já havia diversos modelos que descreviam satisfatoriamente a interação das partículas com a matéria e o movimento de elétrons e íons em gases. A existência e o constante aprimoramento de modelos e programas computacionais dedicados à reprodução destes fenômenos é uma evidência da importância dada a este tema [24, 28].

O Garfield [34], utilizado neste trabalho, é um programa desenvolvido para a simulação de detectores gasosos, amplamente empregado por experimentos de larga escala. É o caso da Drift Chamber do PHENIX, do Time Projection Chamber e do detector de radiação de transição (TRD) do experimento ALICE [35, 36], e dos Muon Drift Tubes do experimento ATLAS [37].

O Garfield permite o cálculo do campo elétrico no detector, do movimento de elétrons e íons no gás, e dos sinais induzidos nos eletrodos. As propriedades de transporte dos gases são calculadas pelo programa Magboltz [38, 39], e a interação de partículas com o gás é calculada pelo programa Heed [40, 41], utilizando uma adaptação do modelo de foto-absorção e ionização, descrito na seção 4.1.1.

As referências destacadas trazem diversas aplicações do programa, e descrevem também algumas limitações, relacionadas ao cálculo da multiplicação das cargas e dos sinais induzidos no detector. Isso motivou um estudo para verificação destas limitações através da comparação de medidas e simulações de um sistema relativamente simples - um detector proporcional monofilar, descritas no cap. 5.

Este capítulo descreve os processos relacionados à detecção das partículas no TEC / TRD - perda de energia de partículas carregadas, absorção de fótons, produção de radiação de transição, movimento e multiplicação das cargas - com exemplos baseados nos cálculos para o desenvolvimento do simulador. 


\subsection{Perda de energia de partículas carregadas}

A detecção de uma partícula carregada é possível graças às interações sofridas por esta ao atravessar um meio. Dentre as interações possíveis, a eletromagnética, correspondente à troca de fótons entre a partícula e os átomos do material, é ordens de grandeza mais provável.

No caso de uma câmara a gás, uma pequena fração da energia cinética da partícula incidente, tipicamente alguns $\mathrm{keV} / \mathrm{cm}$, é utilizada na excitação e ionização dos átomos.

Historicamente utiliza-se o modelo de Bethe-Bloch, derivado no contexto da mecânica quântica relativística, como descrição para a perda de energia média por unidade de comprimento $d E / d x[22]$ :

$$
-\frac{d E}{d x}=K z^{2} \frac{Z}{A} \frac{1}{\beta^{2}}\left[\frac{1}{2} \ln \frac{2 m_{e} c^{2} \beta^{2} \gamma^{2} T_{\max }}{I^{2}}-\beta^{2}-\frac{\delta}{2}\right]
$$

onde $K=4 \pi N_{A} r_{e}^{2} m_{e} c^{2}, N_{A}$ é o número de Avogadro, $r_{e}$ o raio clássico do elétron, $m_{e}$ a massa do elétron, $c$ a velocidade da luz, ze a carga da partícula incidente, $Z$ e $A$ os números atômico e de massa do meio absorvedor, $\beta=\frac{v}{c}$ a velocidade da partícula incidente, $T_{\max }$ a energia cinética máxima que pode ser transferida a um elétron, $I$ a energia média de excitação e $\delta$ é a correção devido ao efeito de densidade.

Uma análise da perda de energia descrita pela equação de Bethe-Bloch e representada na figura 4.1 mostra que não existe dependência explícita com a massa da partícula, mas com sua velocidade $\beta$.

A região inicial, de baixas velocidades é descrita por uma queda proporcional a $\beta^{-2}$, seguida pela região que contém o mínimo e finalmente um aumento para $\beta \rightarrow 1$ chamada alta relativística (relativistic rise). Na região onde a perda de energia é mínima e igual para todas as espécies, a partícula é chamada mínimo-ionizante $[22,28]$.

Este modelo, no entanto, descreve somente a energia média perdida, e não leva em conta as flutuações, que podem ser particularmente importantes no caso de detectores a gás. A distribuição de probabilidade associada é conhecida genericamente como distribuição de Landau, devido ao modelo desenvolvido por Landau em 1944 [28]. Diversas extensões a este modelo foram propostas [22], e exemplos desta distribuição baseados em cálculos recentes estão mostrados na fig. 4.2. Geralmente estes modelos falham ao descrever a perda de energia em detectores de pouca espessura $[22,24]$. 


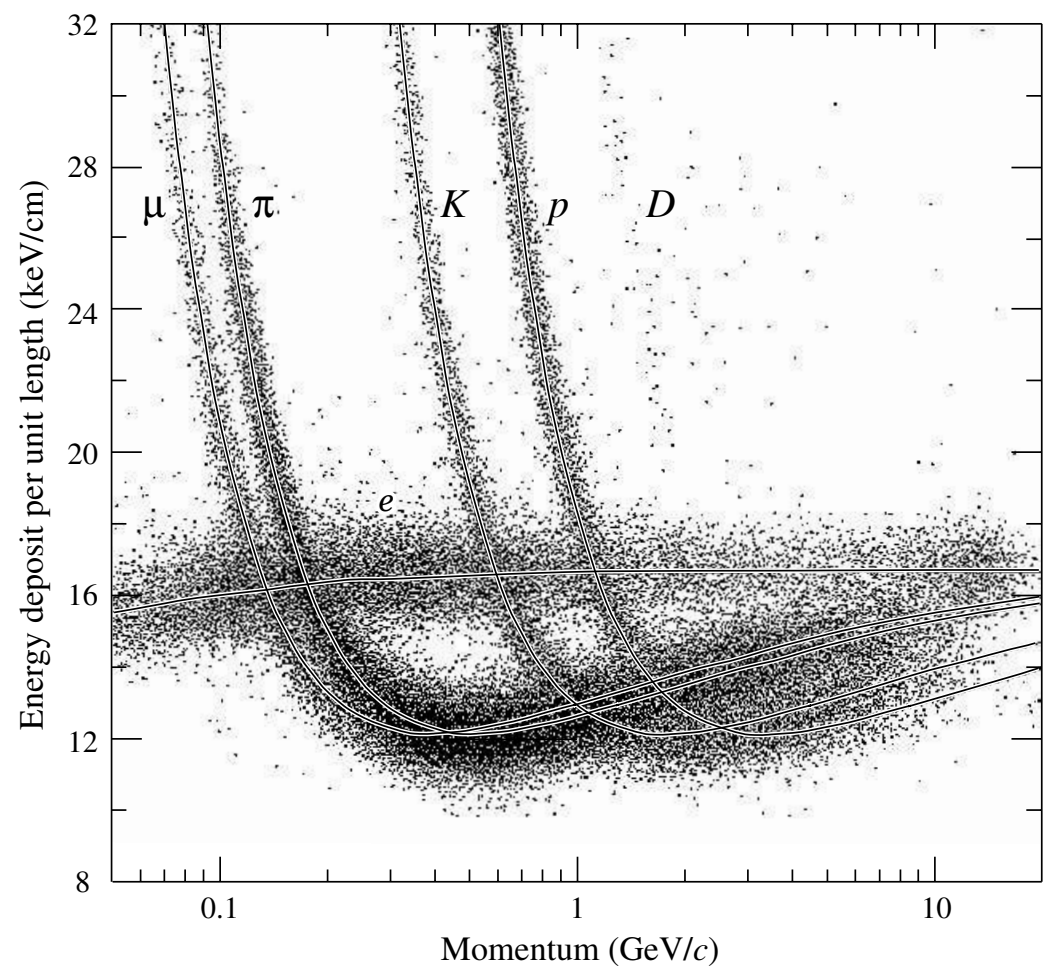

Figura 4.1: Energia depositada por diversas partículas numa câmara a gás. [22]

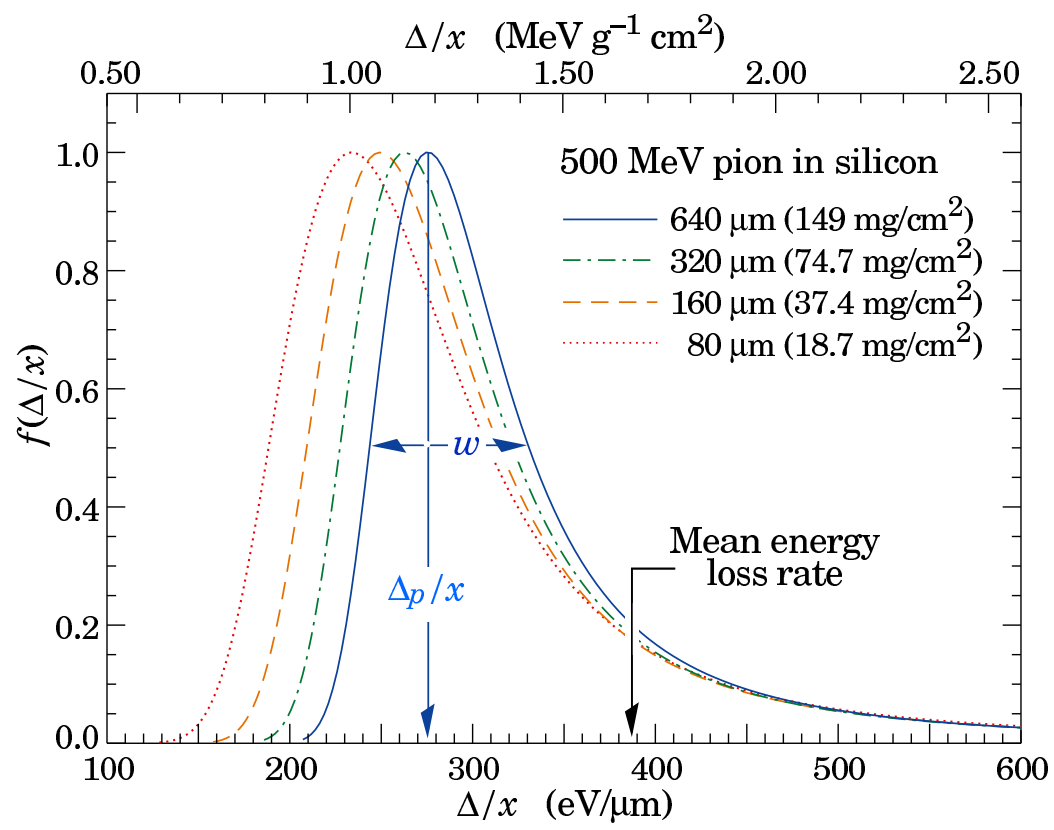

Figura 4.2: Distribuições da energia depositada $\Delta$ num absorvedor de espessura $x$ por píons de $500 \mathrm{MeV}$, normalizadas no valor mais provável. $w$ representa a largura à meia altura [22]. 


\subsubsection{O modelo de foto-absorção e ionização}

Uma formulação alternativa aos modelos de Bethe-Bloch e Landau foi apresentada em 1980 por Allison e Cobb [42]. O modelo de foto-absorção e ionização (photoabsorption ionization - PAI) permite o cálculo do espectro de energia dos elétrons primários considerando que a seção de choque para a produção de um elétron de energia $E$ é basicamente a seção de choque de absorção de um fóton de energia $E$ pelo material.

Este modelo descreve satisfatoriamente medidas dos valores médios e das distribuições de probabilidade da perda de energia (fig. 4.3), e é utilizado por programas de simulação da interação da radiação com a matéria, como o Heed [40, 41], utilizado neste trabalho.

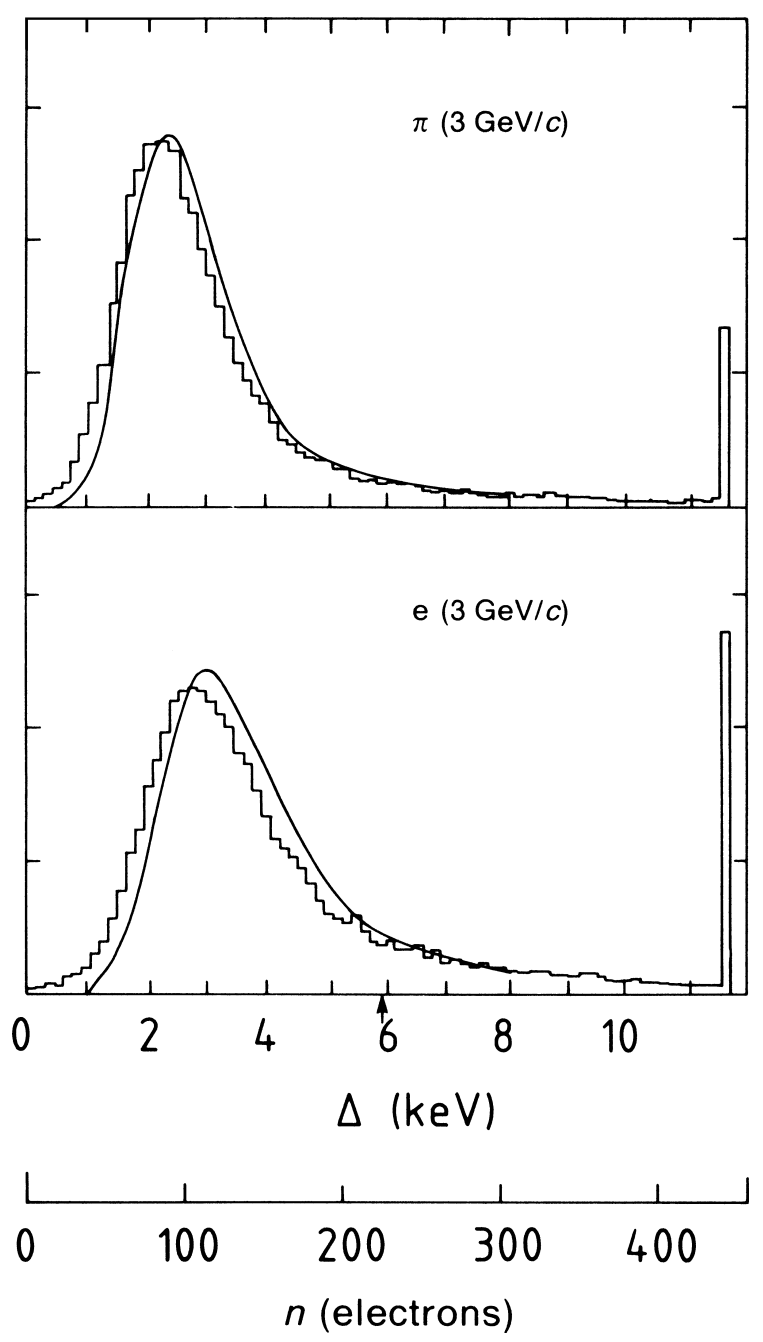

Figura 4.3: Comparação entre a distribuição da altura de pulso medida e cálculos do modelo PAI [24]. 


\subsection{Absorção de fótons}

A interação responsável pela absorção dos fótons num detector, assim como para o caso de partículas carregadas, é a interação eletromagnética. Basicamente três processos ocorrem: o efeito fotoelétrico, dominante a energias de até centenas de keV, o efeito Compton numa região de energias intermediárias, e a produção de pares, que é o processo mais provável a partir de alguns $\mathrm{MeV}$.

O efeito fotoelétrico é o fenômeno responsável pela absorção de raios-X, como a radiação de transição. Trata-se de um processo quântico, no qual um elétron de uma camada $i$, com energia de ligação $E_{i}$ é emitido com energia $E$ devido a absorção de um fóton de energia $E_{\gamma}$, tal que:

$$
E=E_{i}-E_{\gamma}
$$

O átomo ou molécula ionizado fica num estado excitado, e pode retornar ao estado fundamental basicamente através de dois processos:

- Fluorescência, ou seja, transição de um elétron de uma camada $j$ para a camada $i$ com a emissão de um fóton de energia $E_{i}-E_{j}$.

- Emissão Auger, no qual é emitido um elétron do átomo com energia próxima à energia de ligação $E_{i}$.

A probabilidade de absorção de um fóton é descrita pela seção de choque $\sigma$, de modo que a intensidade $I$ de um feixe que atravessa um meio de espessura $x$ com $N$ moléculas por unidade de volume é dado por:

$$
I=I_{o} e^{-\sigma N x},
$$

onde $I_{o}$ é a intensidade original do feixe. É costume utilizar o chamado coeficiente mássico de absorção $\mu$, ou o livre caminho médio $\lambda$, de modo que a eq. 4.3 pode ser reescrita como:

$$
I=I_{o} e^{-\mu \rho x}=I_{o} e^{-x / \lambda},
$$

onde $\rho$ é a densidade do meio. A fig. 4.4(a) mostra os coeficientes de absorção dos materiais que compõe o radiador do TEC / TRD e a fig. 4.4(b) mostra o livre caminho médio dos fótons nas misturas gasosas. 


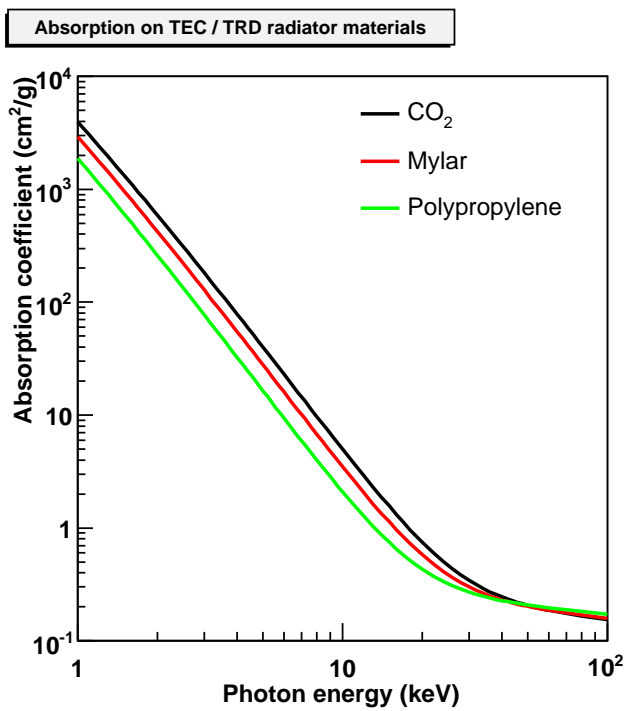

(a)

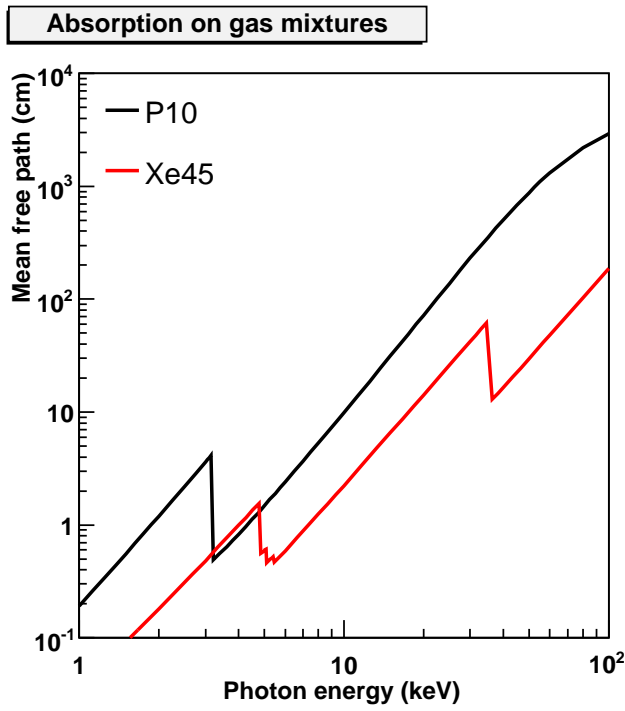

(b)

Figura 4.4: (a) Coeficientes de absorção dos materiais que compõe o radiador do TEC / TRD. (b) Livre caminho médio dos fótons nas misturas que preenchem as câmaras. Os dados foram obtidos da ref. [43], que traz uma compilação de resultados experimentais.

\subsection{Produção de cargas num detector a gás}

Na realidade um detector proporcional não mede diretamente a energia perdida por uma partícula, mas o número de cargas produzidas na sua passagem pelo meio. A relação direta entre as duas grandezas é observada devido à independência da energia média necessária para criação de um par elétron-íon $W$ com a energia da partícula incidente. Este fato não é verificado em geral para vapores orgânicos ou no caso da incidência de elétrons de baixo momento, mas independe da espécie da partícula ou de sua energia acima de alguns keV para gases nobres (fig. 4.5).

Um tratamento estatístico simples deste fenômeno pode ser obtido da seguinte forma:

Uma partícula incidindo num gás colide com os átomos do meio de acordo com o livre caminho médio $\lambda$ entre as colisões, dado pela densidade $N$ de elétrons no meio e pela seção de choque $\sigma$, de forma que:

$$
\lambda=\frac{1}{N \sigma}
$$

Para um caminho percorrido $L \gg \lambda$, ocorrem em média $L / \lambda$ colisões, e dado que a probabilidade de colisão é pequena e proporcional à distância percorrida, o 


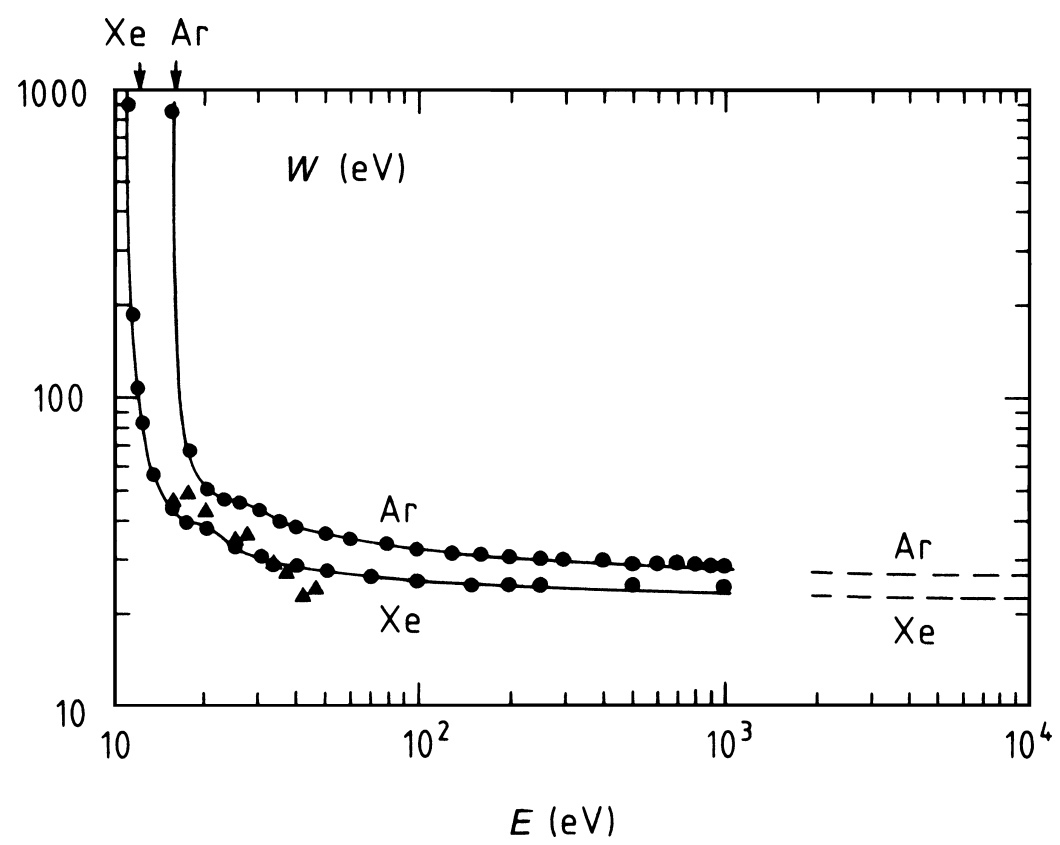

Figura 4.5: Energia média necessária para criação de um par elétron-íon $W$ em função da energia $E$ da partícula incidente. [24]

número de choques $k$ segue uma distribuição de Poisson:

$$
P(L / \lambda, k)=\frac{(L / \lambda)^{k}}{k !} e^{-L / \lambda}
$$

Nestes choques ocorre excitação e ionização das moléculas do gás, que podem levar a novas excitações e/ou ionizações secundárias. Devido ao baixo alcance dos elétrons no gás (fig. 4.6), as ionizações secundárias ocorrem muito próximas ao primeiro choque, formando juntamente com o elétron primário clusters de cargas livres. O número de cargas presentes em cada cluster pode ser obtido através de medidas ou simulações e permite o conhecimento da distribuição do número total de cargas produzidas $G(x, n)$, por uma trajetória de comprimento $x$. Essa é uma grandeza que pode ser medida num contador proporcional, e é utilizada na identificação de partículas [30-32]. A fig. 4.7 mostra uma distribuição medida para partículas relativísticas.

Uma maneira alternativa de obter esta distribuição baseia-se no conhecimento da distribuição de Landau $F(x, \Delta)$ da energia depositada $\Delta$ num caminho $x$. Considerando que para uma perda de energia $\Delta$ são formadas $n$ cargas de acordo com $\Delta=n W$, a distribuição $G(x, n)$ é dada por:

$$
G(x, n)=F(x, n W) \cdot W
$$




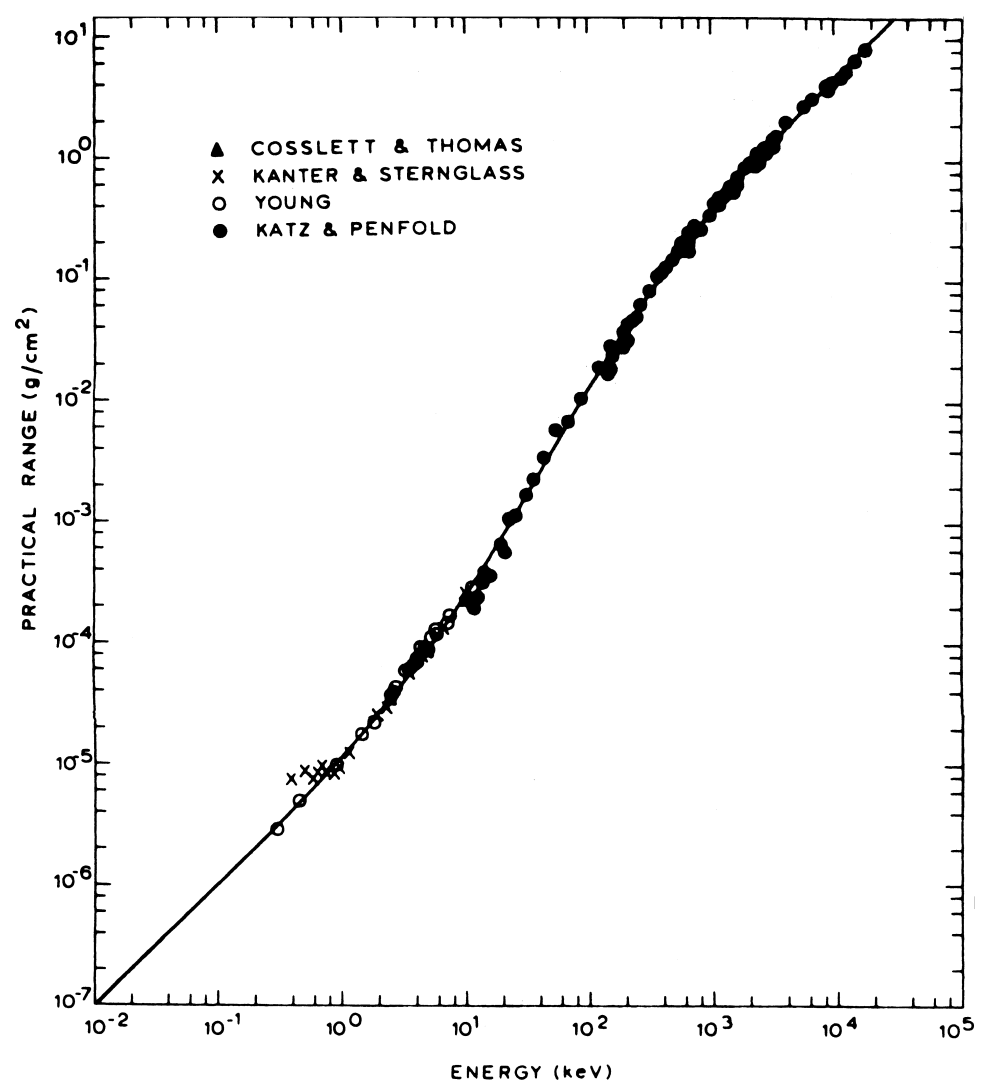

Figura 4.6: Alcance em função da energia para elétrons em alumínio [24].

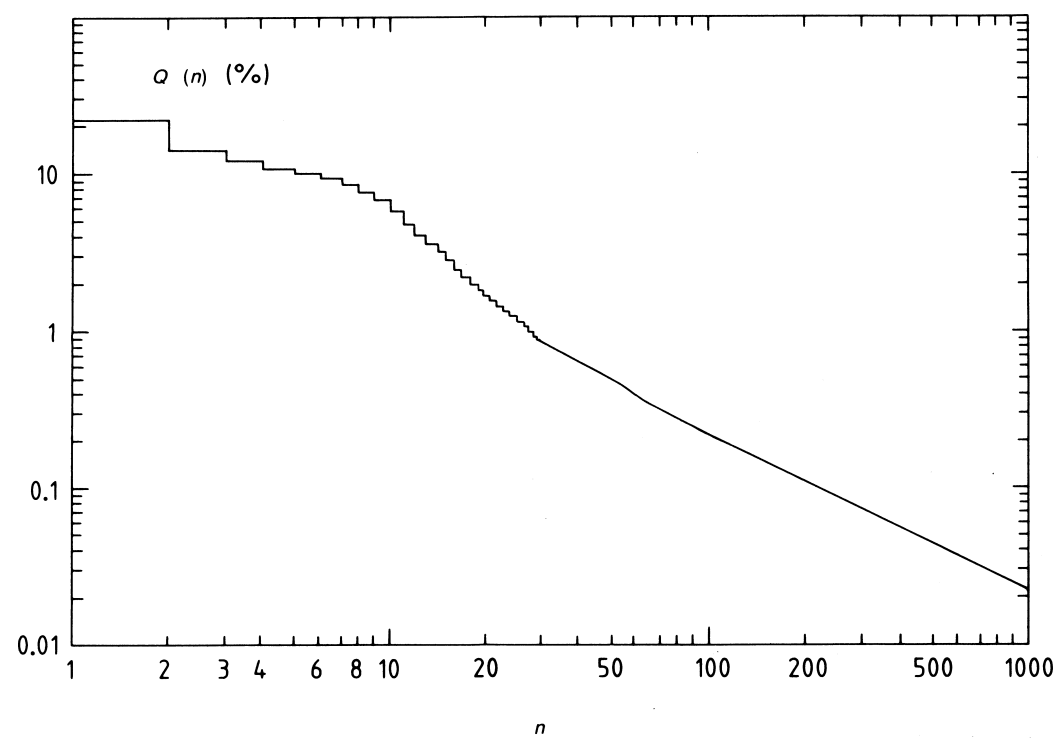

Figura 4.7: Distribuição do número de cargas em cada cluster para partículas com fator de Lorentz $\gamma=1000$ em argônio. $Q(n)$ é a probabilidade do cluster possuir mais de $n$ elétrons [24]. 


\subsection{Movimento das cargas}

A detecção das cargas formadas pela passagem de partículas depende criticamente da mobilidade dos elétrons e íons no gás. Nas simulações essas grandezas são calculadas pelo Magboltz, que é capaz de calcular as propriedades de transporte dos elétrons em misturas gasosas formadas pelos compostos normalmente utilizados em detectores em qualquer proporção. Esta seção descreve o movimento das partículas com exemplos baseados nos cálculos para as misturas utilizadas no TEC / TRD P10 (90\% Ar, 10\% $\left.\mathrm{CH}_{4}\right)$ e Xe45 (45\% Xe, 45\% He, $\left.10 \% \mathrm{CH}_{4}\right)$. Estes resultados possuem precisão estatística superior a $0.1 \%$, e consumiram cerca de 2000 horas de computação ${ }^{1}$.

Em condições normais de pressão, um gás é um meio bastante rarefeito, de modo que o tratamento dos fenômenos utiliza um formalismo clássico. Macroscopicamente, na presença de um campo elétrico $\vec{E}$, as cargas assumem uma velocidade de arrasto $\vec{u}$, paralela à direção do campo, dada por:

$$
\vec{u}=\frac{q \tau}{m} \vec{E},
$$

onde $\tau$ representa um tempo característico, $q$ e $m$ são a carga e a massa da partícula, respectivamente.

Microscopicamente, o movimento é alterado pelos constantes choques sofridos, que fazem com que a velocidade instantânea da partícula possua valor e direção aleatórios. Nesse caso $\tau$ corresponde ao intervalo médio entre as colisões.

No caso mais simples, as colisões geram um desvio em relação à posição original igual em todas as direções, de modo que a posição de uma carga criada em $t=0 \mathrm{e}$ movendo-se no eixo $z$ segue uma distribuição gaussiana em $r=\sqrt{x^{2}+y^{2}+z^{2}}$ com média dada por $z=u t$ e desvio padrão $2 D t$, onde $u$ é a velocidade de arrasto, e $D$ é o chamado coeficiente de difusão.

Os valores dos coeficientes de difusão para os íons são tipicamente desprezíveis no caso de drift chambers. No caso dos elétrons estes valores afetam significativamente a determinação da posição de formação das cargas. Na realidade existe uma anisotropia entre as direções longitudinal e transversal, e a ref. [24] apresenta uma dedução de um modelo que leva em conta esse efeito.

A fig. 4.8 mostra a comparação entre as velocidades de arrasto das duas misturas utilizadas no TEC / TRD, calculadas pelo Magboltz e a fig. 4.9 mostra os coeficientes de difusão transversal e longitudinal.

\footnotetext{
${ }^{1} \mathrm{~A}$ justficativa para essa precisão é apontada na seção 5.4 .
} 


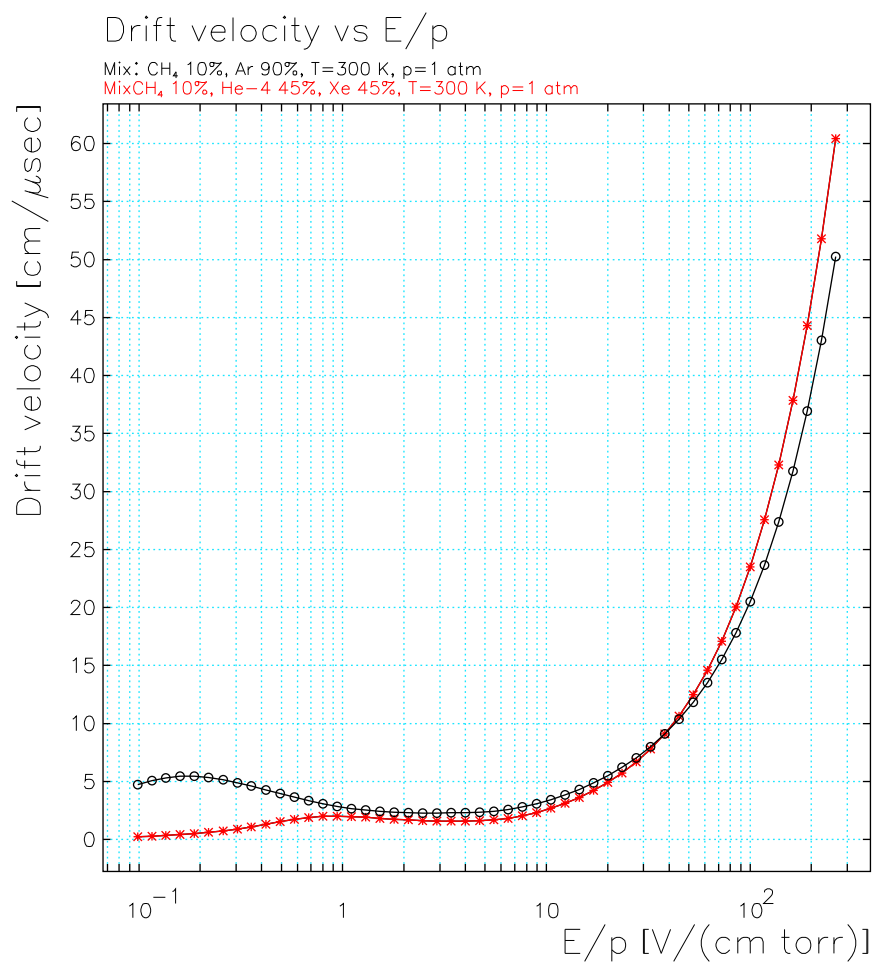

Figura 4.8: Velocidades de arrasto calculadas pelo Magboltz para as duas misturas utilizadas (P10 em preto e Xe45 em vermelho).

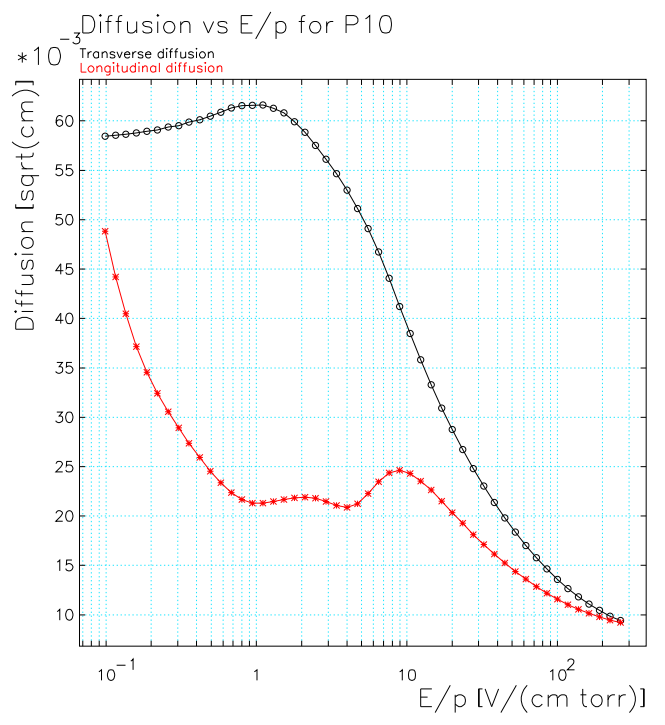

(a)

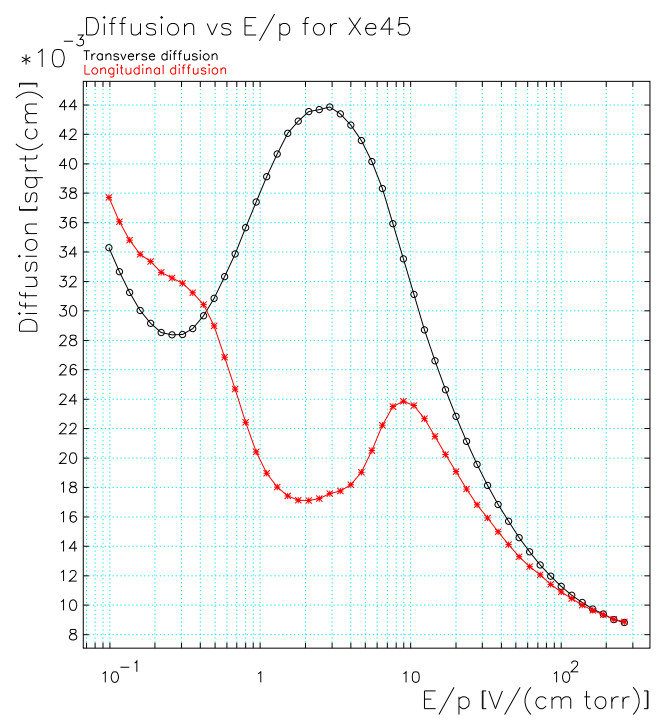

(b)

Figura 4.9: Coeficientes de difusão transversal (em preto) e longitudinal (em vermelho) calculados pelo Magboltz para as duas misturas utilizadas. - (a) P10. (b) Xe45. 


\subsubsection{Mobilidade iônica}

No caso dos íons, observa-se que a velocidade de arrasto cresce linearmente com o campo elétrico até valores bem altos de $\vec{E}$. É conveniente, portanto, definir uma mobilidade iônica $\mu$, dada por:

$$
\mu=\frac{|\vec{u}|}{|\vec{E}|}
$$

No caso de misturas gasosas, a mobilidade total do íon $j$ é dada pela lei de Blanc [28], de acordo com a proporção $p_{i}$ de cada gás, e a mobilidade iônica $\mu_{i j}$ da espécie $j$ neste gás:

$$
\frac{1}{\mu_{j}}=\sum \frac{p_{i}}{\mu_{i j}}
$$

Durante a colisão dos íons com as moléculas do meio existe a possibilidade de ocorrer transferência de carga para as espécies com menor potencial de ionização. A seção de choque associada à este fenômeno é comparável à seção de choque de espalhamento entre íon e molécula, o que faz com que após cerca de 100 a 1000 colisões basicamente todos os íons pertençam à espécie com menor potencial de ionização [28].

\subsubsection{Mobilidade iônica das misturas utilizadas no TEC / TRD}

Como a difusão iônica é geralmente desprezível, a mobilidade é o único coeficiente necessário para simular o movimento dos íons no gás, que tem grande importância para o cálculo dos sinais induzidos [24, 28]. O Magboltz não é capaz de calcular estes coeficientes, e as simulações basearam-se nas medidas apresentadas nas refs. [35, 44-46]. Devido à ausência de alguns dados e dada a precisão dos dados obtidos (em torno de $5 \%$ ) foram consideradas somente as mobilidades dos íons dominantes nos respectivos gases $\left(\mathrm{Ar}^{+}\right.$em $\mathrm{Ar}$ e $\mathrm{Xe}^{+}$em Xe), mostradas nas figs. 4.10(a) e 4.10(b).

Para a mistura de $45 \%$ de xenônio, $45 \%$ de hélio e $10 \%$ de metano, foi utilizada a mobilidade de $\mathrm{Xe}^{+}$em Xe dividida pela concentração deste elemento na mistura. Essa aproximação considera que os íons formados provavelmente são íons de xenônio, já que o seu potencial de ionização $(12.1 \mathrm{eV})$ é menor que o potencial de ionização do metano $(13.0 \mathrm{eV})$ e muito menor que o do hélio $(24.6 \mathrm{eV})$, e que a mobilidade do íon em hélio e em metano são muito maiores que no próprio xenônio. 
$\mathrm{Na}$ literatura somente foram encontrados dados sobre a mobilidade de $\mathrm{Xe}^{+} \mathrm{em}$ He a $\mathrm{T}=82 \mathrm{~K}$. O valor a $\mathrm{T}=300 \mathrm{~K}$ poderia ser estimado a partir da relação entre a mobilidade e a densidade do gás, descrito na ref. [44], que é consistente no caso de íons de $\mathrm{Ar}^{+}$em He. Dessa forma a contribuição seria de apenas 3\%, já que a mobilidade do $\mathrm{Xe}^{+}$em He é 40 vezes maior que a mobilidade em Xe a $\mathrm{T}=82 \mathrm{~K}$, ou seja, desprezível na precisão dos dados.

No caso da mistura de $90 \%$ de argônio e 10\% de metano, ainda que o potencial de ionização do metano seja inferior ao do argônio $(15.8 \mathrm{eV})$, é 9 vezes mais provável que um elétron encontre um íon de argônio durante a avalanche. Nessa situação, os íons de $\mathrm{Ar}^{+}$seriam substituídos por íons $\mathrm{CH}_{4}^{+}$através do processo de transferência de carga em cerca de 100-1000 $\mu \mathrm{m}$, que é um intervalo grande sob o ponto de vista da formação do sinal [24]. A mobilidade do $\mathrm{CH}_{4}^{+}$em $\mathrm{Ar}$ para valores baixos de campo elétrico é cerca de $25 \%$ maior que a mobilidade de $\mathrm{Ar}^{+}$em $\operatorname{Ar}[28,35]$.

Mobility of $\mathrm{Ar}+$ in $\mathrm{Ar}$

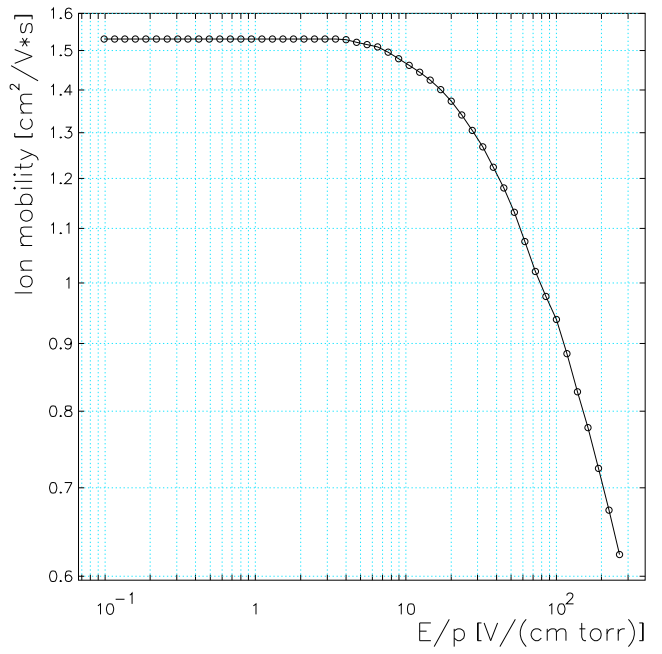

(a)

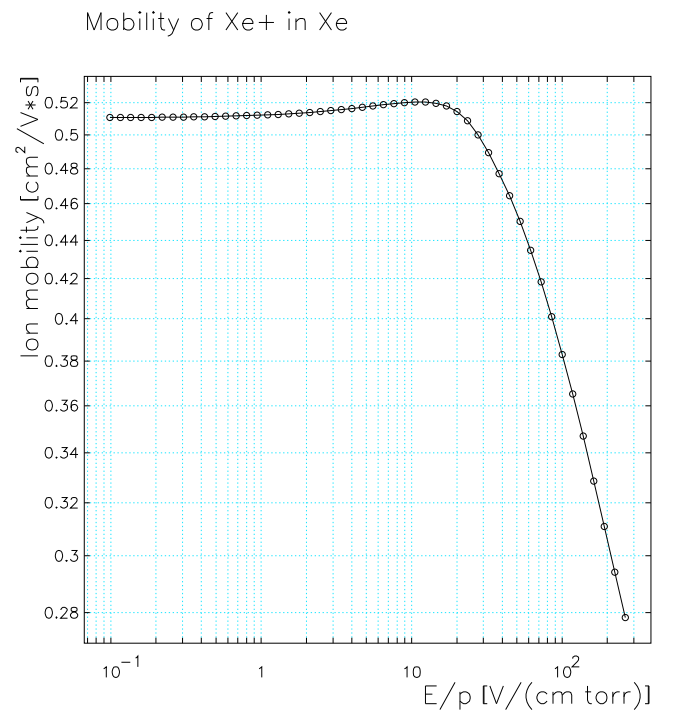

(b)

Figura 4.10: Mobilidades iônicas de (a) $\mathrm{Ar}^{+}$em $\mathrm{Ar}$ e (b) $\mathrm{Xe}^{+}$em Xe, obtidas das refs. [35, 45], respectivamente. Incertezas de 5\%.

\subsection{Multiplicação e absorção das cargas}

Ao penetrarem numa região de campo elétrico intenso, os elétrons podem adquirir energia suficiente para criar um novo par elétron-íon. As cargas formadas, por sua vez, são aceleradas pelo campo elétrico e eventualmente criam novas cargas, num processo que gera uma avalanche. 
A variação $d N$ do número de cargas por unidade de comprimento $d x$ é dada pelo produto entre o número de cargas existentes $N$ e um coeficiente $\alpha$ chamado primeiro coeficiente de Townsend, através da expressão:

$$
d N=N \alpha d x
$$

Considerando a dependência de $\alpha$ com o campo elétrico, o número final de cargas é dado integrando-se a equação 4.11 entre o ponto de início da avalanche $x_{0}$ e o raio do fio $a$, de modo que o ganho ou fator de multiplicação $M$ é dado pela razão entre o número de cargas finais $N$ e iniciais $N_{0}$ :

$$
M=\frac{N}{N_{0}}=\exp \int_{x_{0}}^{a} \alpha(x) d x
$$

Durante o arrasto e a multiplicação, eventualmente pode ocorrer também a absorção dos elétrons livres no gás com a formação de íons negativos. Esse processo é particularmente importante no caso de moléculas orgânicas contendo elementos eletronegativos como oxigênio. O número médio de partículas absorvidas por unidade de comprimento é chamado coeficiente de attachment. As figuras 4.11(a) e 4.11(b) mostram respectivamente os coeficientes de Townsend e de attachment calculados para as misturas utilizadas.

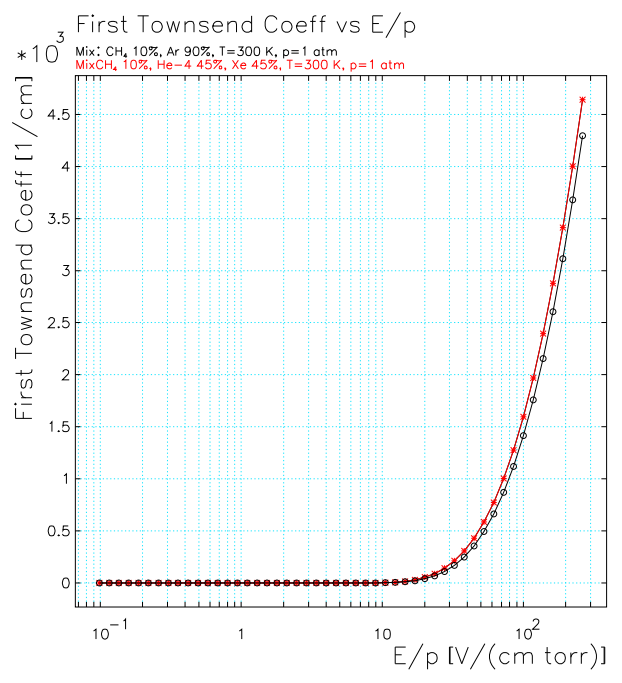

(a)

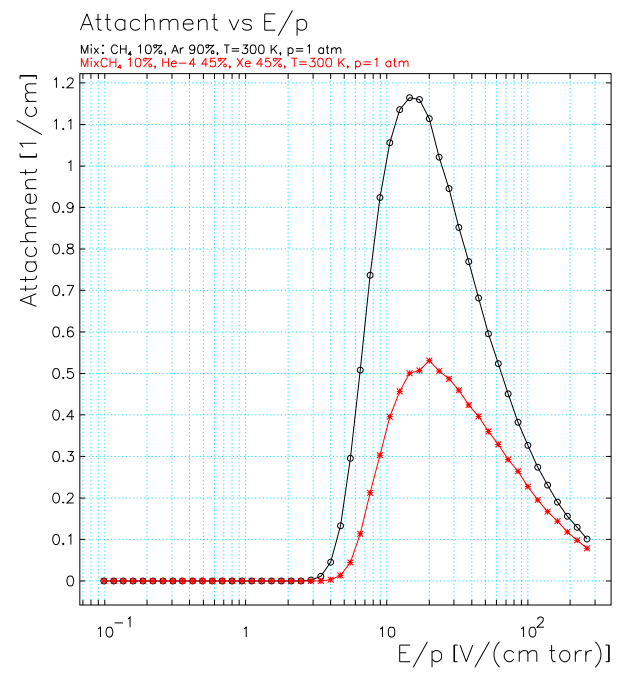

(b)

Figura 4.11: Coeficientes de (a) Townsend (a) e (b) de attachment calculados para as duas misturas utilizadas no TEC / TRD. 


\subsubsection{Estatística do processo de multiplicação}

A distribuição de probabilidade associada ao processo de multiplicação pode ser obtida considerando que cada carga inicia um processo de avalanche independente.

O modelo mais simples, descrito na ref. [24] e reproduzido nesta seção, considera que a probabilidade de uma carga ser produzida é proporcional a um produto $\lambda t$, onde $t$ é um parâmetro associado ao tempo ou ao número de colisões, mas não necessariamente corresponde ao tempo físico. Seja $P(n, t)$ a probabilidade de haver $n$ elétrons após um 'tempo' $t$. O início da avalanche é dado por uma carga em $t=0$ :

$$
P(1,0)=1 \text {. }
$$

Após um intervalo de tempo $\Delta t$ pode haver ou não a criação de um e somente um elétron, com probabilidade dada por:

$$
P(n, t+\Delta t)=P(n, t)(1-n \lambda \Delta t)+P(n-1, t)(n-1) \lambda \Delta t .
$$

Tomando $\Delta t \rightarrow 0$ e utilizando a condição inicial dada pela equação 4.13, obtémse uma expressão para $P(n, t)$ :

$$
P(n, t)=e^{-\lambda t}\left(1-e^{-\lambda t}\right)^{n-1},
$$

onde a média e a variância são dadas por:

$$
\begin{aligned}
\bar{n} & =e^{\lambda t} \\
\sigma^{2} & =e^{\lambda t}\left(e^{\lambda t}-1\right) .
\end{aligned}
$$

Substituindo 4.16 em 4.15, o que elimina o parâmetro $t$, e tomando o limite $\bar{n} \rightarrow \infty$, obtém-se a distribuição exponencial:

$$
\begin{aligned}
P(n) & =\frac{1}{\bar{n}} e^{-n / \bar{n}}, \\
\sigma^{2} & =\bar{n}^{2} .
\end{aligned}
$$

O modelo anterior considera que a formação de novas cargas independende do histórico da avalanche, o que se verifica para campos elétricos pouco intensos. Uma alternativa consiste em considerar uma probabilidade de criação de uma carga que decresce com o desenvolvimento da avalanche. A distribuição associada a este mo- 
delo é chamada distribuição de Polya e tem a forma [24]:

$$
P(n)=\frac{1}{b \bar{n}} \frac{1}{k !}\left(\frac{n}{b \bar{n}}\right)^{k} e^{-n / b \bar{n}},
$$

onde $k=\frac{1}{b}-1$, e $\sigma^{2}=b \bar{n}^{2}$. Para $b=1$, obtém-se a distribuição exponencial.

Segundo a ref. [47], a multiplicação em câmaras multifilares obedece a uma distribuição de Polya com $b=1.5$. No entanto, medidas feitas com o TPC 90 do experimento ALEPH indicam que a flutuação é bem descrita pela distribuição exponencial [24].

O Garfield permite que o usuário defina a estatísica associada ao processo de multiplicação para determinação da flutuação na amplitude dos sinais induzidos. Como nas refs. citadas são apresentadas duas alternativas diferentes, a distribuição utilizada foi definida através de uma simulação detalhada do processo de avalanche nos detectores, descrita nas seções 5.3 e 6.1.3.

\subsection{Radiação de Transição}

Radiação de transição ( Transition radiation - TR) é a radiação emitida por uma partícula carregada movendo-se com velocidade constante num meio não-homogêneo, como a interface entre dois meios de constantes dielétricas diferentes. Foi prevista em 1946 por Frank e Tamm, e observada somente em 1959 por Goldsmith e Jelley [48].

No caso de partículas ultra-relativísticas, o espectro da radiação emitida apresenta um pico na região dos raios-X, e depende basicamente do fator de Lorentz $\gamma$ da partícula. Os detectores de radiação de transição (TRDs) tipicamente consistem em câmaras multifilares preenchidas com gases nobres de alto número atômico $Z$ como o xenônio, de modo a maximizar a absorção dos raios-X. Dado o baixo ângulo de emissão dos fótons em relação à trajetória da partícula, da ordem de $1 / \gamma$, normalmente se observa o sinal da radiação de transição sobreposto ao sinal de ionização $(d E / d x)$ produzido pela partícula incidente.

A dificuldade para observação dessa radiação deve-se à baixa probabilidade de emissão, que é da ordem da constante de estrutura fina $\alpha \approx 1 / 137$. Isso exige que se utilize radiadores compostos por centenas de intefaces de materiais de baixo número atômico $Z$, de modo a minimizar a absorção dos fótons. Os primeiros radiadores eram compostos por placas de lítio, berílio ou plásticos, separados por intervalos constantes preenchidos por um gás como o ar ou gás carbônico. Mais recentemente têm-se utilizado radiadores compostos por fibras ou espumas de plásticos como po- 
lietileno ou polipropileno, que apresentam um rendimento próximo ao radiador de placas, e diversas vantagens mecânicas.

A radiação de transição oferece um método não destrutivo e de baixo custo para a identificação de partículas com massas diferentes, ao contrário da calorimetria por exemplo. Segundo o Review of Particle Physics [22], TRDs têm se difundido em experimentos envolvendo aceleradores e missões espaciais, sendo os exemplos mais recentes e proeminentes em experimentos de larga escala os TRDs dos experimentos NOMAD, ALICE e PHENIX. 


\section{Capítulo 5}

\section{Simulação de um detector proporcional}

Simulações foram comparadas aos dados de um detector proporcional monofilar construído no Laboratório de Instrumentação e Partículas da USP. O detector, esquematizado na fig. 5.1, consiste num fio de anodo de $50 \mu \mathrm{m}$ de diâmetro envolto por um tubo de $2.01 \mathrm{~cm}$ de raio e $15 \mathrm{~cm}$ de comprimento, preenchido com uma mistura de $90 \%$ de argônio e 10\% de metano (P10).

As simulações foram realizadas com a versão 9 do Garfield, escrita em Fortran, considerando a geometria do detector e as propriedades de transporte dos elétrons e íons em P10, descritas no capítulo anterior.

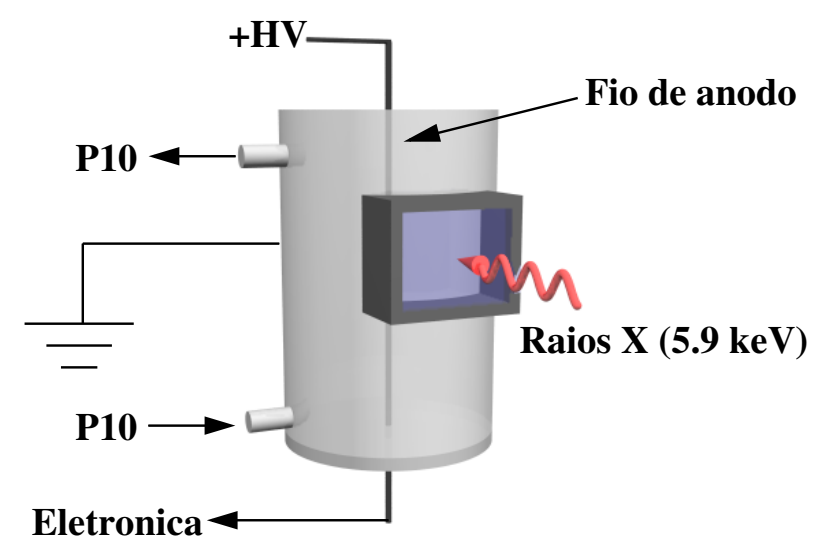

Figura 5.1: Esquema do detector monofilar construído no LIP.

Foram comparados o ganho do gás variando-se a tensão no fio, um espectro da energia depositada obtido com uma fonte de raios-X e o sinal gerado pela absorção de um fóton. 


\subsection{Eletrônica}

A aquisição foi feita com uma eletrônica padrão NIM ligada a um ADC-multicanal e a um osciloscópio digital. A fig. 5.2 mostra o esquema da eletrônica utilizada.

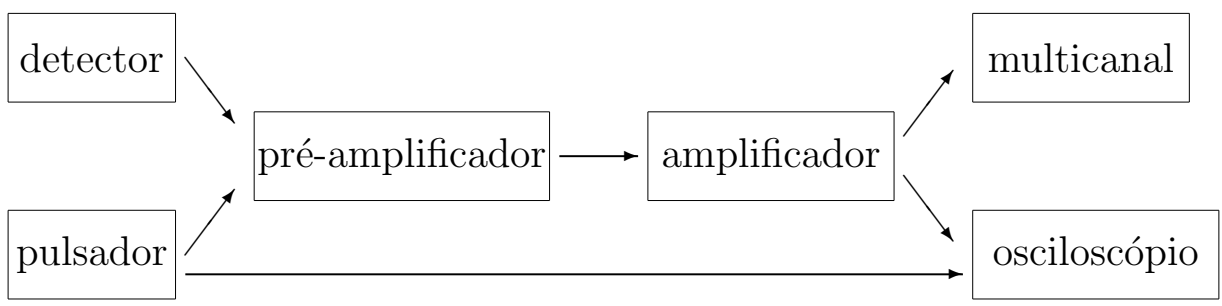

Figura 5.2: Esquema da eletrônica de aquisição de dados para o detector proporcional.

Um pulsador permitiu que se obtivesse o ganho da eletrônica através da razão entre as amplitudes do sinal injetado, medida no osciloscópio, e do sinal de saída, de acordo com o valor medido no multicanal. A relação entre a carga injetada no préamplificador $q$ e a amplitude do sinal $V$ é dada por $q=C V$, onde $C$ é a capacitância da entrada do sinal do pulsador no pré-amplificador $(1 \mathrm{pF})$.

O papel da eletrônica (pré-amplificador + amplificador) na formatação dos sinais pode ser descrito por uma função resposta $h(t)$ que é convoluída ao sinal de entrada $x(t)$, fornecendo um sinal de saída $y(t)$ de acordo com a expressão:

$$
y(t)=\int_{-\infty}^{+\infty} h\left(t^{\prime}-t\right) x\left(t^{\prime}\right) d t^{\prime}
$$

Aplicando a transformada de Fourier em ambos os lados da equação e utilizando o teorema da convolução, a integração pode ser convertida numa multiplicação:

$$
Y(\omega)=H(\omega) \cdot X(\omega)
$$

onde $Z(\omega)$ é a transformada de Fourier de $z(t)$. Utilizando esta expressão, dados os sinais de entrada e saída é possível obter a função de resposta através da deconvolução dos sinais:

$$
h(t)=\mathcal{F}^{-1}\left(\frac{Y(\omega)}{X(\omega)}\right)
$$

onde $\mathcal{F}^{-1}(Z)$ representa a transformada inversa de Fourier de $Z$. Esse procedimento foi aplicado, armazenando-se os sinais de entrada do pulsador e de saída com o osciloscópio digital (fig. 5.3). A deconvolução foi feita através da transformada rápida de Fourier (FFT) e sua inversa do pacote "Scipy" [49, 50]. A fig. 5.4 mostra a função resposta obtida. 


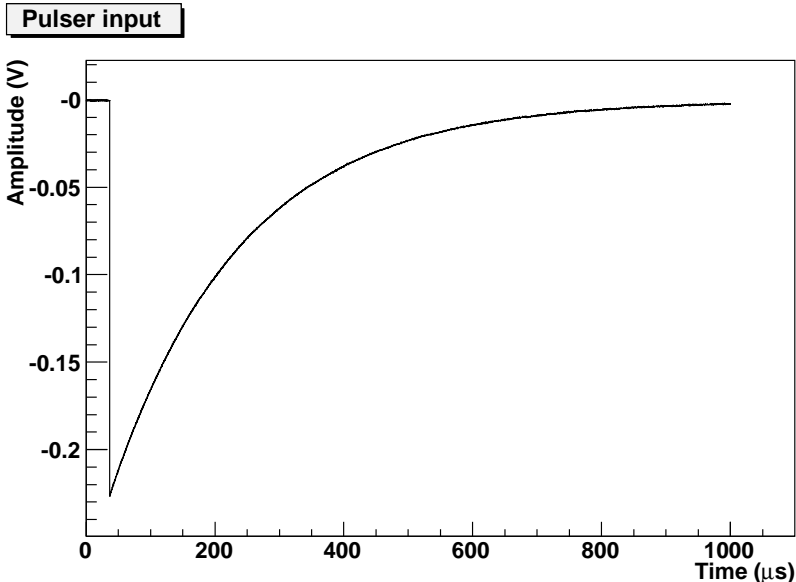

(a)

\section{Shaper output}

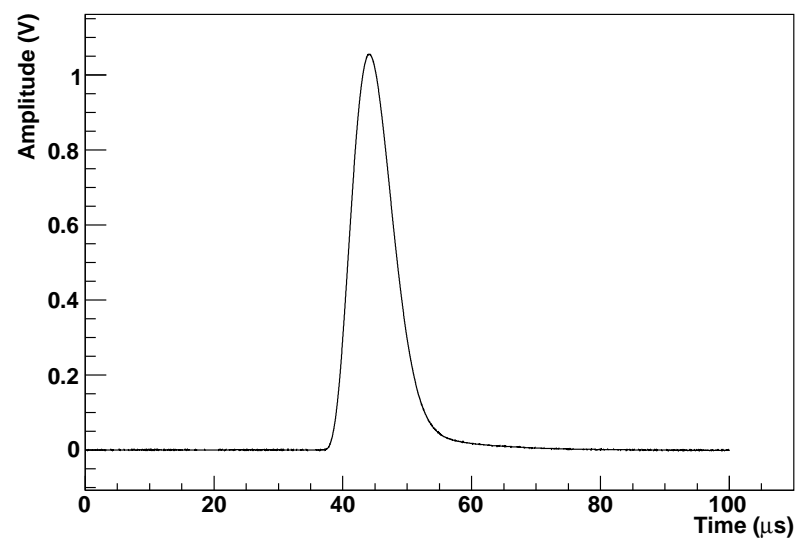

(b)

Figura 5.3: (a) Sinal do pulsador (entrada). (b) Sinal formatado (saída).

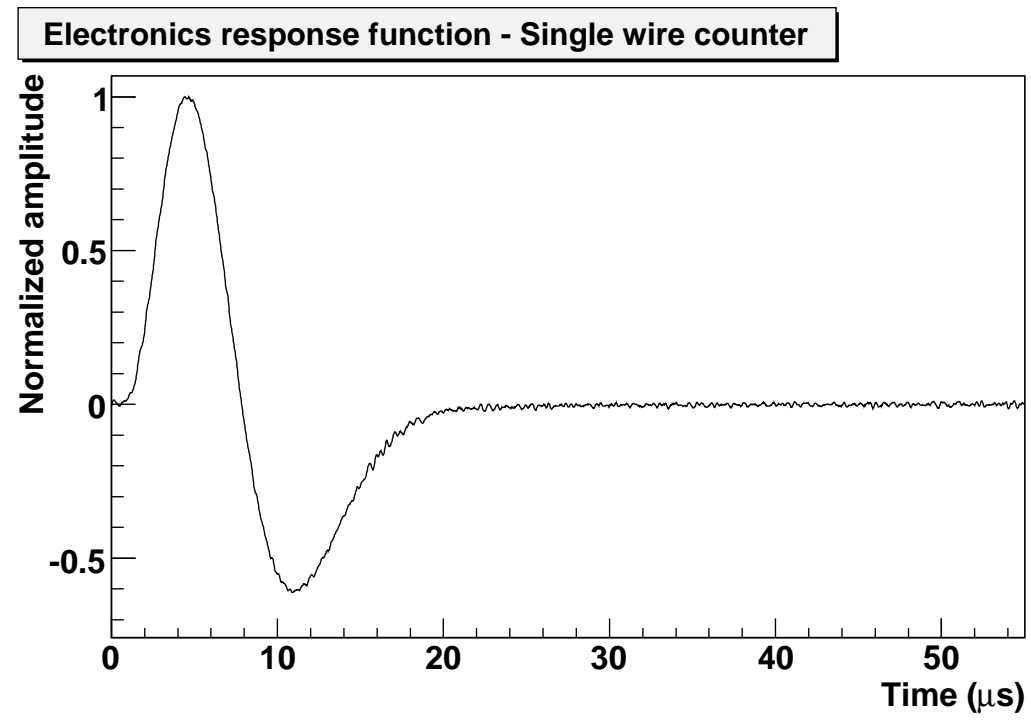

Figura 5.4: Função resposta da eletrônica associada ao detector monofilar. 


\subsection{Absorção dos fótons no argônio}

Todas as medidas foram realizadas com uma fonte de raios-X de $5.9 \mathrm{keV}$ de ${ }^{55}$ Fe. Nesse caso, a absorção dos fótons no argônio se dá através da emissão de um fotoelétron com energia $E=2.7 \mathrm{keV}$ que pertencia a uma camada $\mathrm{K}$ de energia $3.2 \mathrm{keV}$. Essa emissão deixa o íon num estado excitado, que pode retornar ao estado fundamental basicamente de duas formas [28]:

- Em 85\% das vezes através da emissão de um elétron Auger, que rapidamente é absorvido no detector e juntamente com o fotoelétron geram cerca de 226 pares elétron-íon ${ }^{1}$, correspondendo ao pico de absorção total.

- Em $15 \%$ das vezes através da emissão de fótons de energia $E_{\gamma}$ menor que a energia de ligação do elétron. O fóton mais energético frequentemente escapa do volume de detecção e nesse caso induz o chamado pico de escape.

A simulação da absorção dos fótons pelo gás é feita pelo Heed, que fornece ao Garfield a localização dos clusters e a energia depositada, mostrada na figura 5.5. Este resultado considera que quando o fóton de fluorescência não é detectado toda a energia de ligação do elétron é perdida, o que na realidade não acontece. Somente a energia de um raio-X das transições mais prováveis (no caso do Ar uma transição $K_{\alpha}$ de $2.96 \mathrm{keV}$ [51]) escapa do volume de detecção.

\footnotetext{
${ }^{1}$ Esse número corresponde à razão entre a energia do fóton e a energia média para criação de um par elétron-íon em P10, que é da ordem de $26 \mathrm{eV}$.
} 


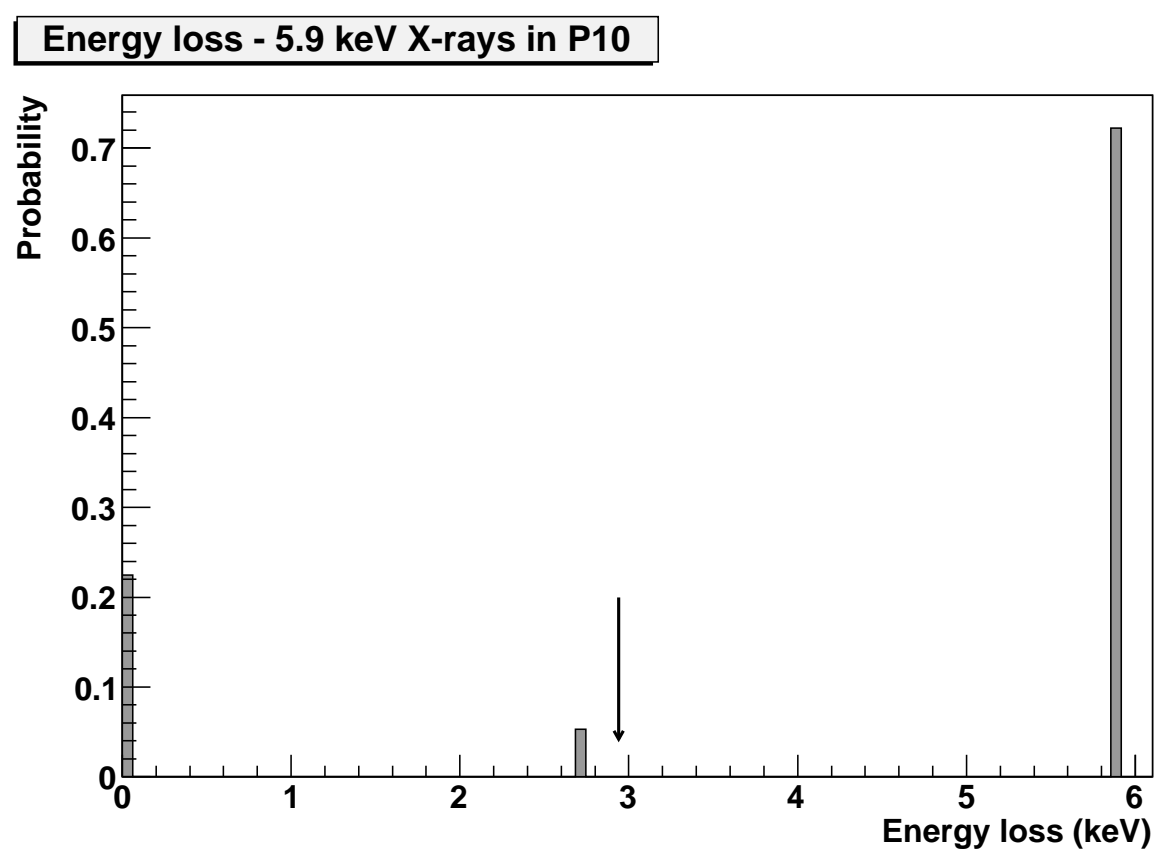

Figura 5.5: Simulação com o Heed da energia depositada por raios-X de $5.9 \mathrm{keV}$ em P10. A seta indica a posição correta do pico de escape.

\subsection{Simulação do processo de avalanche}

O Garfield permite a simulação detalhada do processo de avalanche transportando cargas de um ponto dado até sua absorção pelo fio de anodo através de um algoritmo de Monte Carlo. A cada step são levadas em conta as probabilidades do elétron ser absorvido ou gerar novas cargas, de acordo com os coeficientes de attachment e de Townsend, respectivamente.

Este procedimento é aplicado para cada carga criada, permitindo que se armazene seu ponto de criação, o número total de cargas produzidas e uma representação gráfica da avalanche, mostrada na fig. 5.6.

Repetindo este processo, foram obtidas a distribuição de probabilidade para o número de cargas totais, mostrada na fig. 5.7, e a distância entre o ponto de produção das cargas e a superfície do fio, mostrada na fig. 5.8.

Os resultados obtidos pela simulação detalhada mostram que a distribuição exponencial descreve corretamente a estatística do processo de multiplicação neste detector. Não existe, portanto, nenhuma razão para que se utilize a distribuição de Polya. 


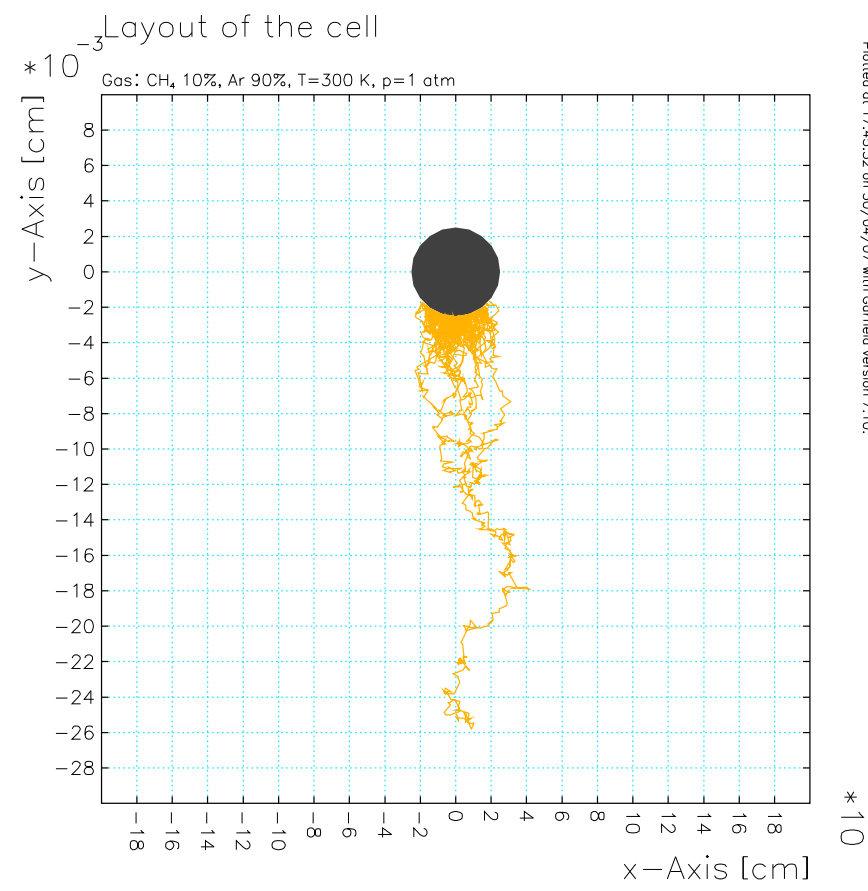

Figura 5.6: Simulação do processo de avalanche induzido por uma carga, mostrando a região próxima ao fio de anodo (circulo escuro) do detector monofilar.

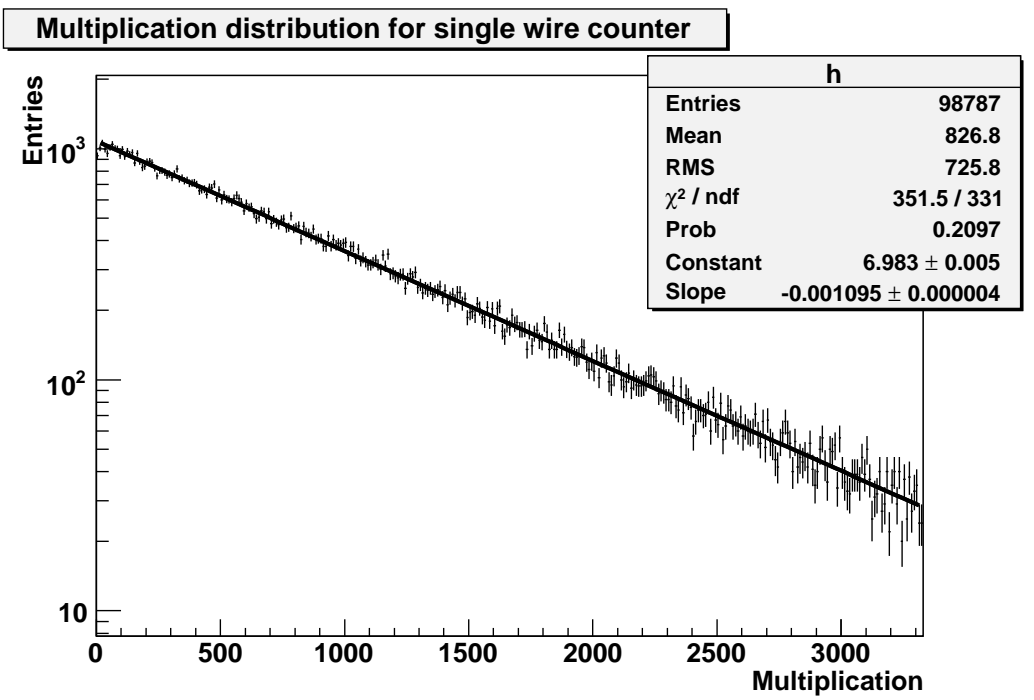

Figura 5.7: Distribuição do número de cargas formadas durante a avalanche para uma tensão de $1800 \mathrm{~V}$ no fio de anodo, e função exponencial ajustada. 


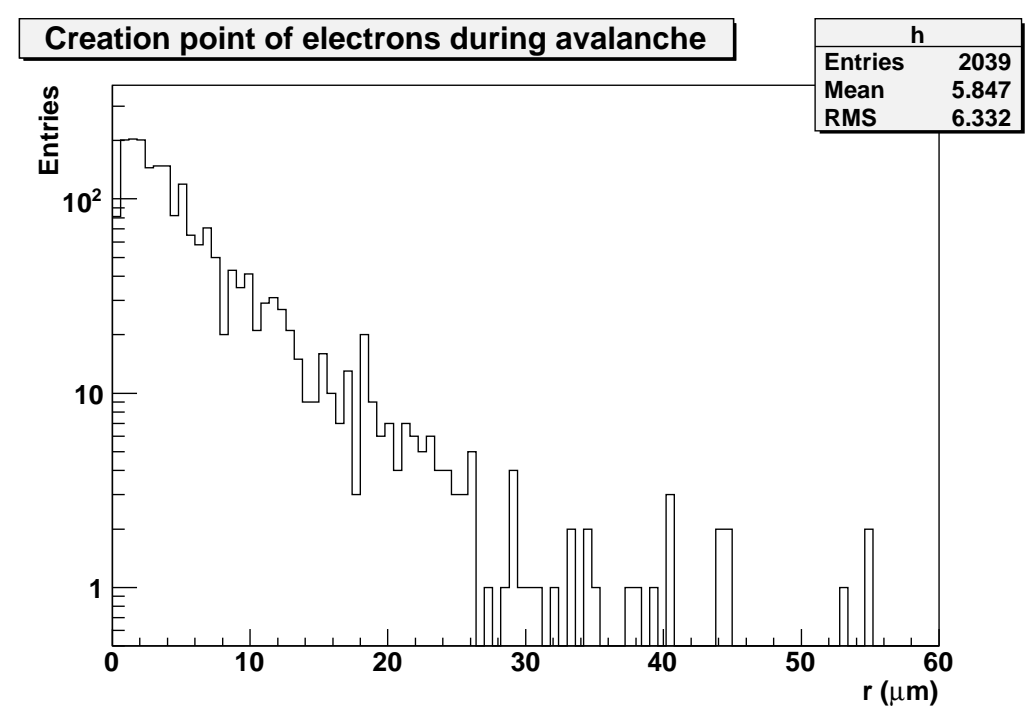

Figura 5.8: Distância entre o ponto de produção das cargas em P10 e a superfície do fio durante a avalanche.

\subsection{Curva de multiplicação}

A curva de multiplicação foi levantada variando-se a tensão no fio de anodo e medindo-se no multicanal a posição do pico correspondente à absorção total da energia dos fótons. O ganho do gás foi calculado de acordo com a razão entre a carga medida e a carga primária (226 pares elétron-íon).

No caso das simulações tomou-se a razão entre o número de cargas após o processo de avalanche e o número de cargas primárias calculado pelo Heed, considerando somente o pico de absorção total. A comparação entre os valores está mostrada na fig. 5.9.

A discrepância entre simulações e medidas já havia sido relatada nas refs. [37, 52]. A ref. [37] atribui as diferenças à incerteza no coeficiente de Townsend calculado pelo Magboltz. Esse coeficiente foi determinado com precisão estatística superior a $0.1 \%$, e as diferenças observadas não podem ser justificadas por erros estatísticos. A ref. [52] mostra que é possível reproduzir os ganhos em alguns casos considerando-se a ionização das moléculas do gás ao colidirem com moléculas num estado excitado meta-estável (efeito Penning). Este problema, no entanto é facilmente solucionado fornecendo os valores medidos para o Garfield. 


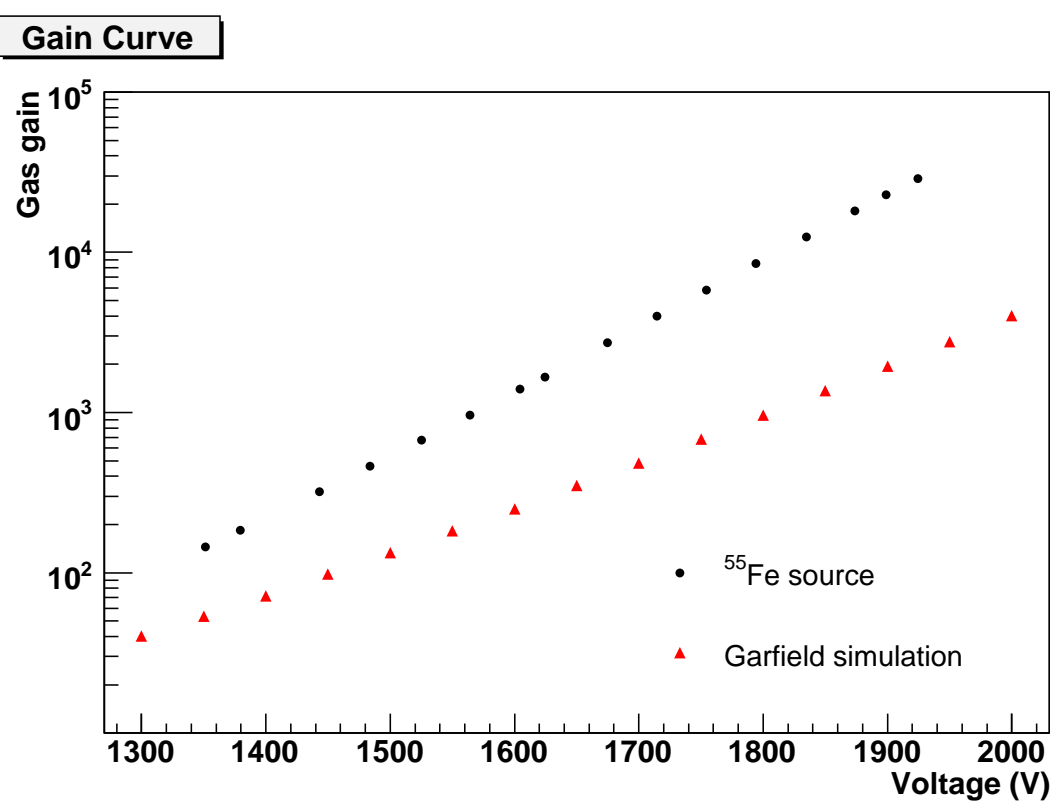

Figura 5.9: Comparação entre os valores medidos e simulados para o ganho do gás (P10 a 951 mbar).

\subsection{Espectro da energia depositada}

Um espectro da energia depositada por raios-X de $5.9 \mathrm{keV}$, para uma tensão de $1800 \mathrm{~V}$ foi medido e comparado aos resultados da simulação na fig. 5.10. Ambos foram calibrados considerando que a posição do pico principal corresponde a uma energia de $5.9 \mathrm{keV}$. Devido à falha na simulação da perda de energia pelo Heed (fig. 5.5), observa-se uma discrepância na posição do pico de escape.

Apesar desta falha, a simulação descreve corretamente as amplitudes relativas e a largura do pico principal, o que indica que a distribuição exponencial, usada para caracterizar as flutuações no ganho, é adequada. A diferença na posição do pico de escape não é um fator crítico nas simulações do TEC / TRD já que sua amplitude é pequena em relação à amplitude do pico correspondente à absorção total. 


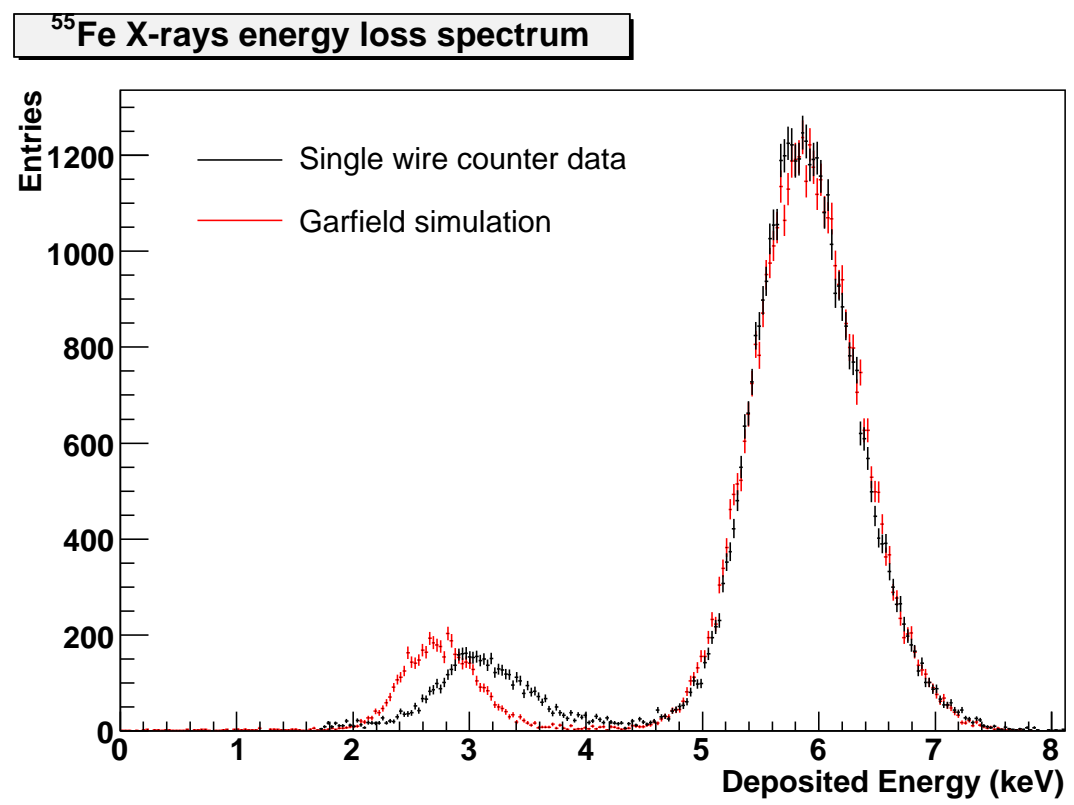

Figura 5.10: Espectros de energia obtidos com uma fonte de ${ }^{55} \mathrm{Fe}$ medidos com o detector de testes e simulados com o Garfield. Ambos foram calibrados a partir da posição do pico principal. Os espectros possuem o mesmo número de dados.

\subsection{Sinal induzido pela absorção de um fóton}

Comparou-se também um sinal induzido pela absorção de um fóton, adquirido com o osciloscópio digital. O sinal simulado pelo Garfield foi convoluído à função de tranferência da eletrônica, e ambos foram normalizados pela amplitude máxima.

A fig. 5.11(a) mostra que existe um bom acordo entre ambos. O resíduo (fig. $5.11(\mathrm{~b}))$ foi calculado através da diferença entre as amplitudes divida pelo ruído RMS do sinal medido. O valor de $\chi^{2}$ correspondente é de 6200 para 1000 graus de liberdade. Observa-se uma flutuação um pouco superior à flutuação estatística, possivelmente devido aos seguintes fatores:

- Diferenças na posição dos picos devido a incertezas na determinação do início do sinal através do trigger do osciloscópio.

- Erros sistemáticos na mobilidade iônica

- Incertezas no cálculo da função de transferência da eletrônica

- Erros no cálculo do sinal pelo Garfield

A precisão obtida é mais que suficiente para as simulações do TEC / TRD, cujos sinais são digitalizados por um ADC de 32 canais. 


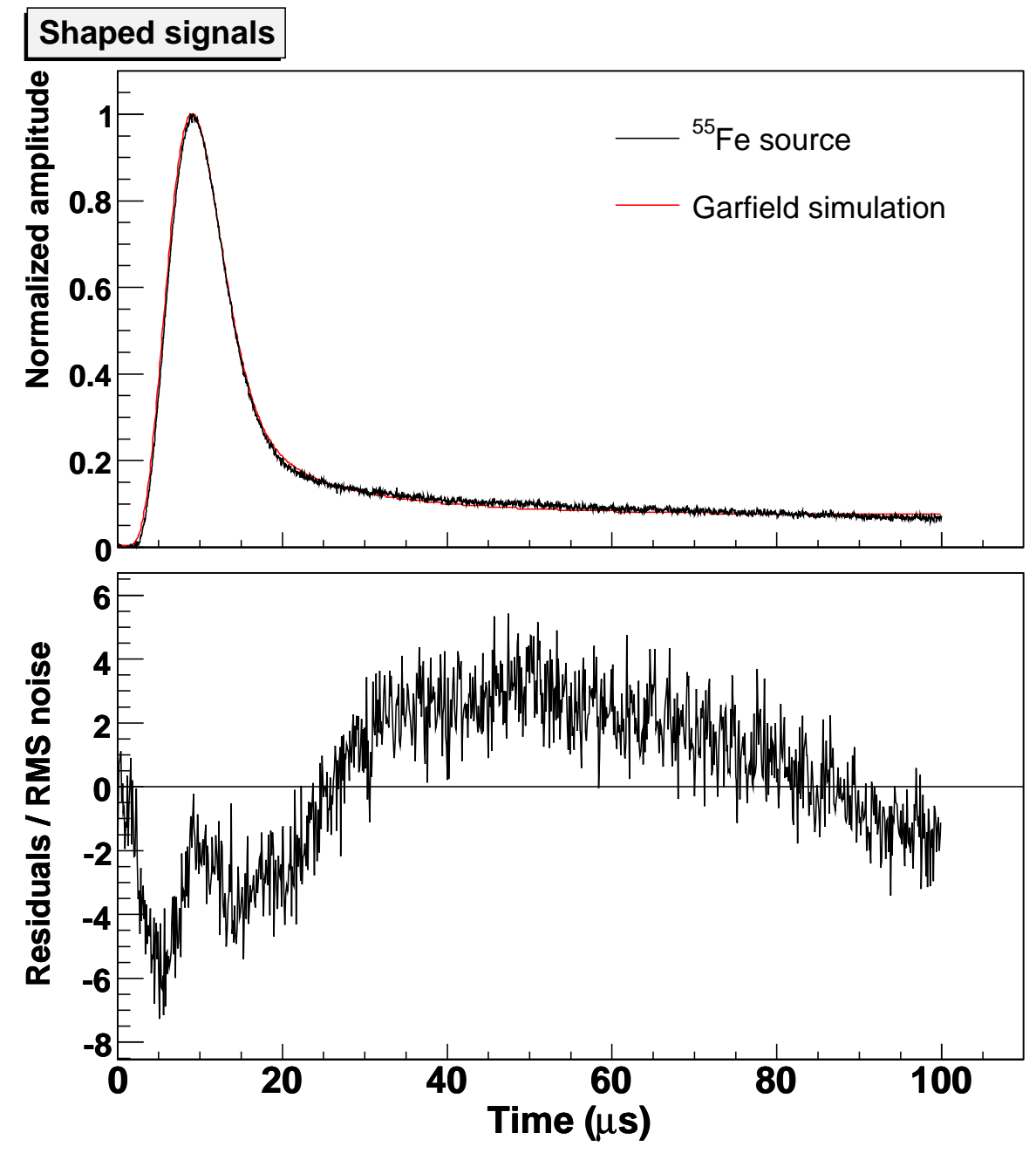

Figura 5.11: (a) Comparação entre o sinal induzido pela absorção de um fóton de uma fonte de ${ }^{55} \mathrm{Fe}$ medido com o detector de testes e a simulação. (b) Diferença entre os sinais divida pelo ruído rms. 


\subsection{Conclusões}

Os seguintes pontos podem ser destacados da comparação entre os resultados da simulação do detector monofilar e os dados obtidos:

- A simulação subestima os valores para o ganho do gás, sendo necessário fornecer este número como entrada, seja através do próprio ganho, ou de uma calibração em energia ou em altura de pulso de um espectro.

- O Heed não considera as transições de energia inferior à energia de ligação do fotoelétron ejetado do material, o que provoca um desvio na posição do pico de escape. Esse fator não afeta significativamente os resultados já que a seção de choque associada a esse processo é baixa.

- A amplitude do pico de absorção total, ou seja, as seções de choque relativas entre os processos e as probabilidades de absorção são calculadas corretamente pelo Heed.

- A largura do pico correspondente à absorção total é bem reproduzida pela simulação, o que indica que o Heed calcula corretamente a flutuação no número de cargas primárias, e a distribuição exponencial representa satisfatoriamente as variações no fator de multiplicação.

- Os sinais calculados pelo Garfield reproduzem os sinais medidos com precisão um pouco menor que o ruído do sistema, bastando que se introduza a função de resposta da eletrônica. Essa precisão é mais que suficiente para que se reproduza o sinal induzido nas câmaras do TEC / TRD. 



\section{Capítulo 6}

\section{Um simulador para o TEC / TRD}

Seguindo o mesmo procedimento adotado no caso do detector monofilar, um simulador baseado no Garfield foi desenvolvido para o TEC / TRD. Foram simuladas as respostas à passagem de píons, elétrons e fótons de radiação de transição. Os resultados foram comparados a dados de colisões p+p do run-6 do RHIC (2006).

\subsection{Parâmetros do simulador}

\subsubsection{Geometria}

A geometria das câmaras foi reproduzida no Garfield, levando em conta os tamanhos das regiões de arrasto e de multiplicação, a distância entre os fios de anodo e catodo, e o espaçamento médio entre os fios $(4 \mathrm{~mm})$.

As câmaras do TEC / TRD possuem da ordem de 400 fios de anodo, para permitir a cobertura de uma grande área com alta resolução espacial. No entanto, a passagem de uma partícula sensibiliza um número pequeno de fios por câmara, conforme mostrado na distribuição da fig. 6.1. Em $82 \%$ dos casos, a trajetória é registrada por até 2 fios. Essa fração chega a $95 \%$ para 3 fios e $99 \%$ para até 4 fios.

Na simulação foram considerados somente 20 fios numa câmara, de modo a evitar efeitos de borda do campo elétrico e permitir cálculos com menor tempo de processamento.

Dadas as tensões típicas de operação das câmaras, o Garfield calcula o campo elétrico e as linhas de drift das cargas, mostradas na fig. 6.2. Observa-se que a região central, compreendida por cerca de 5 fios apresenta linhas de drift paralelas, ou seja, basicamente livres de efeitos de borda. 


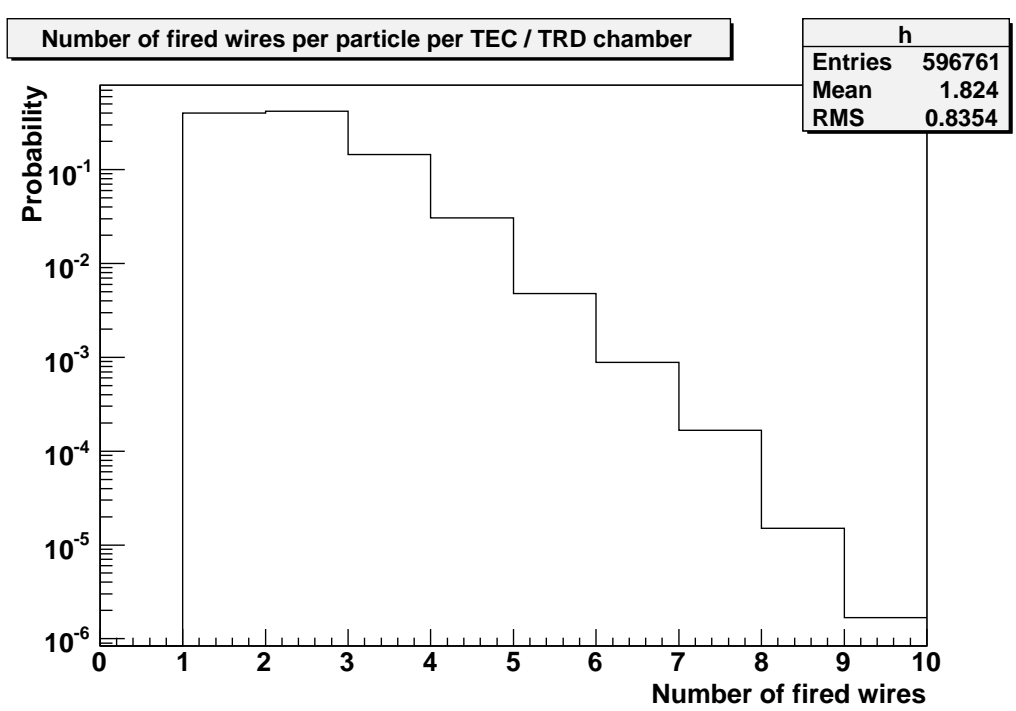

Figura 6.1: Número de fios sensibilizados por partícula por câmara do TEC / TRD.

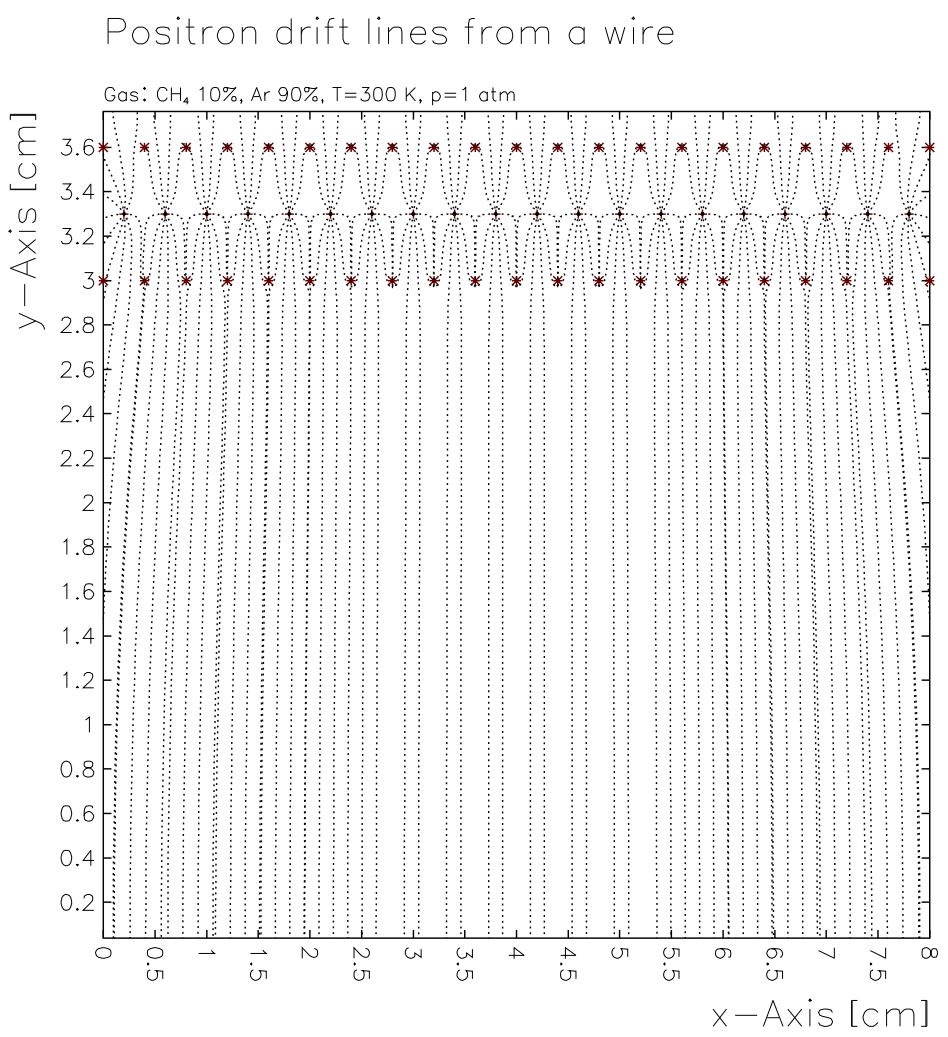

Figura 6.2: Linhas de drift dos elétrons calculadas pelo Garfield na simulação das câmaras do TEC / TRD. Os pontos escuros representam os fios de anodo (+) e catodo $(*)$.

\subsubsection{Resposta da eletrônica}

A resposta dos pré-amplificadores foi medida seguindo o mesmo procedimento adotado no caso do detector monofilar: o sinal de um pulsador foi injetado em um 
dos canais de um pré-amplificador e os sinais de entrada e de saída foram medidos num osciloscópio digital. A resposta foi obtida através da deconvolução dos sinais de entrada e de saída.

$\mathrm{Na}$ realidade, os fios de anodo estão ligados aos pré-amplificadores por meio de placas de desacoplamento. Um circuito foi montado para reproduzir as capacitâncias dessas placas. As capacitâncias utilizadas - 500 pF e 20 pF - correspondem a uma aproximação das capacitâncias das placas - 470 pF e 18 pF - de acordo com os capacitores disponíveis no LIP.

As figuras 6.3 e 6.4 mostram respectivamente o esquema do circuito utilizado na medida e a resposta da eletrônica do TEC / TRD. Futuramente essa resposta deverá ser medida utilizando uma placa de desacoplamento do TEC / TRD.

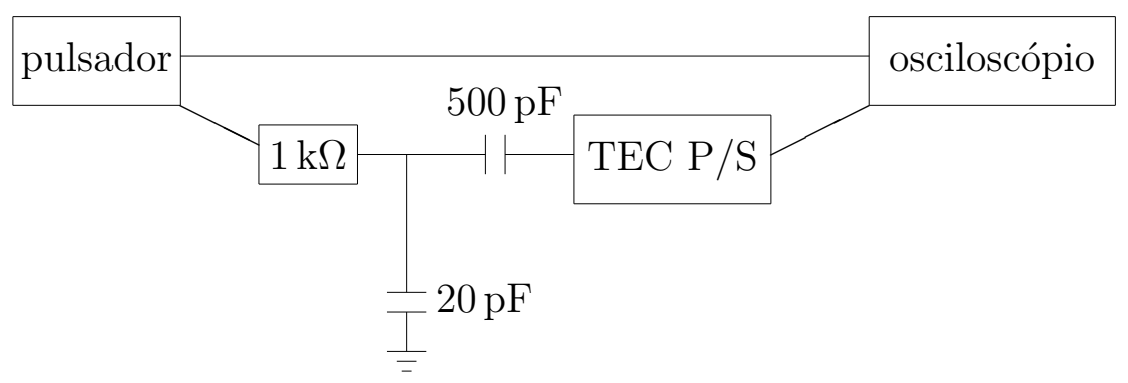

Figura 6.3: Esquema da eletrônica utilizada na medida da resposta dos préamplificadores do TEC / TRD.

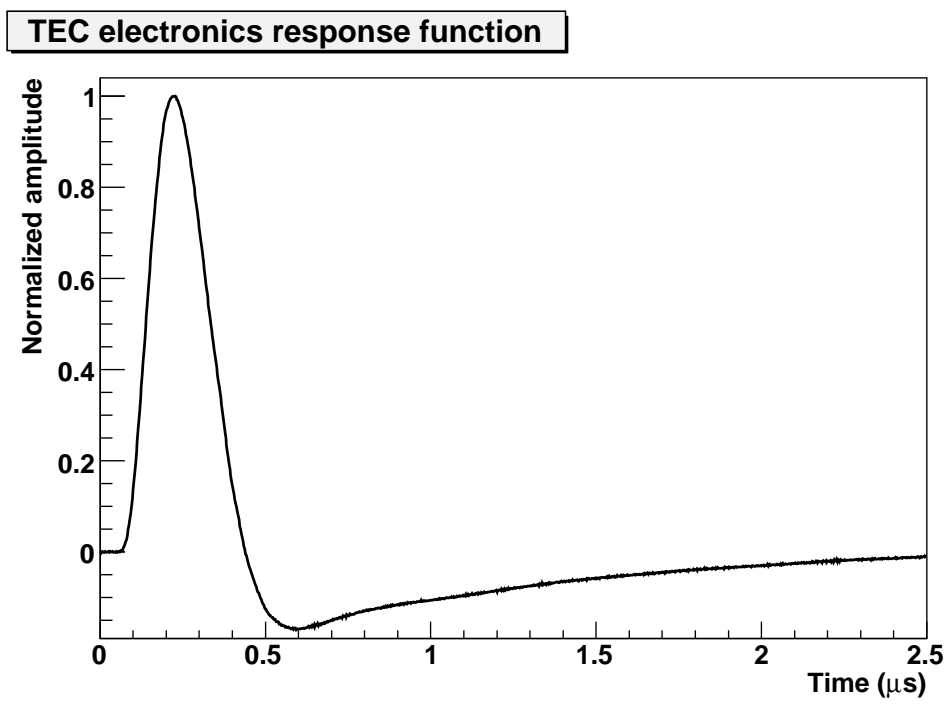

Figura 6.4: Função resposta da eletrônica do TEC / TRD. 


\subsubsection{Processo de avalanche}

O processo de avalanche gerado por uma carga foi simulado para as duas misturas utilizadas no TEC. A exemplo do que foi feito para o detector monofilar, a distribuição do número final de cargas utilizada nas simulações foi definida de acordo com estes resultados. Observou-se que a distribuição exponencial descreve satisfatoriamente os dados, mostrados nas figs. 6.5(a) e 6.5(b), não havendo razão para que se utilize a distribuição de Polya.

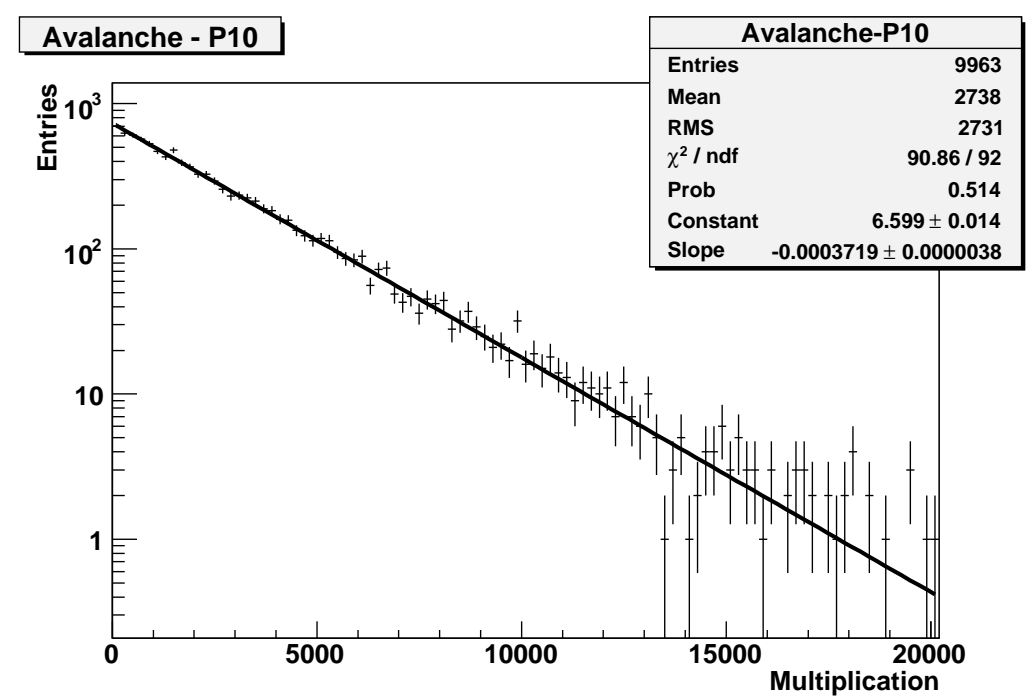

(a)

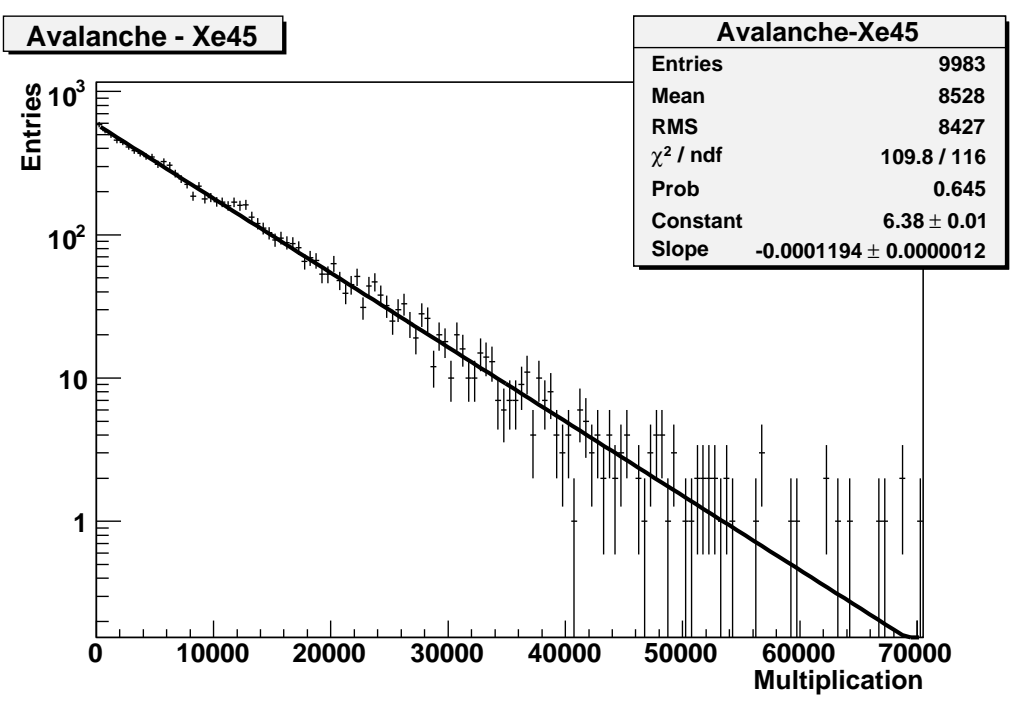

(b)

Figura 6.5: Distribuição do número de cargas formadas durante a avalanche em (a) P10 e (b) Xe45 e função exponencial ajustada. 


\subsection{Simulação da produção de TR}

A produção e absorção dos fótons de radiação de transição foi incluída nas simulações, de modo a reproduzir a resposta das câmaras à passagem de elétrons.

O tratamento teórico adequado da produção de fótons em radiadores irregulares, como os radiadores do TEC / TRD, requer o conhecimento das distribuições associadas à espessura e aos espaçamentos no meio. Essa informação, no entanto, não é conhecida com precisão. A alternativa nesse caso consiste em encontrar parâmetros que reflitam as dimensões típicas do radiador e reproduzam os espectros medidos, utilizando-se o modelo do radiador regular, descrito no apêndice B.

Esse procedimento é aplicado na ref. [53], que apresenta medidas do espectro de radiação de transição gerado por radiadores regulares e irregulares, incluindo os futuros radiadores do TRD do experimento ALICE. Os resultados são comparados às simulações de radiadores regulares e apresentam bom acordo.

Os radiadores do ALICE TRD e do TEC / TRD são compostos pelos mesmos materiais, diferindo somente no número de camadas de fibras de polipropileno. Esse fator, descrito pelo número de interfaces efetivas (eq. B.5), influencia basicamente a altura do espectro, e não a sua forma (fig. 6.6). Devido à ausência de medidas no caso do TEC / TRD foram utilizados os mesmos valores para o tamanho das folhas e dos espaçamentos ( $d_{1}$ e $\left.d_{2}\right)$, variando-se somente o número de interfaces $N$ de acordo com a razão entre as espessuras dos radiadores. Os parâmetros utilizados na simulação estão mostrados na tabela 6.1.

\begin{tabular}{ccc}
\hline Parâmetro & ALICE TRD & TEC / TRD \\
\hline$d_{1}(\mu \mathrm{m})$ & 13 & 13 \\
$d_{2}(\mu \mathrm{m})$ & 400 & 400 \\
$N$ & 115 & 164 \\
\hline
\end{tabular}

Tabela 6.1: Valores para os parâmetros utilizados na simulação da produção de TR pelo ALICE TRD [53] e para o TEC / TRD. 


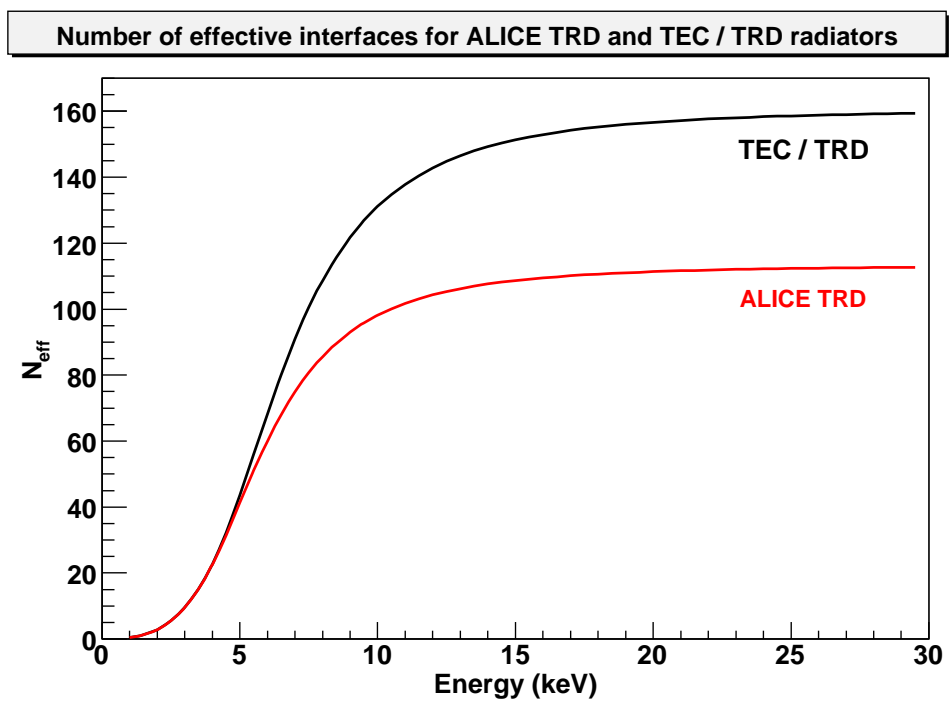

Figura 6.6: Número efetivo de interfaces em função da energia (eq. B.5) para os radiadores do TEC / TRD e do TRD do experimento ALICE.

\subsubsection{Espectros de energia e número médio fótons produzi- dos}

O espectro de energia dos fótons produzidos nos radiadores do TEC / TRD foi calculado utilizando-se a eq. B.6 e os valores da tabela 6.1. A fig. 6.7 mostra os espectros para alguns valores do fator de Lorentz $\gamma$ entre 1000 e 10000.

Uma grandeza mais relevante para as simulações é o número de fótons que de fato entram na região de detecção, após a produção no radiador, a absorção pela camada de mylar que envolve as fibras e a passagem pela janela do detector. A partir desse espectro, o espectro dos fótons detectados em cada mistura pode ser obtido considerando o livre caminho médio dos fótons no gás.

A fig. 6.8 apresenta estes espectros para $\gamma=5000$. Os coeficientes de absorção dos materiais que compõe os radiadores e o livre caminho médio dos fótons nas misturas que preenchem as câmaras foram obtidos da ref. [43], e estão mostrados nas figs. 4.4(a) e 4.4(b).

O número médio de fótons produzidos por uma partícula com fator de Lorentz $\gamma$ é dado pela integral do espectro correspondente. Essa função foi calculada através da integração numérica dos espectros e está mostrada na fig. 6.9. 


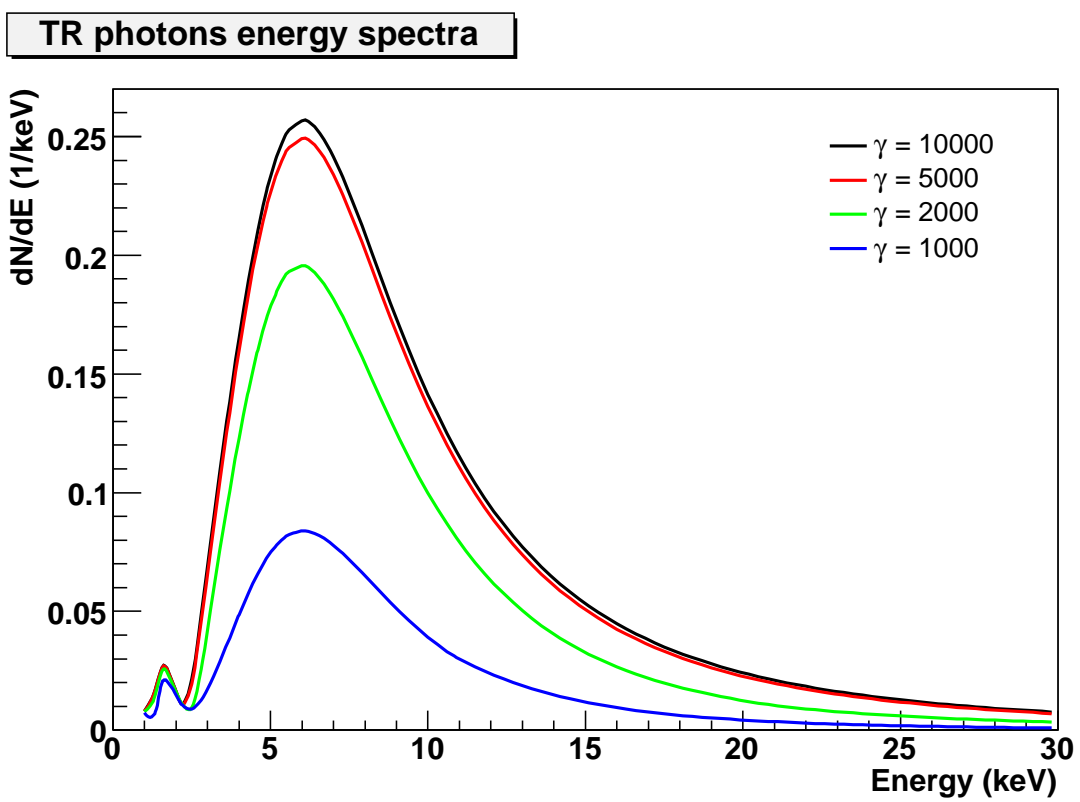

Figura 6.7: Espectros de energia dos fótons produzidos no radiador do TEC / TRD para alguns valores do fator de Lorentz $\gamma$.

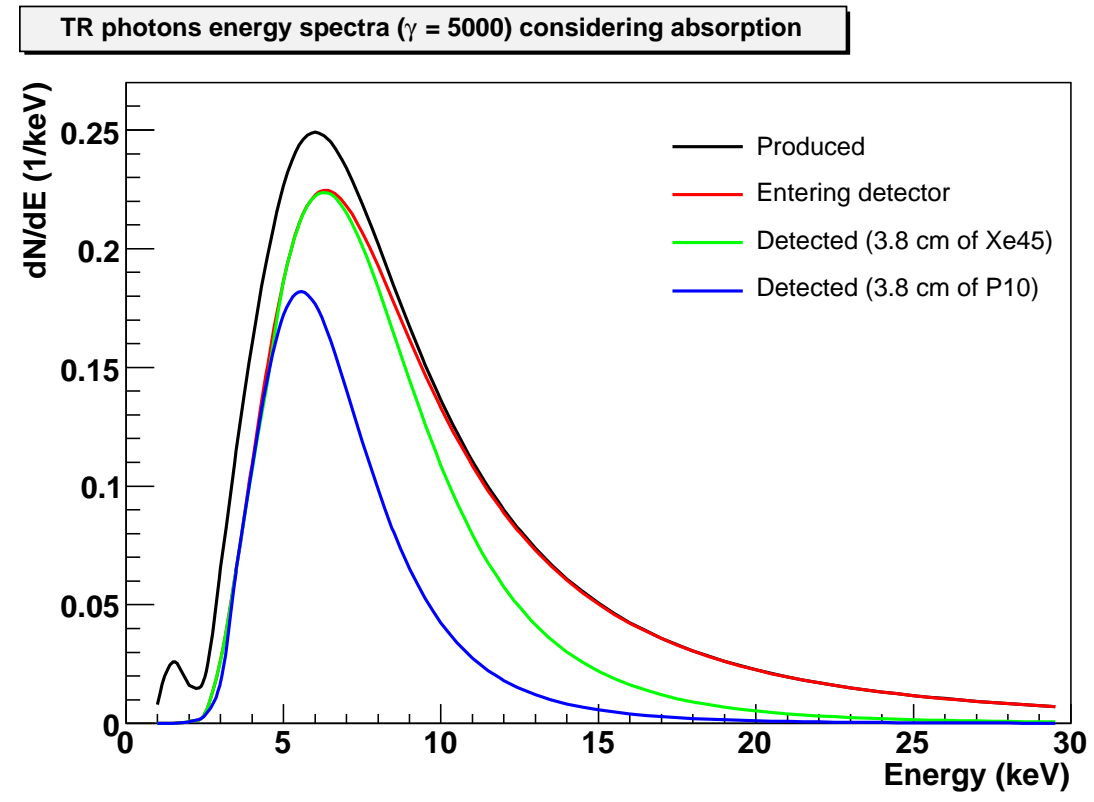

Figura 6.8: Espectros de energia dos fótons produzidos, entrando no detector e detectados por uma câmara $(3.8 \mathrm{~cm})$ preenchida com as misturas utilizadas no TEC / TRD para $\gamma=5000$.

\subsubsection{O processo de simulação}

A simulação da produção de TR baseia-se no procedimento apresentado nas refs. $[53,54]$ e consiste nas seguintes etapas: 


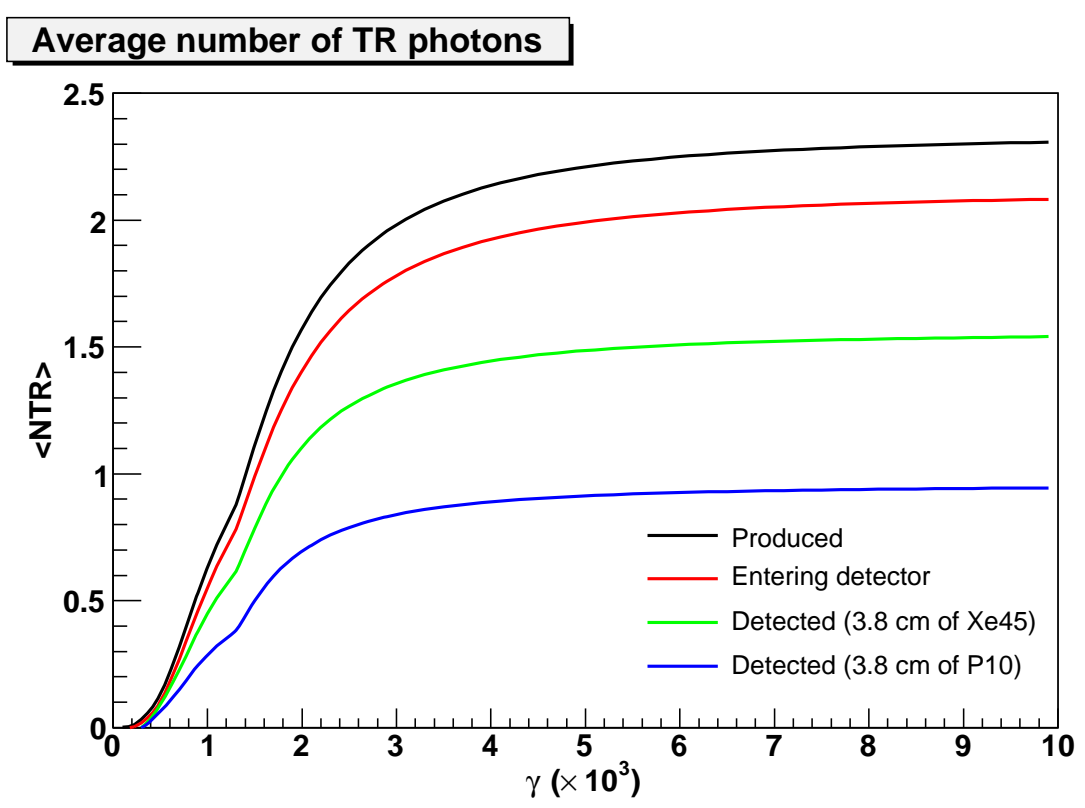

Figura 6.9: Número médio de fótons produzidos, entrando no detector e detectados por uma câmara $(3.8 \mathrm{~cm})$ preenchida com as misturas utilizadas no TEC / TRD em função do fator de Lorentz $\gamma$.

- Dada uma partícula que atravessa o radiador do TEC / TRD com fator de Lorentz $\gamma$, é calculado o número médio de fótons produzidos $\langle n\rangle$.

- O número de fótons produzidos $n$ é sorteado de acordo com uma distribuição de Poisson com média $\langle n\rangle$.

- A energia dos fótons é determinada sorteando $n$ números aleatórios de acordo com o espectro de energia correspondente ao valor de $\gamma$ da partícula.

- Os fótons são introduzidos no simulador do TEC, descrito na seção 6.3.

Na realidade, o número de fótons produzidos $n$ é sorteado a partir do número médio de fótons que entram no detector, para que não seja necessário gerar fótons, depois calcular a probabilidade de absorção na janela do detector e eventualmente eliminá-los caso tenham sido absorvidos. A determinação da energia desses fótons é feita a partir do espectro de fótons que entram no detector.

A ref. [53] compara o número de fótons medidos com os protótipos dos radiadores do TRD do experimento ALICE a uma distribuição de Poisson, mostrando um acordo razoável. Os números aleatórios baseados na distribuição de Poisson são obtidos a partir do gerador do pacote Scipy $[49,50]$, enquanto os baseados no espectro de energia são calculados pelo ROOT [55]. O procedimento adotado é descrito no apêndice A. 


\subsection{Descrição do simulador}

O simulador desenvolvido neste trabalho consiste basicamente numa interface entre o Python [49] e o Garfield que calcula os sinais induzidos nos fios de anodo pela passagem de partículas. A interface foi desenvolvida para permitir a escolha dos parâmetros da simulação e a análise dos dados fora do ambiente do Garfield. O Python é uma linguagem orientada a objetos que conta com ferramentas extremamente eficientes e simples para análise estatística, processamento de sinais, interpolação e produção de gráficos, além de uma interface com o ROOT [55], que é um software amplamente empregado na análise de dados em física de altas energias.

A geometria das câmaras, as propriedades das misturas gasosas e as rotinas para geração dos sinais são pré-definidas. O usuário pode, através da interface, definir as tensões nos eletrodos, a mistura gasosa que será utilizada, quantas câmaras serão consideradas e as partículas que atravessam as câmaras. Para cada partícula é possível escolher a espécie (elétron, píon ou fóton), o momento e a trajetória, através das posições de entrada e saída na câmara.

O simulador então gera um código de acordo com a sintaxe do Garfield, que contém os parâmetros escolhidos e os locais onde devem ser salvos os resultados. O código é executado e os resultados podem ser lidos a partir dos arquivos gerados pelo Garfield e importados para o Python. Para cada sinal gerado, são armazenadas as informações da partícula incidente, o número da câmara e o número do fio sensibilizado, além do próprio sinal, a exemplo do que ocorre no caso dos dados reais do TEC.

A simulação dos elétrons e dos fótons de radiação de transição correspondentes é feita separadamente, e os sinais podem ser somados fora do ambiente do Garfield. No caso dos fótons é possível escolher entre quais câmaras ocorreu a produção, e a simulação é feita somente até a absorção da partícula.

\subsection{Comparação com os dados do TEC / TRD}

Nas simulações do detector monofilar, foram comparados um espectro da energia depositada por fótons de raios-X e a forma do sinal produzido pela absorção de um fóton. A absorção de fótons resulta na produção localizada de cargas e na indução de sinais de forma basicamente idêntica. Observam-se somente variações no instante de formação do sinal de acordo com o ponto de absorção, e na amplitude, devido a flutuações no processo de multiplicação.

No caso de píons e elétrons, as interações produzem ionizações em pontos aleatórios 
e clusters com números de cargas também aleatórios, conforme descrito na seção 4.3. Isso significa que um sinal medido é único, e não pode ser comparado diretamente a uma simulação.

Nesse caso, somente é possível uma comparação do comportamento médio do detector. A grandeza correspondente a um sinal médio é a distribuição da carga depositada por um conjunto de partículas em função do tempo. Essa grandeza pode ser definida pela relação:

$$
\langle q(t)\rangle=\frac{1}{N} \sum_{i=1}^{N} q_{i}(t),
$$

onde $N$ é o número de sinais considerados, e $q_{i}(t)$ é a carga medida em função do tempo para o sinal $i$. A amostragem dos sinais em 80 timebins faz com que essa relação seja discretizada no tempo:

$$
\left\langle q_{j}\right\rangle=\frac{1}{N} \sum_{i=1}^{N} q_{i j},
$$

onde agora $q_{i j}$ é a carga medida em cada uma das 80 amostras $j$ do sinal $i$.

Cada valor $q_{i j}$, na realidade corresponde a um certo valor de carga atribuído ao valor de ADC correspondente. A maneira como deve ser feita a conversão entre as duas grandezas é uma questão complicada, pois não existe nenhuma informação a respeito da distribuição dos valores que preenchem cada canal de ADC.

Algumas possibilidades consideradas foram: utilizar o valor médio da faixa de carga que é convertida por cada canal, sortear um valor baseado numa distribuição uniforme ou utilizar o menor valor de cada canal. As duas primeiras alternativas consideram que a média da distribuição dos valores que preenchem um dado canal é igual à posição do centro do canal. No caso de uma distribuição exponencial, por exemplo, para a qual essa consideração não é válida, esse método introduz um desvio sistemático no cálculo do valor médio da distribuição.

No caso dos sinais do TEC selecionados, cerca de $80 \%$ das entradas possuem valor de ADC igual a zero. Essas entradas não são registradas pelo sistema de aquisição do PHENIX, e não são utilizadas nas análises em geral, descritas na seção 3.6, mas é necessário considerá-las para uma comparação da forma dos sinais. A atribuição de qualquer valor de carga não nulo para essas amostras, como no caso de uma distribuição uniforme, deslocaria a carga média para valores mais altos. Optou-se por fazer a conversão no menor valor de cada canal, o que certamente gera um desvio sistemático na carga média, e possivelmente subestima as flutuações, já que o mesmo valor é atribuído a um intervalo de cargas. 
No entanto, os dados simulados foram submetidos exatamente aos mesmos critérios aplicados aos dados reais, através da conversão da carga em valor de ADC e em valor de carga novamente segundo esse método. Isso faz com que em ambos os casos os valores absolutos da carga média sejam subestimados, mas em princípio os erros cometidos são equivalentes.

\subsubsection{Seleção dos dados do TEC / TRD}

Os dados reais utilizados na comparação com os resultados do simulador foram selecionados a partir de medidas de colisões $\mathrm{p}+\mathrm{p}$ do run-6 do RHIC em 2006. Durante o período inicial da tomada de dados neste run, as câmaras do TEC foram operadas com P10. A comparação utilizou os dados deste período, por tratar-se da mesma mistura utilizada no detector monofilar montado no LIP.

Foram processados cerca de $400 \mathrm{~GB}$ contendo os dados brutos de todos os subsistemas do PHENIX. Isso corresponde a cerca de 7 milhões de eventos, registrados durante apenas 50 minutos de tomada de dados. A reconstrução das trajetórias pelo sistema de tracking do PHENIX, e o armazenamento somente das informações das trajetórias medidas pelo TEC / TRD, associadas aos dados dos detectores responsáveis pela identificação de elétrons - RICH e EmCal, reduz esse número para cerca 400 MB. A associação entre as informações dos subsistemas e os critérios para identificação de elétrons seguiu o mesmo procedimento adotado nas referências [20, 21]. Ao todo foram registradas cerca de 157 mil trajetórias.

O tracking do TEC fornece vetores associados às trajetórias medidas no sistema de coordenadas globais do PHENIX e os ângulos $\phi$ e $\alpha$, descritos na seção 3.5. Para o simulador, no entanto, a informação relevante é o ângulo entre a janela de entrada das câmaras e a trajetória. Esse ângulo, denominado por $\delta$, foi calculado a partir do produto escalar entre um versor $\hat{S}$, paralelo à janela de entrada das câmaras, e o vetor $\vec{T}$, paralelo à trajetória:

$$
\cos \delta=\frac{\hat{S} \cdot \vec{T}}{|\vec{T}|}
$$

O versor $\hat{S}$ foi determinado de acordo com a diferença entre as posições dos fios de uma mesma câmara, conforme ilustrado na fig. 6.10. Definindo $\beta$ como o cosseno de $\delta$, a projeção da trajetória na direção da janela da câmara $\Delta$, que é o que de fato é introduzido no simulador, pode ser calculada sabendo-se o comprimento da câmara $L$, através da relação: 


$$
\begin{aligned}
\beta & =\cos \delta \\
\Delta & =L \cdot \frac{\beta}{\sqrt{1-\beta^{2}}}
\end{aligned}
$$

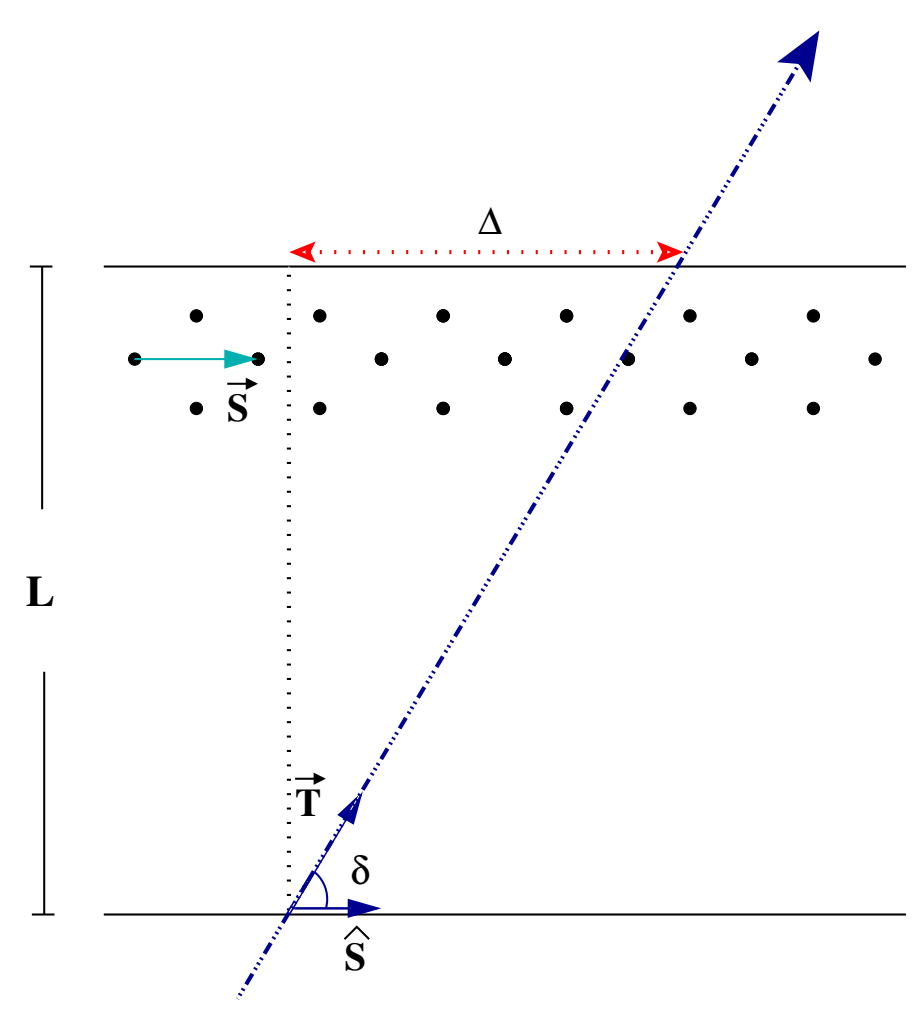

Figura 6.10: Esquema de uma partícula atravessando uma câmara do TEC / TRD representando os vetores $\vec{S}$ e $\vec{T}$, utilizados no cálculo do ângulo $\delta$ e do parâmetro $\Delta$ da eq. 6.5.

A comparação utilizou os sinais induzidos pela passagem de píons e elétrons em 3 câmaras de 2 setores distintos ${ }^{1}$. A tabela 6.2 mostra o número de sinais e de trajetórias associadas a píons em cada uma das 3 câmaras. As câmaras foram escolhidas por apresentarem distribuições da carga média em função do tempo razoavelmente diferentes entre si, mostradas na fig. 6.11, e um ruído baixo em relação às demais, estimado de acordo com o número de entradas (hits) medidas quando não há cruzamento entre os feixes. O ruído do sistema não foi considerado na simulação.

\footnotetext{
${ }^{1}$ A numeração das câmaras obedece a seguinte convenção: braço (E), setor (0-3), lado ( $\mathrm{N}$ ou $\mathrm{S})$, plano (1-5). Por exemplo, E2NP1 corresponde ao plano 1 do setor 2, lado N.
} 
A fig. 6.11 mostra que ao menos dois parâmetros variam de câmara para câmara: a posição da distribuição no eixo horizontal e o ganho da câmara, que determina a altura da distribuição. Nos testes com o detector monofilar, já havia sido notado que o ganho do gás não é calculado corretamente pelo Magboltz, sendo necessário ajustálo aos dados. Na comparação, estes dois parâmetros foram definidos de acordo com um ajuste de mínimos quadrados.

\begin{tabular}{ccc}
\hline Câmara & Trajetórias & Sinais \\
\hline E1SP0 & 13144 & 20791 \\
E1SP1 & 14111 & 23970 \\
E2NP1 & 22666 & 39648 \\
\hline
\end{tabular}

Tabela 6.2: Número de sinais e trajetórias associadas a píons, medidas por três câmaras do TEC / TRD e utilizadas na comparação com os resultados do simulador.

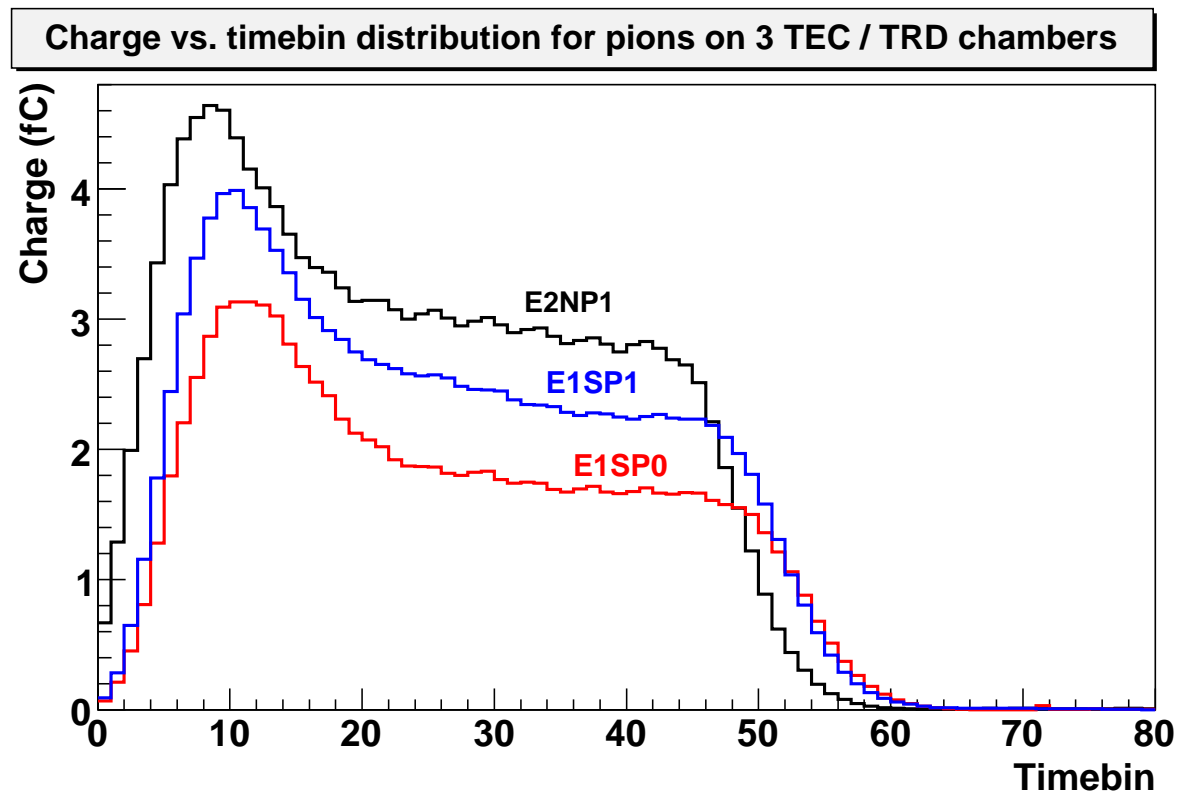

Figura 6.11: Distribuições da carga média depositada por píons em função do timebin para as três câmaras do TEC / TRD utilizadas na comparação com os resultados do simulador.

\subsubsection{Comparação com os resultados para píons}

A simulação foi feita reproduzindo as distribuições de momento e da variável $\Delta$, definida na equação 6.5, medidas para a câmara E1SP1. O gerador de números 
aleatórios do ROOT, descrito no apêndice A, foi utilizado para reproduzir essas distribuições, mostradas nas figs. 6.12(a) e 6.12(b).

Foram consideradas 5000 trajetórias e a simulação foi processada 3 vezes para que fosse observada a flutuação estatística nos resultados. Cada conjunto de dados simulados foi ajustado aos dados reais de uma câmara do TEC.

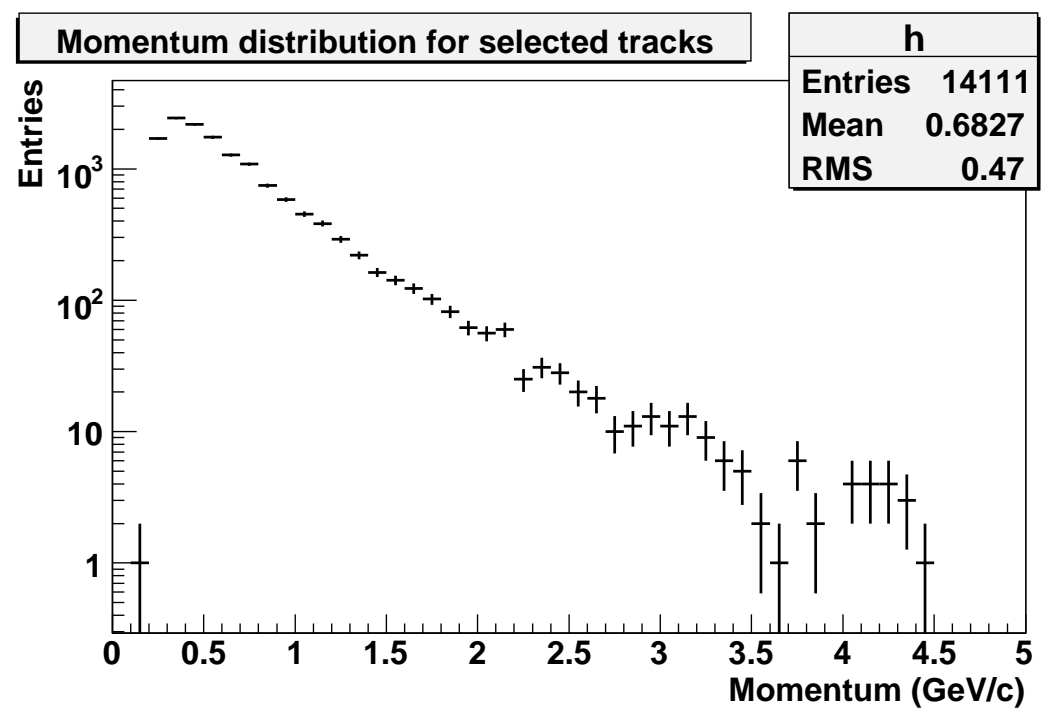

(a)

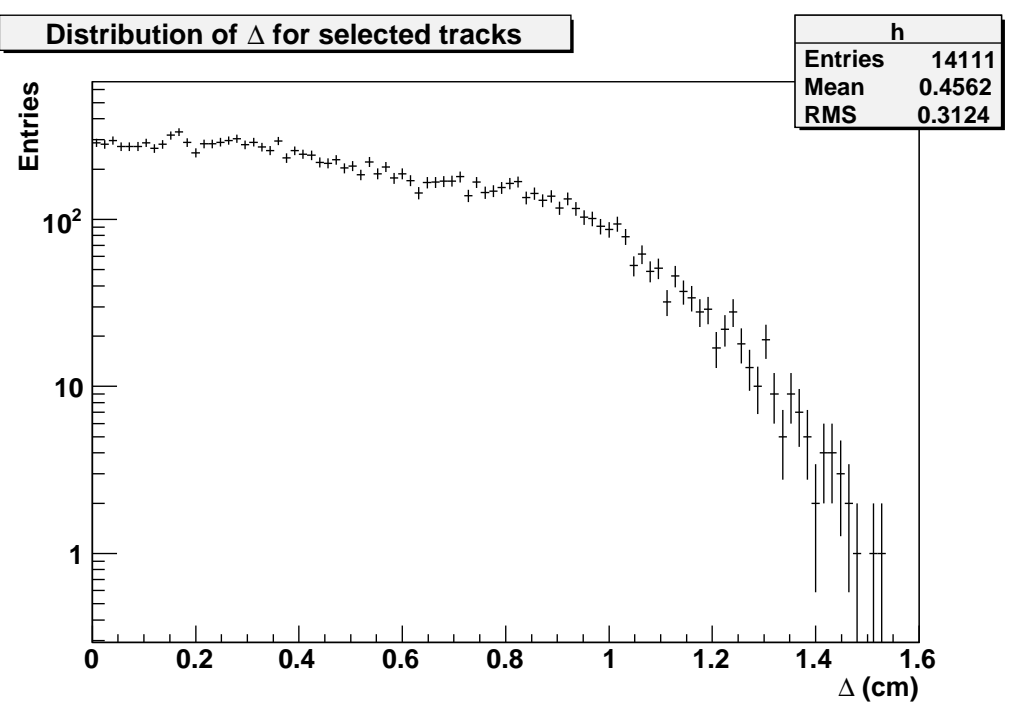

(b)

Figura 6.12: Distribuições (a) do momento das partículas, medidos pela Drift Chamber do PHENIX e (b) da variável $\Delta$, definida na equação 6.5, utilizadas na comparação com os resultados do simulador. 
Cada sinal simulado foi amostrado 80 vezes e a amplitude de cada amostra foi convertida em valor de ADC e novamente em carga, seguindo os mesmos critérios utilizados para os dados do detector. A amostragem e a conversão de carga em valor de ADC dependem da posição da distribuição e do ganho da câmara, determinados através de um ajuste de mínimos quadrados. A função de $\chi^{2}$ minimizada no ajuste foi definida através da seguinte expressão:

$$
\chi^{2}=\sum_{i} \frac{\left(q_{d i}-q_{s i}\right)^{2}}{\left(\sigma_{d i}\right)^{2}+\left(\sigma_{s i}\right)^{2}},
$$

onde $q_{d_{i}}$ e $q_{s i}$ denotam a carga média na amostra $i$ para os dados e a simulação, respectivamente, calculadas através da eq. $6.2 ; \sigma_{d i}$ e $\sigma_{s i}$ são os desvios das respectivas médias.

Os resultados dos ajustes estão mostrados nas figs. 6.13, 6.14 e 6.15. Os valores de $\chi^{2}$, relacionados na tabela 6.3 , são bastante elevados para um ajuste com 78 graus de liberdade, sendo praticamente nula a probabilidade de serem excedidos.

Uma justificativa para os altos valores de $\chi^{2}$ é o fato da conversão de valor de ADC em carga não reproduzir as flutuações na amplitude dos sinais, subestimando o desvio na carga média. Por outro lado, é possível que o simulador seja muito simples para descrever os dados. De fato, diversos efeitos não são levados em conta, como o ruído nas câmaras e as possíveis diferenças entre os ganhos dos canais de eletrônica.

A região de timebins acima de 60, mostrada na fig. 6.16, é a que apresenta a maior discrepância. Essa é também a região onde a média é mais suscetível ao ruído. A fração de entradas com carga diferente de zero para os dados reais, para timebins acima de 64 , varia entre $10^{-3}$ e $10^{-5}$, enquanto na simulação essa fração é nula. Um estudo detalhado do ruído seria necessário para uma comparação mais adequada. 


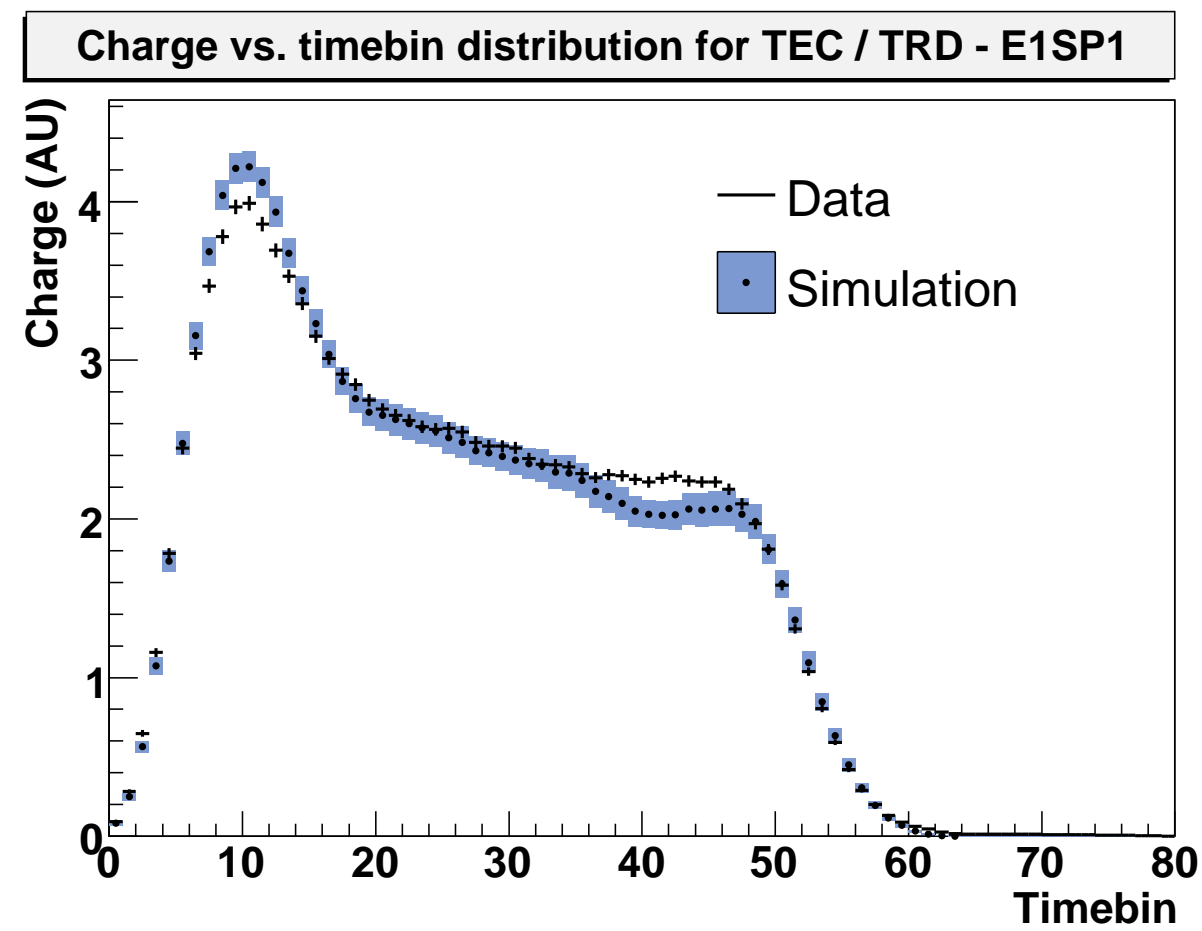

Figura 6.13: Comparação entre as distribuições da carga média depositada por píons em função do timebin para a câmara E1SP1 do TEC / TRD e a simulação.

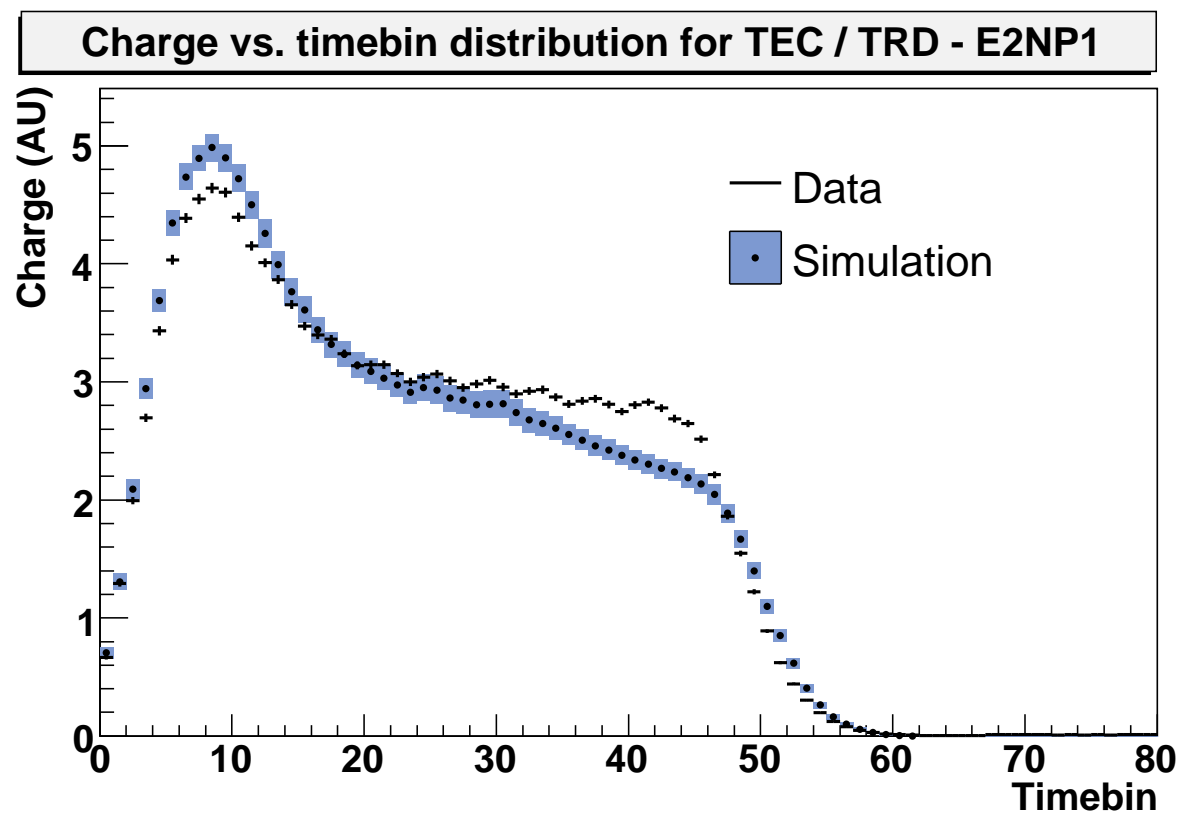

Figura 6.14: Comparação entre as distribuições da carga média depositada por píons em função do timebin para a câmara E2NP1 do TEC / TRD e a simulação. 


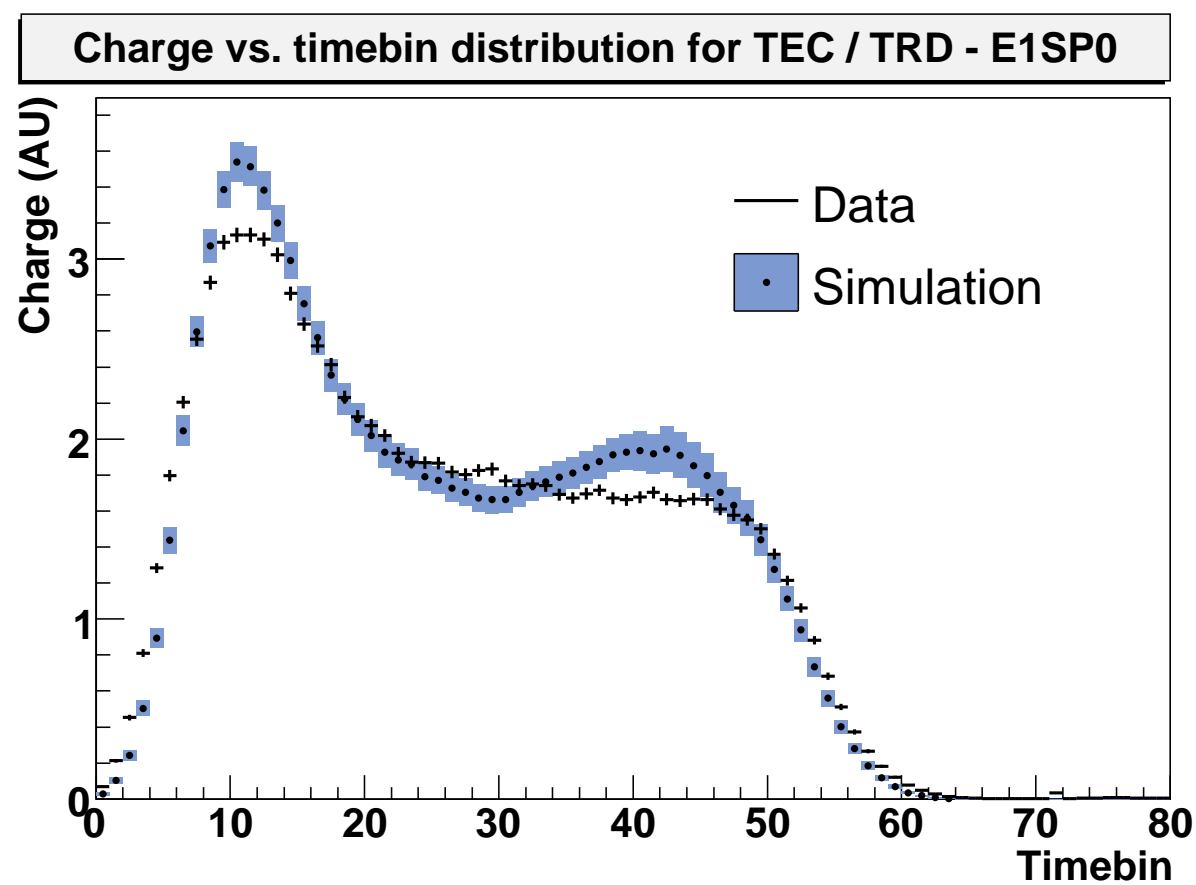

Figura 6.15: Comparação entre as distribuições da carga média depositada por píons em função do timebin para a câmara E1SP0 do TEC / TRD e a simulação.

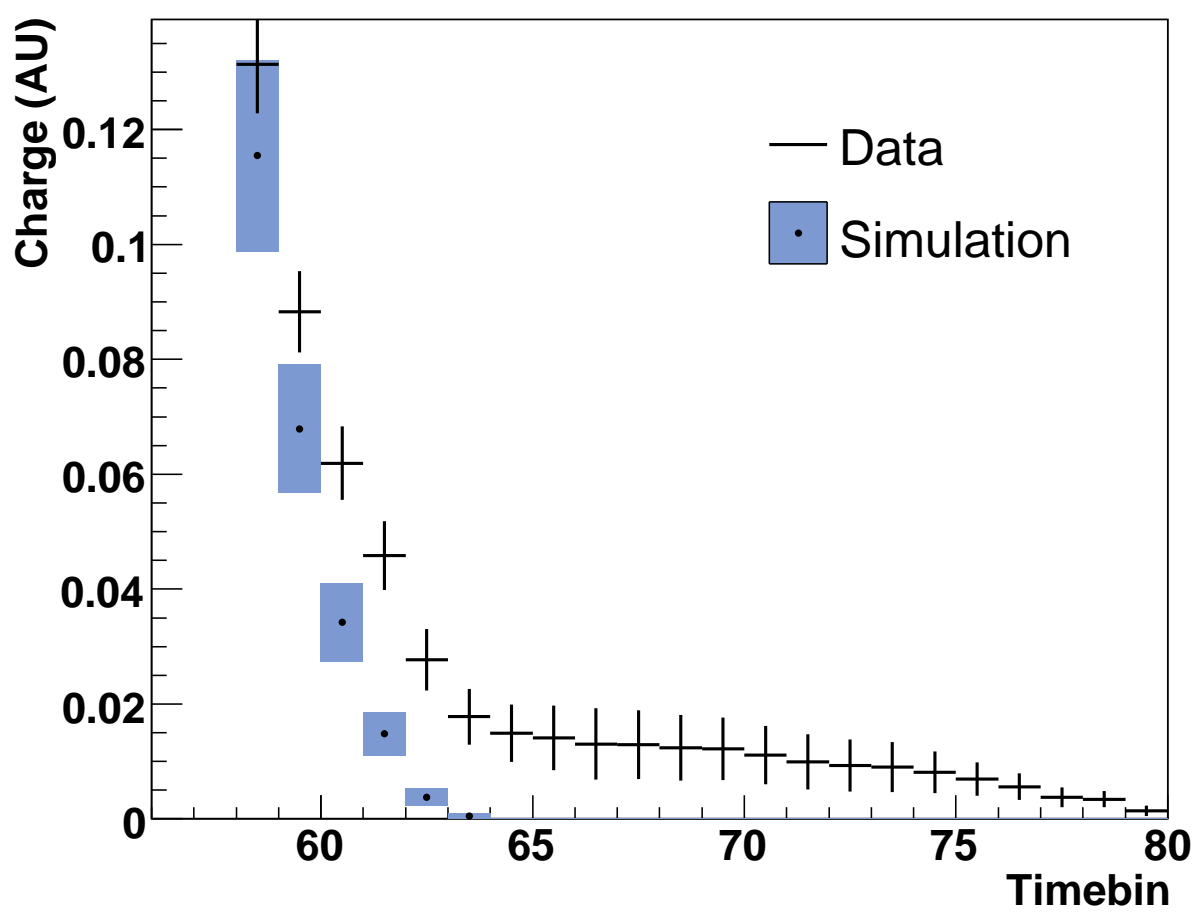

Figura 6.16: Detalhe da fig. 6.13 mostrando a região de timebins maiores que 60, onde se observa a maior discrepância entre os dados e a simulação. 


\begin{tabular}{cc}
\hline Câmara & $\chi^{2}$ \\
\hline E1SP1 & 230 \\
E2NP1 & 642 \\
E1SP0 & 577 \\
\hline
\end{tabular}

Tabela 6.3: Valores de $\chi^{2}$ para os ajustes das distribuições de carga média em função do timebin mostrados nas figs. 6.13, 6.14 e 6.15. Os ajustes possuem 78 graus de liberdade.

\subsubsection{Comparação com os resultados para elétrons}

A simulação dos sinais induzidos pela passagem de elétrons foi comparada aos dados do TEC, através da distribuição da carga média em função do tempo. A estatística dos dados reais para elétrons é uma ordem de grandeza menor que no caso dos píons. O número de sinais registrados em cada câmara é de cerca de 1000 .

A simulação foi feita utilizando o mesmo conjunto de 5000 valores de momento e das posições de entrada e saída nas câmaras usado para a comparação com os sinais dos píons. A produção de radiação de transição por essas partículas foi considerada, e os sinais dos fótons foram somados aos sinais dos respectivos elétrons. Cerca de 3500 fótons foram produzidos na simulação, dos quais aproximadamente 1500 foram absorvidos. Os sinais simulados foram amostrados utilizando os parâmetros de ganho e posição horizontal definidos para cada câmara nos ajustes das distribuições dos píons.

A distribuição para a câmara E1SP1, mostrada na fig. 6.17, mostra um bom acordo entre os dados e a simulação. O valor de $\chi^{2}$, calculado com a equação 6.6, é de 48 para 80 graus de liberdade (nenhum parâmetro foi ajustado aos dados). 


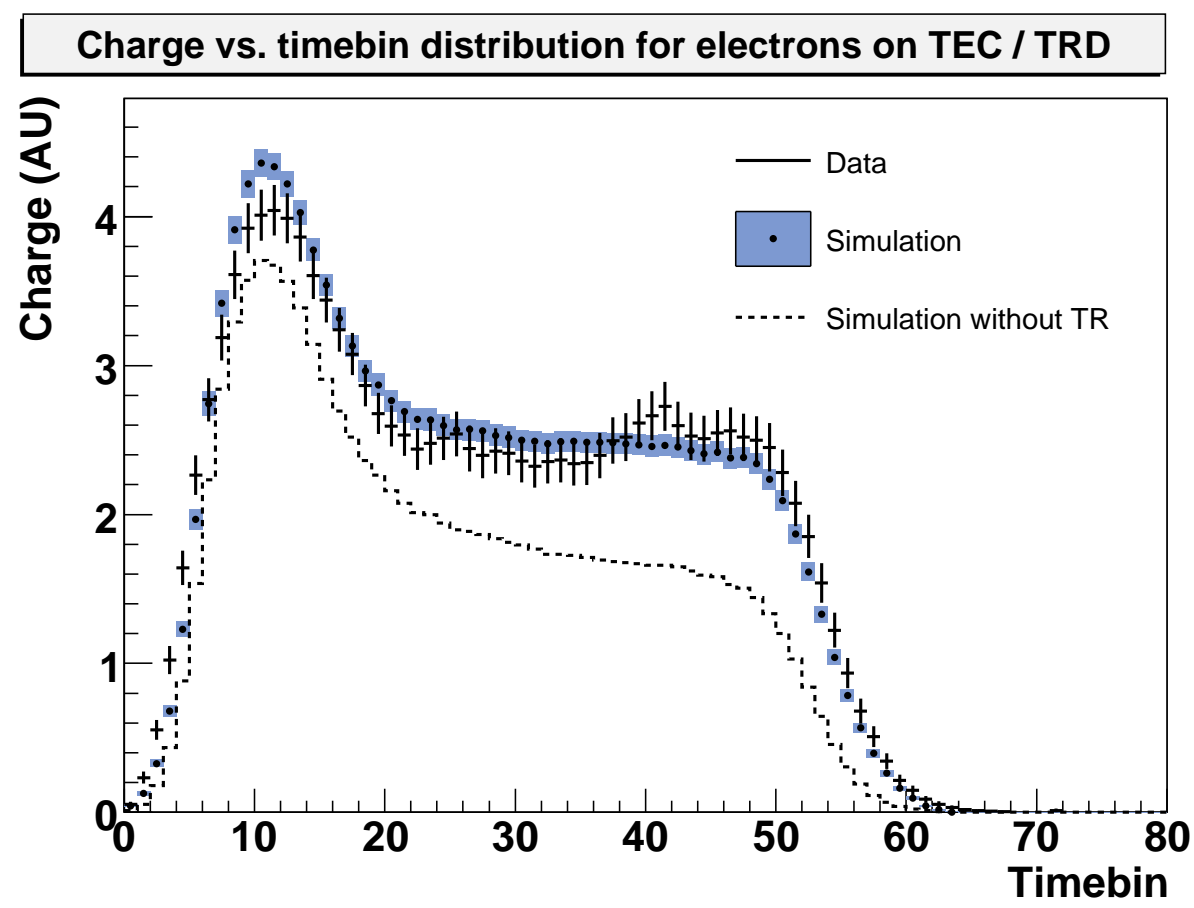

Figura 6.17: Comparação entre as distribuições da carga média depositada por elétrons em função do timebin para a câmara E1SP1 do TEC / TRD e a simulação. A linha tracejada mostra os resultados da simulação desconsiderando a produção de radiação de transição.

\subsection{Conclusões}

Um simulador para o TEC / TRD baseado no Garfield, que permite o cálculo dos sinais induzidos pela passagem de partículas, foi desenvolvido. Foi criado também um simulador da produção de radiação de transição, baseado em medidas realizadas com os protótipos dos radiadores do TRD do experimento ALICE, semelhantes aos radiadores do TEC / TRD. Simulações foram comparadas a dados do detector, através da distribuição da carga média em função do tempo para píons e elétrons. Os seguintes pontos podem ser destacados:

- A comparação com os dados reais foi feita através de um comportamento médio do detector, já que uma comparação direta dos sinais medidos e simulados não é possível no caso de píons e elétrons.

- A distribuição da carga média em função do tempo, utilizada na comparação, é calculada a partir da conversão entre os valores de ADC registrados e a carga correspondente a estes valores. Não existem outras medidas que indiquem a melhor forma para essa conversão, que utilizou o menor valor associado a cada 
canal. Esse método certamente gera um desvio sistemático na carga média e possivelmente subestima as flutuações associadas a essa grandeza.

- As distribuições medidas para píons foram comparadas às simulações por meio de um ajuste de mínimos quadrados com dois parâmetros: o ganho do gás e a posição horizontal da distribuição. Os valores da função de $\chi^{2}$ minimizada no ajuste variam entre 200 e 700, para um ajuste com 78 graus de liberdade.

- Os altos valores de $\chi^{2}$ indicam que possivelmente as incertezas foram subestimadas, e que o simulador não reproduz exatamente os sinais induzidos. O ruído do sistema não foi considerado nas simulações, e um estudo desse efeito é necessário para uma comparação mais adequada.

- A resposta da eletrônica de aquisição foi medida em condições próximas às condições do detector para um canal de eletrônica e introduzida no simulador. A mesma função é utlizada na reprodução da resposta de cerca de 400 canais, que podem apresentar variações no ganho e na própria forma da função.

- A comparação com medidas para elétrons, utilzando os parâmetros ajustados às distribuições medidas para píons, mostram um bom acordo entre os dados e a simulação, indicando que a simulação da produção de TR descreve corretamente esse fenômeno. 


\section{Capítulo 7}

\section{Conclusões}

O estudo da matéria nuclear em condições extremas, através da produção e caracterização do chamado plasma de quarks e glúons (QGP), é o grande objetivo do colisor de íons pesados relativísticos (RHIC) do Laboratório Nacional de Brookhaven nos EUA. A medida dos observáveis físicos que permitem a sua caracterização é feita por detectores de grande escala, compostos por diversos subsistemas especializados na identificação das partículas emergentes das colisões.

O PHENIX, um dos quatro experimentos instalados no RHIC, tem como principal meta a medida de sinais eletrofracos, que fornecem evidências diretas da formação do QGP. O experimento conta com três subsistemas para a identificação de elétrons na região de pseudo-rapidez central $(|\eta|<0.35)$ - o detector Cherenkov de imagem anular (RICH), o calorímetro eletromagético (EmCal) e as câmaras de expansão temporal / detectores de radiação de transição (TEC / TRD).

As câmaras de expansão temporal, com as quais o Laboratório de Instrumentação e Partículas (LIP) da USP está particularmente envolvido, são o único sistema do PHENIX capaz de identificar elétrons de forma eficiente para momentos superiores a $5 \mathrm{GeV} / \mathrm{c}$, através de medidas de perda de energia $(d E / d x)$ e radiação de transição (TR).

Este trabalho consistiu no estudo dos processos físicos que permitem a detecção de partículas, e no desenvolvimento de um simulador para este detector. O simulador baseou-se no Garfield, um programa amplamente utilizado na simulação de detectores de larga escala em experimentos de física de altas energias.

As limitações do Garfield, relacionadas aos cálculos do fator de multiplicação de misturas gasosas em câmaras proporcionais e dos sinais induzidos pela passagem de partículas [37, 52], foram estudadas através da comparação entre medidas e simulações de um detector proporcional monofilar construído no LIP. Observou-se que de fato o Garfield subestima o fator de multiplicação do gás, mas reproduz adequa- 
damente as flutuações na perda de energia de fótons no meio, e o sinal induzido pela absorção destes. Com base nestes resultados, um simulador para o TEC / TRD foi desenvolvido e comparado a dados reais do subsistema.

O simulador consiste numa interface entre o Garfield e o Python, uma linguagem de programação orientada a objetos bastante utilizada na análise de dados em física de altas energias. A principal função do simulador é o cálculo dos sinais induzidos pela passagem de píons, elétrons e fótons nas câmaras, cabendo ao usuário a definição da espécie, energia e trajetória da partícula, da mistura gasosa e dos potenciais dos eletrodos da câmara.

Um simulador da produção de radiação de transição foi desenvolvido e integrado ao simulador do TEC. O cálculo do espectro de energia dos fótons gerados baseou-se em medidas com os protótipos dos radiadores do TRD do experimento ALICE [53], semelhantes aos radiadores do TEC / TRD.

Os sinais induzidos por píons e elétrons, medidos pelo TEC / TRD em colisões $\mathrm{p}+\mathrm{p}$ do RHIC, foram comparados às simulações. A comparação utilizou a distribuição da carga média coletada em função do tempo para um conjunto de partículas. Os únicos parâmetros ajustados foram o ganho do gás e a origem temporal dos sinais, que variam de câmara para câmara nos dados reais.

A comparação com dados de três câmaras do TEC / TRD mostra que o simulador descreve qualitativamente a forma das distribuições no caso dos píons. Estatisticamente, no entanto, os valores de $\chi^{2}$ obtidos nos ajustes são muito elevados, variando de 200 a 700 para 78 graus de liberdade. Isso indica que possivelmente houve uma subestimação das incertezas e o simulador não considera efeitos importantes no cálculo dos sinais. De fato, o ruído do sistema não é levado em conta nas simulações, e um estudo deste efeito seria necessário para uma comparação mais adequada.

A simulação dos sinais induzidos pela passagem de elétrons e pela absorção dos fótons de TR associados foi comparada a dados reais, utilizando os valores dos parâmetros determinados no ajuste para o caso dos píons. Observou-se um bom acordo entre ambos, evidenciado pela forma da distribuição e pelo valor de $\chi^{2}$ (48) próximo ao número de graus de liberdade (80). Desprezando o efeito da radiação de transição, observa-se uma grande discrepância em relação aos dados, o que indica que o simulador da produção de TR reproduz corretamente esse fenômeno dentro da precisão das medidas. 
Os simuladores desenvolvidos são ferramentas de grande utilidade para a análise dos métodos de identificação de partículas. Em princípio é possível obter distribuições de probabilidade para qualquer grandeza medida pelo detector com qualquer estatística, tendo como única limitação o tempo de processamento. Isso deverá permitir a aplicação dos métodos descritos na literatura e de eventuais estudos de novos métodos, baseados por exemplo na forma dos sinais.

É possível ainda utilizar os simuladores na verificação das condições de operação do detector e no impacto de eventuais mudanças que se façam necessárias. Dentre essas mudanças podemos citar mudanças na composição da mistura gasosa, nas condições de temperatura, nos parâmetros da eletrônica de aquisição, como ganho e tempo de formatação dos sinais, e nos programas de reconstrução das trajetórias.

Estudos a respeito do ruído das câmaras e da flutuação entre os ganhos dos canais de eletrônica estão em andamento e devem levar a uma melhor reprodução da resposta do detector nas simulações.

Comparações de outras grandezas, e de dados com maior estatística devem ser realizadas para permitir a aplicação de métodos para identificação de partículas baseados em simulações. 



\section{Apêndice A}

\section{Gerador de números aleatórios para uma distribuição genérica}

O ROOT [55] conta com um método para geração de números aleatórios baseados em uma distribuição genérica representada em um histograma, que foi utilizado para a simulação dos espectros de energia dos fótons de radiação de transição. O seguinte procedimento é adotado:

- Dado um histograma ou uma função que representem a função densidade de probabilidade $p d f(x)$ da variável $x$, calcula-se por meio de sua integral a distribuição cumulativa normalizada $c d f(x)$, dada por:

$$
c d f(x)=\int_{-\infty}^{x} p d f\left(x^{\prime}\right) d x^{\prime}
$$

- Sorteia-se um número aleatório $a$ entre 0 e 1 de acordo com uma distribuição uniforme.

- O número aleatório $b$, que obedece à distribuição $p d f(x)$, é determinado por $c d f(b)=a$.

O gerador foi testado utilizando-se um histograma de 500 canais para a $p d f$ e outro de 250 canais para comparação. O valor de $\chi^{2}$ foi calculado através da relação:

$$
\chi^{2}=\sum_{i}\left[\frac{K \cdot y_{f}\left(x_{i}\right)-N_{i}}{\sqrt{N_{i}}}\right]^{2}, N_{i} \neq 0,
$$

onde $y_{f}(x)$ é o valor da função de referência no ponto $x, N_{i}$ é número de entradas do canal $i$ do histograma e $K$ é uma normalização da função de acordo com o número 
de entradas sorteadas. A fig. A.1 mostra que a curva é bem descrita pelo gerador, e a probabilidade do valor de $\chi^{2}$ ser excedido é de $50 \%$.

No caso dos espectros de energia, a limitação computacional é a eficiência do gerador. Para cada valor de $\gamma$, o histograma de 500 canais tem de ser preenchido com os valores do espectro de energia, e a $c d f$ tem de ser calculada.

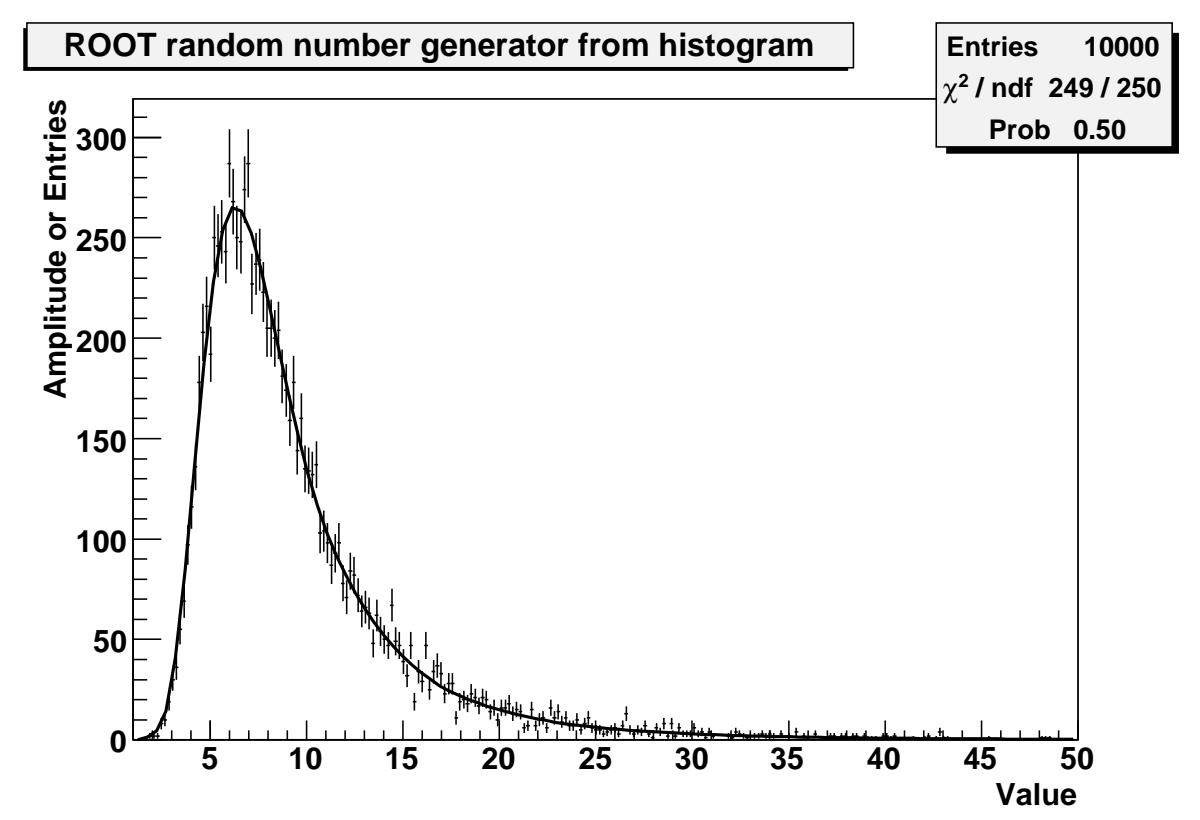

Figura A.1: Comparação entre o gerador de números aleatórios do ROOT utilizado na simulação da energia dos fótons, e a função de referência. O quadro mostra o valor de $\chi^{2}$ e a probabilidade deste valor ser excedido. 


\section{Apêndice B}

\section{Produção de TR em radiadores}

Seguindo o formalismo da ref. [56], a potência irradiada num ângulo $\theta$ em relação à trajetória de uma partícula com fator de Lorentz $\gamma \gg 1$ atravessando a interface entre dois meios 1 e 2 de constantes dielétricas $\epsilon$ diferentes, em função do ângulo sólido $\Omega$ e da frequência angular da radiação $\omega$ é dada por:

$$
\frac{d^{2} W}{d \omega d \Omega}=\frac{\alpha \theta^{2}}{\pi^{2}}\left(\frac{1}{\gamma^{-2}+\theta^{2}+\xi_{1}^{2}}-\frac{1}{\gamma^{-2}+\theta^{2}+\xi_{2}^{2}}\right)^{2}
$$

onde

$$
\xi=\frac{\omega_{p}}{\omega}=\sqrt{1-\epsilon}
$$

$\omega_{p}$ é a frequência de plasma do meio, e pode ser calculada através da relação:

$$
\hbar \omega_{p}=28.8 \sqrt{\rho \frac{Z}{A}} \mathrm{eV}
$$

onde $Z$ e $A$ representam os números atômico e de massa do material, e $\rho$ sua densidade em $\mathrm{g} / \mathrm{cm}^{3}$. A tabela B.1 apresenta valores para a frequência de plasma de alguns materiais utilizados em radiadores.

\begin{tabular}{cc}
\hline Material & $\hbar \omega_{p}(\mathrm{eV})$ \\
\hline $\mathrm{ar}$ & 0.7 \\
$\mathrm{CO}_{2}$ & 0.9 \\
polipropileno & 20 \\
polietileno & 20 \\
\hline
\end{tabular}

Tabela B.1: Valores para a frequência de plasma $\omega_{p}$ de alguns materiais utilizados em radiadores. 
O espectro emitido por uma folha de espessura $d_{1}$ (eq. B.4) é calculado através da interferência entre as duas interfaces, representada por uma fase $\phi$ que depende do tamanho da folha e da energia do fóton.

$$
\left(\frac{d^{2} W}{d \omega d \Omega}\right)_{\text {folha }}=\left(\frac{d^{2} W}{d \omega d \Omega}\right)_{\text {interface }} \times 4 \operatorname{sen}^{2} \frac{\phi}{2} .
$$

Para o caso de um radiador regular, ou seja, de uma série de $N$ folhas de espessura fixa $d_{1}$, separadas por intervalos constantes de tamanho $d_{2}$, o espectro de energia é calculado considerando os efeitos de interferência entre as folhas. Seguindo o formalismo das refs. $[54,56]$, define-se um número efetivo de folhas $N_{\text {eff }}$, que leva em conta a absorção dos fótons nos meios, dado por:

$$
N_{e f f}=\frac{1-e^{-N \sigma}}{\sigma}
$$

onde $\sigma=\frac{\mu_{1}}{\lambda_{1}}+\frac{\mu_{2}}{\lambda_{2}}$ é a absorção por uma folha (índice 1) + um gap (índice 2) e $\lambda_{i}$ é o livre caminho médio de um fóton de energia $E$ no meio $i$. Ignorando a distribuição angular da radiação emitida, o número de fótons produzidos em função da energia é dado por:

$$
\frac{d N}{d E}=\frac{4 \alpha}{E} \frac{N_{e f f}}{(\kappa+1)} \sum_{n} \theta_{n}\left(\frac{1}{\rho_{1}+\theta_{n}}+\frac{1}{\rho_{2}+\theta_{n}}\right)^{2}\left[1-\cos \left(\rho_{1}+\theta_{n}\right)\right]
$$

onde

$$
\begin{aligned}
\kappa & =\frac{d_{2}}{d_{1}}, \\
\rho_{i} & =\frac{E d_{1}}{2 \hbar c}\left(\gamma^{-2}+\xi_{i}^{2}\right), \\
\theta_{n} & =\frac{2 \pi n-\left(\rho_{1}+\kappa \rho_{2}\right)}{1+\kappa}>0 .
\end{aligned}
$$




\section{Referências Bibliográficas}

[1] J. W. Harris e B. Muller, The search for the quark-gluon plasma, Ann. Rev. Nucl. Part. Sci. 46, 71 (1996), hep-ph/9602235.

[2] C. Wong, Introduction to High-Energy Heavy-Ion Collisions (World Scientific, 1994).

[3] K. Adcox et al. (PHENIX), Formation of dense partonic matter in relativistic nucleus nucleus collisions at RHIC: Experimental evaluation by the PHENIX collaboration, Nucl. Phys. A757, 184 (2005), nucl-ex/0410003.

[4] B. Muller e J. L. Nagle, Results from the Relativistic Heavy Ion Collider, Ann. Rev. Nucl. Part. Sci. 56, 93 (2006), nucl-th/0602029.

[5] High efficiency Transition Radiation Detectors for high rate environments, http://qgp.uni-muenster.de/ hoppeme/JRA4/WWU/.

[6] T. L. M. Harrison e S. Ozaki, RHIC project overview, Nucl. Instrum. Meth. A499, 235 (2003).

[7] T. Ludlam, Overview of experiments and detectors at RHIC, Nucl. Instrum. Meth. A499, 428 (2003).

[8] Hunting the Quark Gluon Plasma, Results from the first 3 years at RHIC, http://www.bnl.gov/bnlweb/pubaf/pr/docs/Hunting-the-QGP.pdf.

[9] Relativistic Heavy Ion Collider, RHIC, http://www.bnl.gov/rhic.

[10] The STAR Collaboration, http://www.star.bnl.gov.

[11] Phenix - A Physics Experiment at RHIC, http://www.phenix.bnl.gov.

[12] K. Adcox et al. (PHENIX), Centrality dependence of charged particle multiplicity in $A u+A u$ collisions at $\sqrt{s_{N N}}=130$ GeV, Phys. Rev. Lett. 86, 3500 (2001), nucl-ex/0012008.

[13] K. Adcox et al. (PHENIX), PHENIX detector overview, Nucl. Instrum. Meth. A499, 469 (2003).

[14] W. W. M. Allison e P. R. S. Wright, The Physics of Charged Particle Identification: $d E / d x$, Cherenkov and Transition Radiation, em Experimental Techniques in High Energy Physics, editado por T. Ferbel (Addison-Wesley, 1987). 
[15] M. Allen et al. (PHENIX), PHENIX inner detectors, Nucl. Instrum. Meth. A499, 549 (2003).

[16] C. Adler et al., The RHIC zero-degree calorimeters, Nucl. Instrum. Meth. A499, 433 (2003).

[17] K. Adcox et al. (PHENIX), PHENIX central arm tracking detectors, Nucl. Instrum. Meth. A499, 489 (2003).

[18] S. S. Adler et al. (PHENIX), PHENIX on-line systems, Nucl. Instrum. Meth. A499, 560 (2003).

[19] M. Aizawa et al. (PHENIX), PHENIX central arm particle ID detectors, Nucl. Instrum. Meth. A499, 508 (2003).

[20] K. Adcox et al. (PHENIX), Measurement of single electrons and implications for charm production in $A u+A u$ collisions at $\sqrt{s_{N N}}=130 \mathrm{GeV}$, Phys. Rev. Lett. 88, 192303 (2002), nucl-ex/0202002.

[21] A. Adare et al. (PHENIX), Measurement of high- $p_{T}$ single electrons from heavyflavor decays in $p+p$ collisions at $\sqrt{s_{N N}}=200$ GeV, Phys. Rev. Lett. 97, 252002 (2006), hep-ex/0609010.

[22] W.-M. Yao et al., Review of Particle Physics, Journal of Physics G 33, 1+ (2006), http://pdg.lbl.gov.

[23] L. Aphecetche et al. (PHENIX), PHENIX calorimeter, Nucl. Instrum. Meth. A499, 521 (2003).

[24] W. Blum e L. Rolandi, Particle detection with drift chambers (Springer-Verlag, 1994).

[25] Walenta, The time expansion chamber as a high precision drift chamber (1982), proceedings of the International Conference on Instrumentation for Colliding Beam Physics.

[26] K. Adcox et al. (PHENIX), PHENIX central arm tracking detectors, Nucl. Instrum. Meth. A499, 489 (2003).

[27] K. N. Barish et al., TEC/TRD for the PHENIX experiment, Nucl. Instrum. Meth. A522, 56 (2004). 
[28] F. Sauli, PRINCIPLES OF OPERATION OF MULTIWIRE PROPORTIONAL AND DRIFT CHAMBERS (1977), CERN.

[29] Hough transform - Wikipedia, the free encyclopedia, http://en.wikipedia.org/wiki/Hough_transform.

[30] G. Bassompierre et al., Performance of the NOMAD transition radiation detector, Nucl. Instrum. Meth. A411, 63 (1998).

[31] B. Dolgoshein, Complementary particle ID: Transition radiation and $d E / d x$ relativistic rise, Nucl. Instrum. Meth. A433, 533 (1999).

[32] V. Egorychev, V. Savelev, e S. J. Aplin, Particle identification via transition radiation and detectors, Nucl. Instrum. Meth. A453, 346 (2000).

[33] C. Adler et al. (ALICE), Electron / pion identification with ALICE TRD prototypes using a neural network algorithm, Nucl. Instrum. Meth. A552, 364 (2005).

[34] Garfield - simulation of gaseous detectors, http://consult.cern.ch/writeup/garfield/.

[35] R. Veenhof, Calculations for the Alice TPC read-out, http://rjd.web.cern.ch/rjd/Alice/.

[36] Homepage of the ALICE TRD project, http://www-alice.gsi.de/trd/.

[37] W. Riegler, Limits to drift chamber resolution, Tese de doutorado, Vienna University of Technology (1997).

[38] S. F. Biagi, Monte Carlo simulation of electron drift and diffusion in counting gases under the influence of electric and magnetic fields, Nucl. Instrum. Meth. A421, 234 (1999).

[39] Magboltz - transport of electrons in gas mixtures, http://consult. cern. ch/writeup/magboltz/.

[40] I. B. Smirnov, Modeling of ionization produced by fast charged particles in gases, Nucl. Instrum. Meth. A554, 474 (2005).

[41] Heed - Interactions of particles with gases, http://consult. cern.ch/writeup/heed/. 
[42] W. W. M. Allison e J. H. Cobb, Relativistic Charged Particle Identification by Energy Loss, Ann. Rev. Nucl. Part. Sci. 30, 253 (1980).

[43] XCOM: Photon Cross Sections Database http://physics.nist.gov/PhysRefData/Xcom/Text/XCOM.html.

[44] H. Ellis et al., Transport properties of gaseous ions over a wide energy range, At. and Nucl. Data Tables 17, 177 (1976).

[45] H. Ellis et al., Transport properties of gaseous ions over a wide energy range, part II, At. and Nucl. Data Tables 22, 179 (1978).

[46] H. Ellis et al., Transport properties of gaseous ions over a wide energy range, part III, At. and Nucl. Data Tables 31, 113 (1984).

[47] R. Bellazzini e M. A. Spezziga, Electric field, avalanche growth and signal development in Micro-Strip Gas Chambers and Micro-Gap Chambers, Riv. Nuovo. Cim. 17N12, 1 (1994).

[48] V. L. Ginzburg e V. N. Tsytovich, Transition Radiation and Transition Scattering (Adam Hilger, 1990), pp. 4-5.

[49] Python programming language, http://www.python.org.

[50] Scientific tools for python, http://www.scipy.org.

[51] NIST: X-Ray Transition Energies http://www.physics.nist.gov/PhysRefData/XrayTrans/.

[52] A. Andronic et al., Drift velocity and gain in argon and xenon based mixtures, Nucl. Instrum. Meth. A523, 302 (2004), physics/0402044.

[53] A. Andronic et al. (ALICE), Transition radiation spectra of electrons from 1 $\mathrm{GeV} / \mathrm{c}$ to $10 \mathrm{GeV} / \mathrm{c}$ in regular and irregular radiators, Nucl. Instrum. Meth. A558, 516 (2006), physics/0511229.

[54] M. N. Mazziotta, A Monte Carlo code for full simulation of a transition radiation detector, Comput. Phys. Commun. 132, 110 (2000), physics/9912042.

[55] ROOT - An Object Oriented Data Analysis Framework, http://root.cern.ch.

[56] C. W. Fabjan e W. Struczinski, COHERENT EMISSION OF TRANSITION RADIATION IN PERIODIC RADIATORS, Phys. Lett. B57, 483 (1975). 


\section{Agradecimentos}

Ao Prof. Olácio Dietzsch pela orientação, pelo apoio e pela oportunidade de trabalhar em uma colaboração em física de altas energias. Um agradecimento especial ao Marco Leite pela orientação, pela ajuda constante no trabalho, e por me ensinar um pouco sobre o trabalho em física.

Aos meus colegas do Laboratório de Instrumentação e Partículas, especialmente ao César que me ajudou desde a iniciação científica.

Ao Prof. Philippe Gouffon pelas discussões sobre a análise dos resultados.

A Walter Blum do CERN, que gentilmente cedeu as figuras de seu livro Particle Detection with Drift Chambers, e a Christian Lippmann da colaboração ALICE, que me enviou seus programas para comparação.

Aos meus amigos e colegas do Instituto de Física da USP. À minha família, que sempre me deu carinho e apoio para tudo na vida. E às minhas grandes companheiras até hoje, minha mãe, minha irmã, Teresa e Mariana.

À FAPESP pelo financiamento. 



\section{Trabalhos ligados ao mestrado}

\section{Trabalhos apresentados em conferências (pôsters)}

- B. R. Lenzi and M. A. L. Leite for the PHENIX Collaboration, "Electron Identification Methods and Results Using the PHENIX TEC / TRD", IX International Conference on Nucleus Nucleus Collisions, setembro de 2006. Rio de Janeiro - RJ, Brasil.

- B. Lenzi pela colaboração PHENIX, "Identificação de Partículas e Reconhecimento de Trajetórias com as Câmaras de Expansão Temporal / Detector de Radiação de Transição no Experimento PHENIX", XXVIII Reunião de Trabalho de Física Nuclear no Brasil, setembro de 2005. Guaruja - SP, Brasil.

\section{Participação em escolas (pôsters apresentados)}

- B. R. Lenzi for the PHENIX collaboration, "A new simulator for the PHENIX TEC / TRD", 4th CERN Latin American School of High Energy Physics, fevereiro de 2007. Viña del Mar, Chile. 


\section{Artigos}

\section{Publicados (colaboração PHENIX)}

- A. Adare et al., "Energy loss and flow of heavy quarks in $\mathrm{Au}+\mathrm{Au}$ collisions at $\sqrt{s_{N N}}=200 \mathrm{GeV} "$, Phys. Rev. Lett. 98:172301, 2007

- A. Adare et al., "Measurement of high-p(T) single electrons from heavy-flavor decays in $\mathrm{p}+\mathrm{p}$ collisions at $\sqrt{s_{N N}}=200 \mathrm{GeV}$ ", Phys. Rev. Lett. 97:252002, 2006

- A. Adare et al., "Scaling properties of azimuthal anisotropy in $\mathrm{Au}+\mathrm{Au}$ and $\mathrm{Cu}+\mathrm{Cu}$ collisions at $\sqrt{s_{N N}}=200 \mathrm{GeV}$ ", Phys. Rev. Lett. 98:162301, 2007

\section{Submetidos para publicação (colaboração PHENIX)}

- A. Adare et al., "Correlated production of p and anti-p in Au + Au collisions at $\sqrt{s_{N N}}=200 \mathrm{GeV} "$

Preprint: nucl-ex/0611016

- A. Adare et al., "J/psi production vs transverse momentum and rapidity in $\mathrm{p}$ $+\mathrm{p}$ collisions at $\sqrt{s_{N N}}=200 \mathrm{GeV} "$

Preprint: hep-ex/0611020

- A. Adare et al., "System size and energy dependence of jet-induced hadron pair correlation shapes in $\mathrm{Cu}+\mathrm{Cu}$ and $\mathrm{Au}+\mathrm{Au}$ collisions at $\sqrt{s_{N N}}=200$ $\mathrm{GeV}$ and $62.4 \mathrm{GeV}$ "

Preprint: nucl-ex/0611019 